University of Louisville

ThinkIR: The University of Louisville's Institutional Repository

$5-2021$

\title{
The effects of great leaps reading on the reading fluency of elementary students with reading and behavioral deficits.
}

Gwendolyn Shultz Ashley

University of Louisville

Follow this and additional works at: https://ir.library.louisville.edu/etd

Part of the Curriculum and Instruction Commons

\section{Recommended Citation}

Shultz Ashley, Gwendolyn, "The effects of great leaps reading on the reading fluency of elementary students with reading and behavioral deficits." (2021). Electronic Theses and Dissertations. Paper 3656.

https://doi.org/10.18297/etd/3656

This Doctoral Dissertation is brought to you for free and open access by ThinkIR: The University of Louisville's Institutional Repository. It has been accepted for inclusion in Electronic Theses and Dissertations by an authorized administrator of ThinkIR: The University of Louisville's Institutional Repository. This title appears here courtesy of the author, who has retained all other copyrights. For more information, please contact thinkir@louisville.edu. 
THE EFFECTS OF GREAT LEAPS READING ON THE READING FLUENCY OF ELEMENTARY STUDENTS WITH READING AND BEHAVIORAL DEFICITS

\author{
By \\ Gwendolyn Shultz Ashley \\ B.S. Indiana University, 2006 \\ M.A.T University of Louisville, 2008
}

A Dissertation Submitted to the Faculty of the College of Education and Human Development of the University of Louisville in Partial Fulfillment of the Requirements for the Degree of

Doctor of Philosophy in Curriculum and Instruction

Elementary, Middle and Secondary Teacher Education

University of Louisville

Louisville, Kentucky

May 2021 

THE EFFECTS OF GREAT LEAPS READING ON THE READING FLUENCY OF

\section{ELEMENTARY STUDENTS WITH READING AND BEHAVIORAL DEFICITS}

By

Gwendolyn Shultz Ashley

B.S. Indiana University, 2006

M.A.T. University of Louisville, 2008

\section{A Dissertation Approved on}

April 13, 2021

by the following Dissertation Committee:

Dissertation Director Dr. Terrence Scott

Dr. Amy Lingo

Dr. Jason Immekus

Dr. Justin Cooper 


\section{DEDICATION}

This dissertation is dedicated to my immediate family. Without their faith, sacrifice, and unwavering encouragement, I could not have achieved this goal. I would also like to thank my friends in the academic community. There are too many to list, but I appreciate each of you, and all that you have done to help me in my quest. 


\section{ACKNOWLEDGEMENTS}

I would like to thank my chair, Dr. Terry Scott for his guidance, expertise, patience and perseverance. I would also like to thank my committee members, Dr. Amy Lingo, Dr. Jason Immekus, and Dr. Justin Cooper, for your support and the opportunity to learn from you. I would also like to thank Dr. Robert Pennington for his guidance and teaching. Our journey was long, with every obstacle imaginable, from hurricanes and flooding, to illness, to a global pandemic, but here we are. I would also like to thank my husband for his infinite patience and unwavering support, as it sometimes seemed the delays would never end. His determination and faith that I would finish sometimes exceeded mine. I appreciate each of you and the part you have played in my achieving this milestone. 


\section{ABSTRACT \\ THE EFFECTS OF GREAT LEAPS READING ON THE READING FLUENCY OF ELEMENTARY STUDENTS WITH READING AND BEHAVIORAL DEFICITS Gwendolyn Shultz Ashley}

April 13, 2021

This dissertation is an examination of one reading fluency intervention presented in digital form. It begins as an overview of the academic challenges faced by students classified as emotional behavioral disorder in our P-12 schools, due to challenges accessing the curriculum. Children that also have reading fluency deficits have an even more difficult time accessing grade level curriculum. Several theories of education are presented, with a focus on the instructivist theory.

Instructivist theory focuses on such methodology as Applied Behavior Analysis, which includes Discreet Trial Training and direct instruction. Repeated reading is included. All of these are components of Great Leaps for Reading Digital, which is used in this study.

Chapters one and two provide the literature review of the study, including emotional behavioral disorder, and the co-morbidity with reading deficits. Chapter three provides an overview of education methodology. Chapter four describes the study in detail, as well as results. Chapter five provides discussion of the results, as well as limitations and next steps. 


\section{TABLE OF CONTENTS}

\section{PAGE}

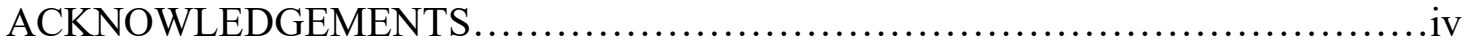

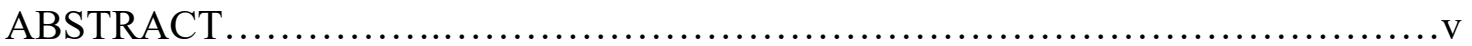

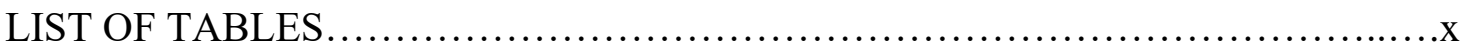

LIST OF FIGURES ............................................................

LITERACY AND EMOTIONAL BEHAVIORAL DISORDER .....................1

The Importance of Literacy.........................................

Essential Components of Literacy....................................2

Impact of Illiteracy.................................................

LITERACY AND CHILDREN WITH EMOTIONAL BEHAVIORAL DISORDER...9

Incidence and Prevalence of EBD.......................................11

Comorbidity: Reading and Behavior....................................13

Conclusions....................................................... 14

REVIEW OF THE LITERATURE........................................ 15

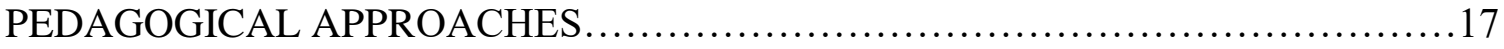

Progressivism.................................................... 17

Constructivism..................................................... 18

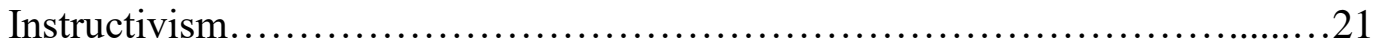

READING FLUENCY ................................................... 
Repetition to Build Fluency: Repeated Reading Interventions.................31

THE GREAT LEAPS FOR READING FLUENCY INTERVENTION .........................36

SUMMARY, CONCLUSIONS, AND REMAINING QUESTIONS ....................38

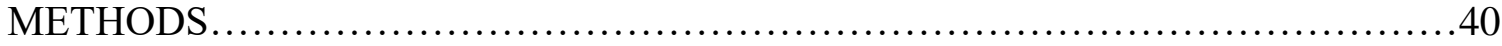

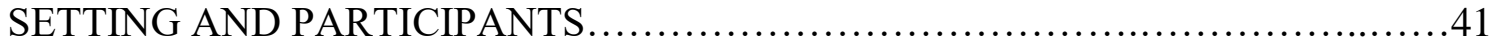

Setting .........................................................41

Participant Selection................................................43

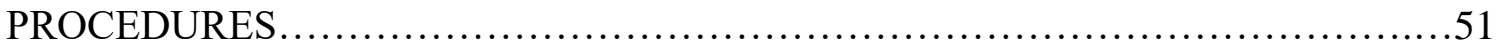

Independent Variable: Great Leaps for Reading Digital......................51

Fidelity of Implementation Procedures.................................53

Measures and Data Collection Procedures.................................54

RESEARCH DESIGN .................................................... 56

Baseline.........................................................57

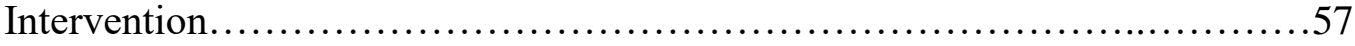

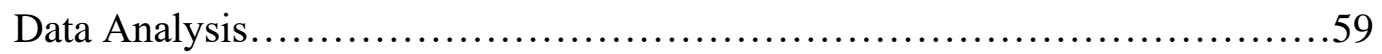

RESULTS................................................................

Participating Students that are not Included in Analysis.....................63

Students that Completed Participation in the Study..........................65

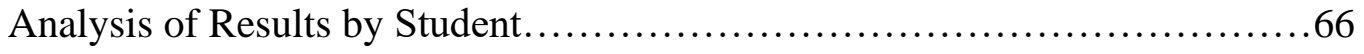

Overall Analysis.......................................................73

Fidelity of Implementation and Inter Observer Agreement..................76 


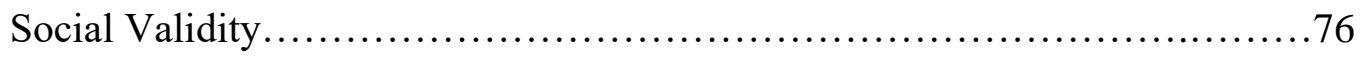

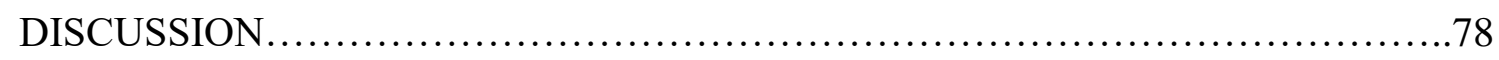

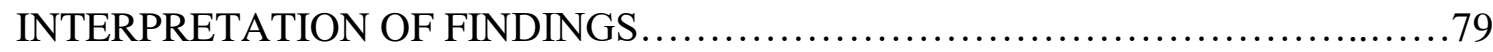

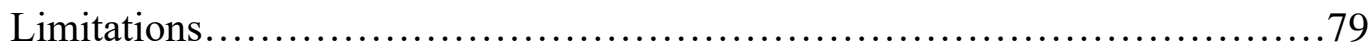

Research Question One................................................. 81

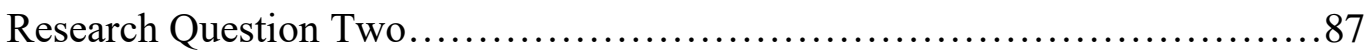

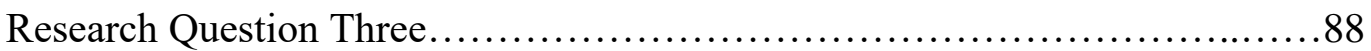

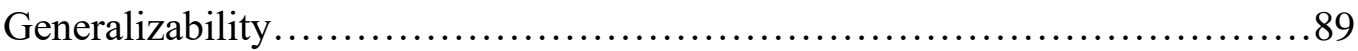

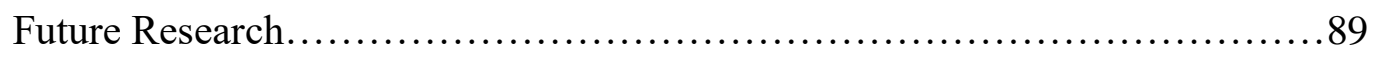

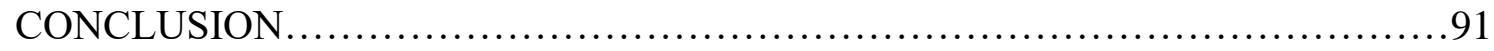

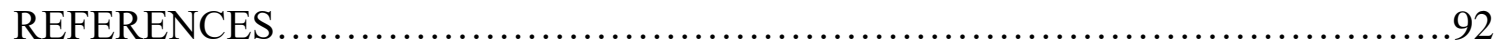

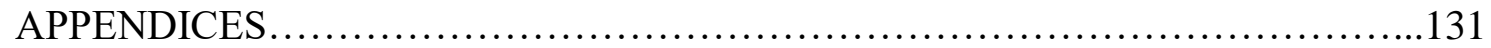

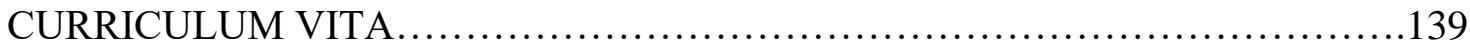




\section{LIST OF TABLES}

TABLE $\quad$ PAGE

i. THE FOUR COMPONENTS OF CONSTRUCTIVISM....,,,,,,,,,,,,,,,,,....29

ii. THE PHILOSOPHICAL FEATURES OF DIRECT INSTRUCTION (di)...34

iii. $\quad$ STEPS TO SUBJECT SELECTION ...................................44

iv. SPRING 2019 READING LEVELS OF SELECTED STUDENTS ..........45

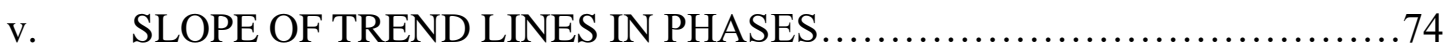




\section{LIST OF FIGURES}

FIGURE

PAGE

i. CONCEPTUAL FRAMEWORK DRIVING REVIEW OF

LITERATURE.............................................16

ii. THE RELATIVE COMPONENTS OF THE INSTRUCTIVIST PEDAGOGY FOR READING INSTRUCTION ..............................28

iii. CONCEPTUAL FRAMEWORK FOR SCIENCE-BASED EFFECTIVE

LITERACY INSTRUCTION ..................................39

iv. LOG FOR TRACKING STUDENT PERFORMANCE ON THE

TOWRE-2..............................................50

v. TAU-U FORMULA............................................61

vi. WORDS PER MINUTE ON DAILY GRADE LEVEL READS.......67

vii. GREAT LEAPS FOR READING ACROSS SUBJECTS DATA......68 


\section{LITERACY AND EMOTIONAL BEHAVIORAL DISORDER}

\section{The Importance of Literacy}

Literacy as a whole is a crucial, if not the most important component of American, and perhaps, worldwide education at this time. Since 1967, the United Nations has proclaimed fundamental literacy as a basic human right. In a statement published April 18, 2013, the United Nations Educational, Scientific and Cultural Organization said, "Literacy is a fundamental human right and the foundation for lifelong learning. It is fully essential to social and human development in its ability to transform lives" (Education for All Global Report, 2013). Much of our daily life involves printed word. Literacy is so important to the people of the United States that billions of dollars have been spent on research to determine the essential components of literacy, and how best to teach them to our diverse population (Botts, Losardo, Tillery, \& Werts, 2014).

Through the research described in this dissertation, the researcher will seek to examine the impact a research-based intervention has on the literacy skills of students that have emotional behavioral deficits, as indicated by an EBD classification on the child's Individualized Education Plan, with behavioral goals, combined with severe reading deficits. In the following pages, I will explain why these students have a difficult time acquiring and retaining reading skills, and why it is important to their long-term outcomes. I will explain the detriments of both disabilities, and the compounded effect of co-morbidity. While research has been conducted with students that fall into both 
categories, it has not specifically focused on elementary students with both academic and behavioral deficits.

\section{Essential Components of Literacy}

The National Reading Panel has established that there are five components to reading and reading instruction. These components are phonics, phonemic awareness, fluency, vocabulary, and finally comprehension. It is evident that each component has equal influence in giving the child a well-rounded understanding, or comprehension, of what is presented through written word. Without any of the components, the child's reading education is incomplete and circle is not able to close. However, as components build upon themselves at each educational level, it is important that students reach mastery in each area before moving on. (National Reading Panel, 2000).

Phonemic awareness. In 2000, the National Reading Panel (NRP) determined that literacy consists of distinct components: phonemic awareness, phonics, fluency, comprehension, and vocabulary (National Reading Panel, 2000). Phonemic Awareness is a knowledge and understanding that words are made of smaller units called phonemes or sounds. There are approximately 41 phonemes in the English language, depending on dialect (NRP, 2000) and students must recognize that letters on the printed page symbolize sounds and combine to make words. Students must also be able to manipulate these smaller units in writing and speech to make words. This skill is the earliest form of what is taught to develop literacy. Research completed by the NRP demonstrates that teaching of phonemic awareness in reading instruction results in more successful reading outcomes, with an average effect size of .86 (NRP, 2000; Castle, et al., 1994; Wise, et al., 
2000; Hatcher, et al., 1994; Iverson \& Tunmer, 1993). Phonemic awareness is one part of the complete circle that makes up literacy, but there are many others.

Phonics. An understanding of phonics is closely related to the concept of phonemic awareness and the two are often confused. While phonics refers to the letter name and individual sound associated with each of the symbols in our alphabet, these sounds can be combined to produce meaningful parts of our language. When phonics pedagogy emphasizes students learning to convert letters (graphemes) into sounds (phonemes) and using these to read words, it has the greatest impact, with a mean effect size of .67 (NRP, 2000) on student reading. Students use these sounds (phonemes) to engage in reading and the construction of words (graphemes) for writing. During the late 1950 's and 60's, the concept of teaching phonics was challenged by an alternative philosophy known as whole language reading instruction (Flesch, 1955; Chall, 1967). This alternative was ubiquitous in schools in the United States despite the fact that research overwhelmingly demonstrated more positive effects for students who were provided early instruction in phonics. The research has been repeated, and the phonics approach to early reading has shown to be more successful than whole language many times (NRP, 2000; Dykstra, 1968; Chall, 1967; Adams, 1990; Anderson, et al., 1985; Balmuth, 1982).

The NRP found that systemic phonics instruction also increased young reader's comprehension skills, but had no or minimal effect on the comprehension skills of older children. The overall growth in reading skills of younger children had an effect of .55, but with older children it was only .27. Thus, the NRP, through much research and meta- 
analysis, found that readers are most successful when provided early instruction in phonics (NRP, 2000; Dykstra, 1968)

Fluency. As a whole, literacy builds upon the foundational components of phonemic awareness and phonics. Kindergarten and first grade students should be immersed in a curriculum that includes explicit teaching of phonics, decoding, and letter recognition as researchers have found that early instruction and mastery in these areas can prevent later school failure (McMaster, Fuchs, Fuchs, \& Compton, 2005, Chall 1996). Mastery of both phonics and phonemic awareness leads students to focus on fluency, which is defined as an ability to decode phonetic code with adequate speed, and prosody (the rate, inflection, expression and tone a person has when reading aloud), allowing the reader to construct meaning from what is read. Ehri (1994) identified four ways humans read text: decoding, sight, analogy, and prediction. The greater the sight word bank, and more rapid the decoding, the more fluent the reader. Created by repetition through practice, fluency is crucial to mastery of literacy, but is perhaps the most neglected skill (National Reading Panel, 2000). Although important, Pinnell et al. (1995) found that fluency is not achieved as often as was once thought. In their study, only $54 \%$ of fourth graders were fluent with grade-level text. They also found that fluency levels are closely related to comprehension levels. It is very difficult, if not impossible for students to progress to higher-level literacy skills if fluency is not achieved (Oakes, Mathur, \& Lane, 2010; Levy \& Chard, 2001). Fluency as a whole has been shown to have a large impact on comprehension (NRP, 2000), so much so that fluency instruction is often the first line of intervention for students with comprehension difficulties. Snow, Burns \& Griffin (1998) go so far as to state that reading 
comprehension cannot progress beyond the emergent stage without fluency. Although reading fluency has been recognized since the 1800 s, it was a novelty, then only studied as a behavior during the age of behaviorism, progressing to the research declaring the processes of reading, and what is necessary for reading fluency (LeBerge \& Samuels, 1974). Through extensive research from the 1970s through the 1990s, reading fluency was demonstrated to be complicated with many components contributing to automaticity (Stanovich, 1990; Logan, 1997; Posner \& Snyder, 1975, Samuels, 1979; Ackerman, 1987). Key among these findings, researchers identified overlaps with fluency and reading comprehension (Thurlow \& van den Broek , 1997; Calfee \& Piontowski, 1981; Herman, 1985; Stanovich, 1990).

Comprehension. Literacy comprehension refers to the ability to make meaning and understanding from what is read or heard and is the third key component of literacy. Durkin (1993) stated that comprehension was crucial to life-long learning, a sentiment echoed by Stevens and colleagues (1991). Comprehension is important whether reading aloud, reading silently, or being read to. In order to distinguish between differing comprehension skill sets, it is often necessary for teachers to define whether the task is to be "reading comprehension" or "listening comprehension." Students often have asynchronous development of these two types and it is important that they be taught a wide variety of comprehension strategies to support them as they read different genres. (NRP, 2000).

Harris \& Hodges (1995) define reading comprehension as follows: "Reading comprehension is the construction of meaning of a written text through a reciprocal interchange of ideas between the reader and the message in a particular text” (pg.39). 
The NRP found that students more effectively comprehended reading passages when taught a variety of comprehension strategies. These strategies include such things as constructing a picture in their mind, making text to self-connections, making text to text connections, predicting, using graphic organizers, and the use of mnemonic devices (Pressley \& Afflerbach, 1995; Palinscar \& Brown, 1984; Paris, et al., 1986; Pressley, et al., 1994; Meir, 1984; Pressley, et al., 1989; Rosenshine \& Meister, 1994; Rosenshine, Meister, \& Chapman, 1996; Pressley, 1998). These strategies are best taught as individual skills, with teachers guiding and modeling while making students aware of their own processes. Teachers should continue to guide students with comprehension until mastery allows practice of the strategies at an independent level (Paris, et al., 1986). Importantly, research demonstrates that prior knowledge of language, print, and word content impacts the level of comprehension and the ability to masterfully comprehend content in a timely manner (Pressley \& Afflerbach, 1995; Pressley, 1998).

Vocabulary. Vocabulary skills are closely related to the ability to comprehend the text that is read. Students need to develop a rich vocabulary, both orally and in text to meet the demands of literacy instruction in the classroom. As early as 1942, Davis divided the skill of comprehension into reasoning and vocabulary (Davis, 1942; NRP, 2000). Studies have shown that the larger the student's vocabulary, the easier it is to learn new words, particularly if those words are not nouns and are concrete in nature (Schwanenflugel, Stahl \& McFalls, 1997; McFalls, Schwanenflugel, \& Stahl, 1996; Robbins \& Ehri, 1994). The development of a vocabulary that is both academic and socially beneficial is an essential for delayed learners, particularly those that also struggle with social skills and behavior. There are numerous studies demonstrating that 
vocabulary instruction has a positive impact on both comprehension and retention (Beck, Perfetti, \& McKeown, 1982; McKeown, Beck, Omanson, \& Perfetti, 1983; Wixson, 1986; Carney, Anderson, Blackburn, \& Blessings, 1984; Stahl \& Fairbanks, 1986; Medo \& Ryder, 1993). Whipple (1925) states that increases in vocabulary are necessary for growth as a reader. Logically, one cannot have reading growth without vocabulary advances. Although it has been shown that reading levels and vocabulary are related, a causal relationship has not been demonstrated through research at this time.

The components of literacy and how they contribute to literacy is wellestablished. Each component builds the foundation upon which lifelong learning takes place. But if any of these building blocks are missing, or incomplete, the foundation is weak, and illiteracy is likely.

\section{Impact of Illiteracy}

Illiteracy in the United States is defined as lacking mastery of the components of literacy, particularly the lower level skills of phonemic awareness, phonics, and fluency (NRP, 2000). Illiteracy is a problem with far reaching effects, as those with poor to below average literacy skills are less likely as adults to have full time jobs and more likely to receive government assistance (Crowley, McLaughlin, \& Kahn, 2012). Not being able to read and write proficiently has also been repeatedly correlated with school grade retention, school failure, unemployment and underemployment, incarceration, and P-12 school dropout (Wagner \& Davis, 2006). Adult literacy levels are an ongoing concern in our country. LiteracyInc (2016), estimates there are thirty-two million adults in our country that cannot read or write above a fifth-grade level, and $19 \%$ of high school graduates cannot read and write at a proficient level. 
Perhaps more concerning, early literacy skill deficits do not appear to improve over the child's lifetime, and actually become more resistant to change as the child ages (Benner, Nelson, Ralston \& Mooney, 2010). The NRP (2000), indicated that 75\% of those students with significant literacy deficits at the end of first grade will have academic struggles throughout high school and are more likely to drop out. Statistics become more daunting for students that do not achieve proficient literacy skills by the end of third grade. These students leave school with lower literacy levels, have among the highest incarceration rates, and are less like to be employed, with the lowest lifetime earning potential of any group (NRP, 1999; NRP, 2000; Stockard \& Englemann, 2010; Levy \& Vaughn, 2002; Rivera, Al Otaiba, \& Koorland, 2006; Oakes, et al., 2010; Benner, Allor \& Mooney, 2008; Trout, et al., 2006; Kamps \& Greenwood, 2005; Lane, 2007).

There is more to the concern than simple academic deficits. McIntosh, Horner, Chard, Dickey, \& Braun (2008) state, "A student with lower academic skills than her classmates faces a considerably less hospitable school experience than a student with average or high academic skills" (p. 132). This inhospitable environment leads to more frequent disenfranchisement, criminal and delinquent activity, school suspension and expulsion, drug and alcohol use, dropout, lower employment rates and lower earnings (Wagner \& Davis, 2006). These issues can also lead to a continuing cycle of physical health concerns. Studies have shown reading competence as assessed by the Dynamic Indicators of Basic Early Literacy Skills (DIBELS) test in kindergarten can be predictive of discipline referrals in first and second grade, with high levels of discipline referrals the next year. The predictive value of the kindergarten DIBELS score combined with 
phonemic fluency at the end of kindergarten has an even more far reaching impact, showing students with deficits in this area continued to have higher levels of discipline referrals in fifth grade (McIntosh, Chard, Boland, \& Horner, 2006).

\section{Literacy and Children with Emotional Behavioral Disorders}

Of all classifications of special education, those identified as EBD have the bleakest outcomes in later life. According to the Casey Foundation (2014), this group has the highest rate of drop out, incarceration, under and unemployment, and accidental death in every state. Compounding the problem, this population often has a very high rate of noncompliance with treatment as well (NIMH, 2017). Emotional Behavioral Disorder (EBD) has a high co-morbidity with Specific Learning Disability in Literacy (USDOE, 2014). The relationship is so well-established that many speculate whether one causes the other. But because of the myriad of compounding factors, such as lost instructional time, inconsistencies in identification and remediation, it seems highly likely that both deficits simply compound the other.

Like literacy deficits, EBD is difficult for children and educators to overcome and has long-range impact on life outcomes (McIntosh, et al., 2006; McIntosh, et al., 2008; Wagner \& Davis, 2008; Stockard \& Englemann, 2010; Levy \& Vaughn, 2002; Rivera, Al Otaiba, \& Koorland, 2006; Oakes, et al., 2010; Benner, Allor \& Mooney, 2008; Trout, et al., 2006; Kamps \& Greenwood, 2005; Lane, 2007). The federal definition of EBD is as follows:

"A condition exhibiting one or more of the following characteristics over a long period of time and to a marked degree that adversely affects a child's educational performance: 
(A) An inability to learn that cannot be explained by intellectual, sensory, or health factors.

(B) An inability to build or maintain satisfactory interpersonal relationships with peers and teachers.

(C) Inappropriate types of behavior or feelings under normal circumstances.

(D) A general pervasive mood of unhappiness or depression.

(E) A tendency to develop physical symptoms or fears associated with personal or school problems.

The term includes schizophrenia. The term does not apply to children who are socially maladjusted, unless it is determined that they have an emotional disturbance.” (Kaufmann \& Landrum, 2013, p. 187)

According to the federal definition, students with EBD often have an inability to learn in the realm of literacy or other academic areas that cannot be explained by other causes. That is, children with EBD may have difficulties in some academic areas and yet be at grade level in others. However, IQ is not related to EBD, as these students have a range of IQ scores. Within the classroom atmosphere, students with EBD typically have other challenges that must be addressed in order for learning to take place. The fact that students with this label must experience academic failure prevents students being classified as having EBD simply as a result of personal crisis or difficulty working with a particular teacher.

Students with EBD often lack the social skills necessary to establish and keep relationships with teachers, staff, and peers. Further, they are prone to having intense feelings and reactions with regard to what would otherwise be considered to be minor 
incidents (Kaufman \& Landrum, 2013). For example, a simple glance from a peer may result in outbursts that can be verbally and physically detrimental to self or others. Students with EBD are rarely mentally and emotionally secure, often causing turmoil during instruction. They may also have intense physical symptoms with no organic basis, and irrational fears toward school. It is difficult to teach students with EBD within the general curriculum and environment without individualized supports and accommodations. To be effective, the curriculum must generally provide intensive learning in a short period of time and be engaging enough to distract from the everpresent disorder (Kauffman \& Landrum, 2013).

\section{Incidence and Prevalence of EBD}

Most recent numbers from the Department of Education indicate that there are 354,000 students in grades K-12 identified with EBD (Department of Education, 2016), which is a decrease from 2004-2005 numbers of 489,000. Although there can be many reasons for the drop in numbers, the fact remains that there is a large population of students with EBD in our public schools. (Department of Education, 2016). Rivera, et al. (2006) attempts to explain this huge fluctuation and seeming decrease by identifying three ways EBD students are identified in addition to general education students with EBD. First, there often are students with EBD who have not completed the testing and data collection process to be identified. These are students that exhibit the behaviors to possibly qualify for EBD classification, but for a myriad of reasons, there is not sufficient data to show that behaviors have been exhibited for three to six months and across settings, or that they are negatively impacting the learning of the child. This can often be caused by transiency, truancy, and other factors that relate to attendance and consistency. 
Second, EBD students may also be identified under the "Other Health Impaired" or other special education category as a primary area, especially in cases where the child has been diagnosed by an outside practitioner with attention deficit hyperactivity disorder, or Developmental Delay if the student is young. Many times, parents and/or schools are reluctant to apply the EBD label to students, particularly those that are younger than third grade. Third, there are students identified with EBD but who simply find academic tasks aversive. Sometimes a student will meet the criteria for classification as EBD, but as time goes by it is found that the student only exhibits behavior that meets the criteria of EBD in isolated settings, particularly those that are academically challenging. Because the student finds tasks in that content area aversive, behaviors are exhibited that may be counterproductive to learning, but do not meet the legal definition of EBD. (Rivera, et al., 2006).

Perhaps a fourth category of misidentified students could also be those that exhibit all other criteria for classification, yet remain academically successful in the classroom. These students can be quite disruptive and are struggling with disorders that manifest in detrimental behaviors. However, as the student remains academically successful, they do not meet the criteria to be classified as EBD and are thus unqualified to receive special education services. (Kauffman \& Landrum, 2013).

Teacher education in how to best prepare pre-service teachers in how to teach students with EBD is often not extensive at the undergraduate, and in some cases, the graduate level (USDOE, 2017). Many states issue licenses that cover the majority of disabilities under IDEA, and the post-secondary curriculum content must cover each of these in addition to law and pedagogy. Data shows our EBD classrooms nationwide 
often have our newest and most inexperienced teachers at the helm (USDOE, 2017). Turnover for these positions is extremely high, with just $37 \%$ of teachers in their fifth year remaining in a position teaching students with EBD (USDOE, 2017). Students with EBD typically spend more time outside of the general education classroom than any other high-incidence disability category. Further, instructional time is often lost in deference to managing behavior and focusing on teaching student's basic self-control and social skills (Kauffman \& Landrum, 2013). Compounding the struggle, researchers estimate that a large percentage of those students with EBD also have a learning disability. (Oakes, et al., 2010; Tommredahl, 2013).

\section{Comorbidity: Reading and Behavior}

It is no secret students with literacy deficits often have co-morbid behavioral challenges as this is well established in the research (Algozzine, et al., 2011; Gage, MacSuga-Gage, Prykanowski, Coyne, \& Scott, 2015; Nelson, Benner, Lane, \& Smith, 2004; Volpe, Young, Piana, \& Zasofsky, 2012). Interestingly, behavior and literacy skills are so intertwined, Nelson Benner and Gonzalez (2003) found that problem behaviors can be predictive of later literacy skill deficits as are poor phonological skills. It has been estimated that between $40-80 \%$ of students with EBD have literacy and language deficits as well, depending on grade level (Oakes, et al., 2010; Scott \& Shearer-Lingo, 2002). Most EBD students are at least two grade levels behind in literacy skills (Rivera, et al., 2006) and some researchers believe that deficits in attention to task is a skill that lends to this comorbid effect (Allington, 2006).

Children with both behavioral and literacy deficits face an often insurmountable task. They not only must master literacy skills at a sufficient level, they must also acquire 
the emotional and behavioral skills to facilitate their own learning. Regardless of the reason for the numbers or the decline in EBD student populations, these are students that clearly struggle. Data for 2012-2013 showed that there were 39,493 students identified as EBD in the age group 14-21 in the first month of the school year and dropping out of school was the choice for an alarming $41 \%$ of these students during that school year. Although there is research on effective interventions for this population of students, much of it focuses solely on behavioral interventions and outcomes, ignoring academic deficits (Rivera, et al. 2006; Levy \& Chard, 2001; Alber-Morgan, Ramp, Anderson, \& Martin, 2007; Strong, Wehby, Falk, \& Lane, 2004; Sutherland \& Snyder, 2007). Similarly, there are concerns from researchers and P-12 educators that teachers too often focus on behavior at the expense of academic instruction. In some studies, researchers found that academic instruction was decreased to levels below that of general education, even for students that were identified as having cognitive impairments and specific learning disabilities (Vaughn, Levy, Coleman, \& Bos, 2002). Levy and Vaughn (2002) found that $40 \%$ of instructional literacy time was focused on independent worksheets as seatwork in the self-contained EBD classrooms that took part in their study. Clearly there is extensive research to be done with our twice-exceptional EBD population that also has literacy deficits. As the research shows, these students fall farther behind and do not improve as they age. The urgency to complete additional research to test interventions and find best practices for this segment of our population is evident.

\section{Conclusions}


Although there is research on the impact of reading instruction on behavioral outcomes, and research on the impact of behavioral interventions on reading outcomes, it is both inconclusive and lacks the ability to be replicated, or involves very small numbers of subjects. One study found that students with reading deficits that continue to improve from 3-6 grade have significantly fewer behavior problems in seventh grade than their peers that did not improve their literacy skills (Fleming, Harachi, Cortes, Abbott, \& Catalano, 2004).

The link between academic and behavioral deficits is strong and welldocumented. There is much debate regarding how these two deficits effect one another and which may occur first, although it is clear that interventions for each may have an impact on the other. For instance, we know that behavioral interventions impact reading levels and research has demonstrated that reading interventions impact behavioral deficits (Rogers-Adkinson, et al., 2008; Gagnon \& Barber, 2014).

We know that we can help students identified as both EBD and having reading deficits by providing effective instruction in reading, combined with behavioral interventions. Because these students are at such great risk for school failure, leading to detrimental life outcomes it is important we choose a reading intervention that is research based and has shown a large positive effect on learning for this population. The next chapter provides a review of the literature with regard to the science-based research on effective pedagogy and teaching strategies in the area of reading. 


\section{REVIEW OF THE LITERATURE}

As has been documented in Chapter 1, students with reading deficits and students with emotional and behavioral disorders are often identified with comorbid deficits. Studies have shown that effective interventions can have somewhat of a comorbid effect, with reading interventions positively impacting behavior, and behavioral interventions positively impacting reading (Algozzine, et al., 2011, Ialongo, Poduska, Werthamer, \& Kellam, 2001). Students that struggle in both areas need to have the most effective interventions available to them in order to be successful. This chapter reviews the literature with regard to science-based pedagogy and instructional strategies for reading. Figure i provides a conceptual framework for approaching this review. This chapter concludes with a more detailed conceptual framework developed from the results of this review. This concluding framework provides a foundation for my research questions.

\section{Figure i.}

Conceptual Framework Driving Review of the Literature

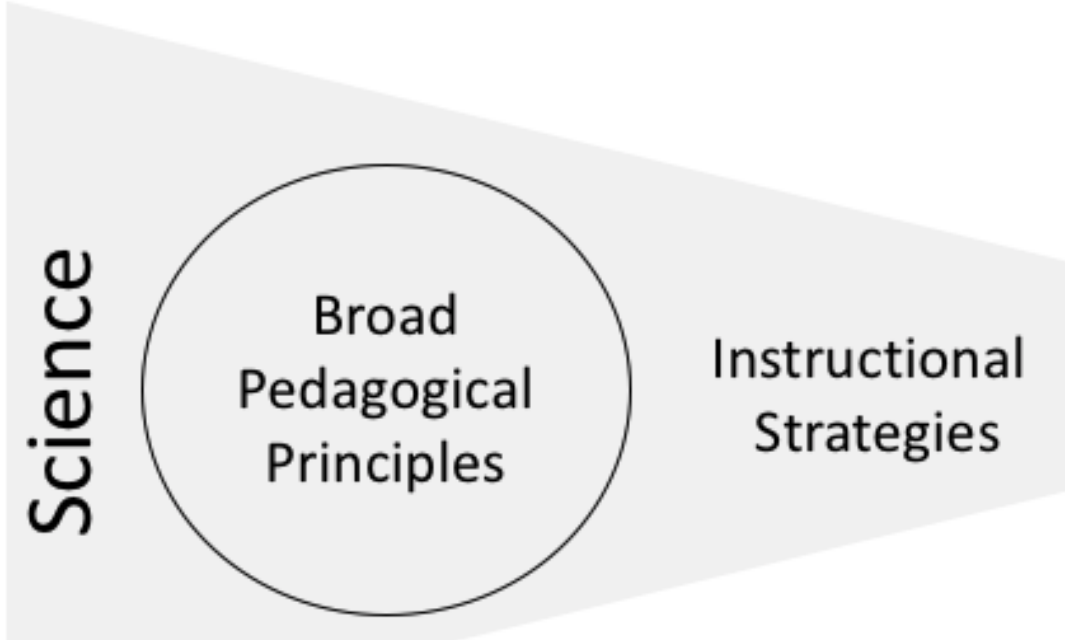




\section{Pedagogical Approaches}

Although pedagogy in our country is exceedingly broad, with many schools allowing school and parent committees to determine the methodology for their students, it is important to determine what methodology works best for our given population. Instruction is not one-size-fits-all and must be tailored to meet the needs of the students with whom we are working. Still, there are some key components of effective instruction that should be considered as foundational. Methods of choosing curricula are varied and do not always consider the needs of all students. It behooves the educator, especially those working with students that are identified as having academic deficits, to look into the effect an intervention has on students, rather than blindly adopting what is currently in vogue within educational circles. It is imperative that educators that work with students with academic or behavioral deficits ensure that they are providing instruction with the largest available positive effect on learning to ensure students have the opportunity to "catch up," or learn at the highest level possible. While there are many and varied curricula for teaching reading, most fall into one of three broad categories, which are described below.

\section{Progressivism}

Progressivism is a pedagogical philosophy that is currently a popular driver of educational practice in many areas of our country (Labaree, 2005). This model touts a progressive approach to learning, generally eschewing the teaching of specific content and adhering to a multidisciplinary approach. Developed by John Dewey, this philosophy has been in practice within education circles since the mid-1920s. The focus 
of a progressive education is on integrating academic and social skills as a means of teaching children to problem solve. Such an approach requires student self-discipline as the entire curriculum is to be directed by the student rather than the teacher. Work is often unequal among group participants, with students doing more or less than their share but there is no individual accountability for meeting objectives. These groupings are heterogeneous, meaning all students are placed together, with no differentiation based on workload or abilities. The belief of this pedagogy is that students will learn material when they have the desire to do so, or when they are ready.

Progressivism has no set instructional strategies, but instead relies on basic tenets of change and progress that result from problem solving. In many progressive classrooms, the teacher simply teaches to the average student. Because of the selfdiscipline required and the extensive group work, this mode of teaching and learning is generally not effective for most students with EBD and learning deficits (Gindis, 1999; Ellis, 2013). Of concern to special educators, students who struggle are often unable to acquire the support they need to be independently successful (Freeman \& Alkin, 2000; Skritic, 1991). In response, Progressivists believe that the student is successful even if he or she is not meeting the standards, as each student is part of a group that did meet standards. (Labaree, 2005; Dewey, 1916).

\section{Constructivism}

Constructivism is another pedagogical approach used with literacy instruction, as well as with most other content areas in the United States. Constructivism has been very popular in the United States since the early 1990's, although it is actually centuries old. This pedagogy has roots in the teachings of Dewey (1916) and the $18^{\text {th }}$ century 
philosopher Immanuel Kant, both of whom believed that a child forms his or her own knowledge set based upon personal experiences (Stanovich, 1994; Delgano, 2001; Schweitzer \& Stephenson, 2008). This construction of knowledge is seen as the key to effective learning and is the basic tenet of modern constructivist thought. Piaget (1978) also contributed to this line of thinking, proposing that children learn by doing and experiencing things that are different than what they already know. The writing of Vygotsky (1986) rounds out constructivism with the thinking that learning is social and should be done with modeling and interaction among a group. He goes on to advocate that students be taught how to think and consider one's thought processes (Delgano, 2001; Schweitzer \& Stephenson, 2008; Golding, 2011; Dewey, 1916).

Clearly, in order for constructivism to be effective in the educational setting, students must be active in the acquisition of their own learning to construct personal knowledge (Golding, 2011; Phillips 1995). Constructivists often refer to a simple principle that "learning is done by, not to the learner" (Fosnot, 1989, pg. 5). Cobb (2005) agrees with other constructivist thinkers but makes a distinction that although all of the above components must be present, they often have differing prominence according to the student, teacher, and setting. Newmann et.al (1995) agree, defining constructivism as follows:

"Constructivism is, primarily, an epistemological and psychological thesis about how we learn, viz, by actively and self-consciously bringing our past experiences and understanding (which may or may not bear the status of knowledge) to bear, in a collaborative exercise with other learners, as e process, interpret, and negotiate the meaning of new information" (pg. 4). 
Constructivism in education can be broken down further into two schools of thought. Erogenous Constructivism requires students to practice and demonstrate what knowledge they have acquired. However, the teacher controls activities, social interaction, and explicitly teaches metacognitive strategies. In contrast, Exogenous Constructivism requires that students select tasks and are active in the learning process while the teacher simply facilitates (Delgano, 2001). As a further clarification, Toshev (2015) and Splitter (2009) make the important clarification that in order to say one is using a constructivist pedagogy, the curriculum, strategies, and assessment must all have real-world connections and have academic and/or social value to the learner (Newmann, 1995). Table i provides a breakdown of four components of constructivism as described by Bostock (1998).

\section{Table i.}

The Four Components of Constructivism (adapted from Bostock, 1998).

\begin{tabular}{lc}
\hline \multicolumn{1}{c}{ Component } & Description \\
\hline Student Responsibility and Initiative & $\begin{array}{c}\text { Students should be given the } \\
\text { opportunity to exhibit self-control } \\
\text { and make choices concerning their } \\
\text { learning. }\end{array}$ \\
Generative Strategies & $\begin{array}{c}\text { Learning should be active, involving } \\
\text { problem solving. }\end{array}$ \\
Authentic Learning Contexts & $\begin{array}{c}\text { Learning should have real-world } \\
\text { connections at all levels. }\end{array}$ \\
Co-Operative Support & $\begin{array}{c}\text { Students should have the opportunity to } \\
\text { work with others to facilitate diverse } \\
\text { thinking. }\end{array}$ \\
\hline
\end{tabular}

Although both the Progressivism and Constructivism approaches may work for some students, research (Levy \& Vaughn, 2002; Rivera, Al Otaiba, \& Koorland, 2006, 
Hattie, 2009, What Works Clearinghouse,2019) has clearly demonstrated that that they are less effective for others. This is particularly true when considering students from disadvantaged backgrounds, those with a history of deficits, and those with disabilities. Methods within these approaches are of particular concern for students with EBD that may have difficulties with self-regulation and internal motivation to learn, as well as for students with literacy deficits who do not have the requisite skills to perform within a group activity.

\section{Instructivism}

Both constructivism and progressivism are popular methodologies (Wagner, 1998; Hay, 2006; Gordon, 2009; Pelstein, 2002; Kozioff, et al., 2000; LaBaree, 2005) in public schools in the United States. Our current licensing and curriculum standards for both Education Preparation Provider (EPP), and Core Curriculum for P12 students nationwide, have been guided by constructivist philosophy, with the following entities adhering to the constructivist principles: National Council for Teachers of English, National Council for Teachers of Mathematics, and the National Council for the Accreditation of Teacher Education, (now CAEP) (Kozioff, et al., 2000). However, the popularity has begun to wane. Although the constructivist approach has been widely adopted and implemented, students under this approach have too often not made sufficient academic progress. Most troubling, once students fall behind, their deficits tend to grow with each year of poor instruction (Benner, et al., 2010). But, by looking to science as a guide, instructivism has long been accepted as a key pedagogy in the education of students at-risk. Indeed, the entire instructivist movement was guided by 
social justice and equal access to marginalized groups when it began back in the 1950's (Becker \& Carnine, 1981; Bereiter \& Engelmann, 1966).

The instructivist methodology includes highly focused and explicit instruction driven by the teacher. From a philosophical perspective, instructivist educators believe that all students can learn and that student failures are indicative of teacher failure and a need to change instruction. As Engelmann and Carnine (1991) have so clearly stated, “...we begin with the obvious fact that the children we work with are perfectly capable of learning anything that we can teach...We know that the intellectual crippling of children is caused by faulty instruction- not by faulty children” ( $\mathrm{p}$. 376).

Instructivist pedagogy has been shown to benefit all types of students with evidence of success with learners at all ages and levels (Gardner, et al., 1994; Ullman \& Krasner, 1966; Ulrich, Stachnick, \& Mabry, 1970; Berieter \& Engelmann, 1966). Direct instruction is an instructional methodology that epitomizes the science-based logic the intructivist pedagogy.

Direct Instruction. Direct instruction is an instructional methodology based on the principles of applied behavior analysis (ABA). Rooted in the work of B. F. Skinner $(1938,1953)$, the fundamental premise of $\mathrm{ABA}$ is that behavior is functionally related to the environment, such that, control of conditions in the environment can be used to both predict and maintain behavior. Control of the environments can be used to design instruction that is individualized to maximize success for students.

As an instructional methodology, direct instruction (with a small d and i) refers to instruction in which the teacher (1) controls the lesson to create environmental 
arrangements and examples to make content explicit, (2) takes responsibility for maintaining student engagement throughout the lesson, and (3) provides multiple opportunities for meaningful practice with high rates of feedback (Hattie, 2009). Direct Instruction with capital letters (DI) refers to a specific type of direct instruction that is typically scripted and requires very specific and precise teacher behaviors in order to be effective. Lessons are scripted to ensure precise wording and the use of predetermined positive and negative examples to illustrate concepts. In addition, DI groups are generally kept small and fluid to accommodate ability grouping and the instructor acts as a remediator to fill in gaps in learning during independent practice (Gersten, Woodward, \& Darch, 1986; Stein, Carnine, \& Dixon, 1998).

Opponents of direct instruction state that it does not allow the student to think on higher and broader levels (Kozioff, LaNunziata, Cowardin, \& Bessellieu, 2000). However, research has shown that direct instruction allows students to feel, think, and act in the same manner as the progressivist and constructivist approaches, and is often chosen by new and tenured teachers as a first step in remediating students with academic difficulties. (Smeaton \& Waters, 2013). In addition, by building upon previous skills and facilitating high rates of success, students are able to more quickly shift to competent independent work, building broader and deeper skills. Thus, Direct Instruction (DI) can be considered as a sub-type of direct instruction (di) and is widely available in packaged curriculum. This review will focus on the larger concept of direct instruction.

Direct instruction was one of several instructional methodologies studied as part of the largest federally funded study of instruction in United States history. Over one billion dollars was spent, and research was conducted with over 75,000 students per year 
in the early years, with the study continuing from 1967-1995. Project Follow Through studied several methods used in our schools, and found that direct instruction was most successful of all methods in all domains. Domains included academic, cognitive, and affective. (National Institute for Direct Instruction, 2016).

Table ii presents the philosophical features of the direct instruction methodology. As noted by Kozioff and colleagues (2006) direct instruction is founded on the belief that all students can learn what a teacher can teach and that the onus for the student learning lies with the teacher This is evidenced in the adage: if a student has not learned, the teacher has not taught (Engelmann \& Carnine, 1991). It has become commonplace in educational circles to include this among the dispositions required for successful completion of teacher education programs. Teacher candidates must show that they can exhibit a belief that all students can learn (INTASC, 2011).

\section{Table ii.}

\section{The Philosophical Features of Direct Instruction (di)}

- All children can be taught

- All children can improve academically and in terms of self-image

- All teachers can succeed if provided with adequate training and materials

- Low performers and disadvantaged learners must be taught at a faster rate than typically occurs if they are to catch up to higher-performing peers

- All details of instruction must be controlled to minimize the chance of students' misinterpreting the information being taught and to maximize the reinforcing effect of instruction

(National Institute of Direct Instruction, 2020) 
The underlying philosophy of these instructivist approaches is that teaching and learning can be maximized through the direct and explicit introduction of content. According to Kirschner, Sweller, \& Clark (2006), science tells us that our brains work like a computer, with working memory being the CPU. The goal is to have learned material converted to the long-term memory, much like important documents in our computer. Learned material that is not converted to long term memory is lost after thirty seconds. Many students with learning difficulties can learn information for the short term. It is retained for that class, maybe that week, but is soon deleted from memory and must be retaught. When true learning takes place, the student is able to retain the information for greater lengths of time, and possibly use that information when working in other areas by generalizing the skill. Guided practice with repetition at high rates of success facilitate the transfer to long term memory. In fact, studies show that students with deficits actually lose previously learned material when instruction is not structured and explicit. (2006). The three components of Instructivism described above work together to ensure students not only learn, but retain what is learned.

Despite frequent objections to the contrary, direct instruction is more than rote memorization as there must also be a focus on cognitive learning that includes concepts, rules, strategies and problem-solving (Binder, 1996). These are known as "tool skills" and "complex skills and knowledge," all of which are taught simultaneously. Students must master and practice with tool skills such as basic math facts, and phonemes, and use them to build and master complex skills and knowledge such as solving equations, or reading a paragraph. 
Scope and sequence are also critical considerations within direct instruction. Teachers must task analyze content as a means of sequencing instructional steps and identifying logical classes and relationships. For example, students are taught phonemes before they are asked to construct words from them. Instruction is designed so that students know what they need at the beginning of the lesson and build upon it, to be used in later lessons. Instruction is explicit, with a teach, model, respond method employed throughout the lesson (Gersten, Woodward, \& Darch, 1986; Stein, Carnine, \& Dixon, 1998). The teacher's purposeful facilitation of student independence is part of a process of mediated scaffolding, in which the teacher gradually fades directed instruction, and provides the student with opportunities for independent success (Kameenui \& Carnine, 1998).

Formative assessment is an essential element of direct instruction. Each lesson builds upon prior knowledge, so it is important to ensure students have mastered the content of each lesson before moving on. In many cases, a brief formative assessment is administered after each lesson. As Binder states, "Educational programs will be more effective in the long run if they produce a more focused, but truly mastered, repertoire rather than a broad but fragile repertoire" (1996, p.179). Thus, through mastery of small concepts, students achieve mastery of big ideas. Big ideas consist of the large concepts, usually stated in the core content that students are to master at each grade level. Formative assessment flows easily within the direct instruction, as lessons are fast paced to enhance student engagement and on-task behavior. However, through this fast paced (sometimes scripted) lesson, teachers provide students a high rate of opportunities to respond, with averages of fifteen per minute common in each 30-45 minute lesson 
(Kozioff, et al., 2000). Through formative assessment of the smaller components, teaching and re-teaching these components until students have reached mastery, not moving on to new material until mastery has been met, successful mastery of big ideas can be achieved (Kameenui \& Carnine, 1998; Kozioff, et al., 2000). This is sometimes referred to as de-constructivist thought, in that content is broken down, and taught in a manner that allows later mastery of big ideas.

John Hattie (2009) conducted a large meta-analysis of over 800 studies of achievement. These studies included more than 42,000 students. As a result of this analysis, direct instruction was found to have an effect size of .57. In contrast, whole language (a constructivist approach) was found to have an effect size of 06. Similarly, inquiry learning and problem-based learning (Progressivism) had effect sizes of .31 and .15 respectively. Overall, in terms of literacy instruction, direct instruction not only had the largest effect size of any instructional methodology with the special education population, but with students of all ability levels.

A strong foundational literacy is important to the academic success of all students, but particularly to students with emotional and/or behavioral problems (Levy \& Chard, 2001; Algozzine, Wang, Violette, 2011; Fleming, et al., 2004). Instructivism is a method that has comparatively greater effects in facilitating student learning and retention of what they've learned. One strategy using the Instructivist approach is precision teaching.

Precision Teaching. Precision teaching can be thought of as an example of how direct instruction can be implemented, highlighting the ABA foundations of both. Figure ii provides a graphic representation of this relationship. Although Precision Teaching can 
be done without a direct instruction component, Lindsley (1990 a, 1990b, 1991, 1995) has found that it is most effective when the two are combined.

\section{Figure ii.}

The Relative Components of the Instructivist Pedagogy for Reading Instruction

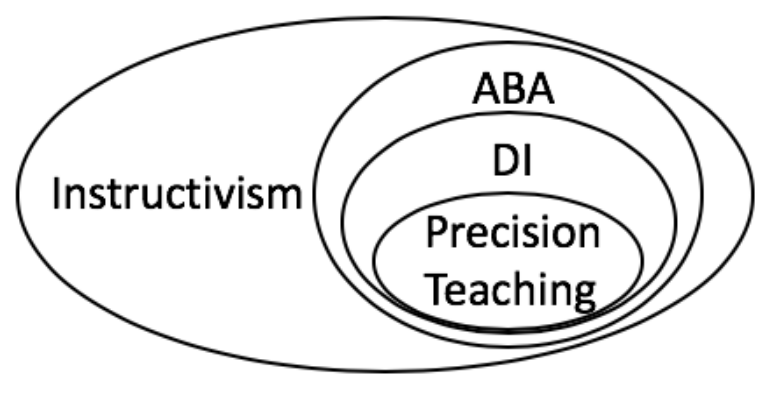

Based on the principles of $\mathrm{ABA}$, precision teaching was developed by Ogden Lindsley (1990a) as a systematic way of planning and implementing instruction. With the components of purposeful scaffolding and student/teacher shared responsibility, it is popular in special education, English language Learners, and general education. Although there are many pre-packaged curricula utilizing these components, teachers are quite capable of designing lessons themselves by adhering to Lindsley's rules. The four equally important rules of precision teaching are as follows: (1) teachers instruct students in basic skills that will be built upon later, (2) lessons are short and combine mastered skills with new content, (3) teachers assist students in using basic skills to build higher-level skills, and (4) teachers and students evaluate progress together (Lindsley, 1972).

Binder, Haughton, \& Von Eyk (1990) report that precision teaching is effective with a wide variety of students including those with behavioral challenges, autism, typical children, persons with brain injuries, and children with mental illnesses. Lindsley began using and developing precision teaching with adults and children with psychotic disorders in the 1950's (Lindsley, 1972). However, it has also been shown to be effective 
in all content areas. Researchers have found that learners exposed to precision teaching become more fluent (defined as high frequency accuracy), retained new knowledge longer, were better able to generalize, and distractions had less impact, than other methods (Binder, 1996, West \& Young, 1992). Although research has been conducted using precision teaching for over forty years, it has recently experienced a rebirth of sorts, with increased research in several academic areas. (Datchuk \& Kabina, Jr., 2017; Griffin \& Murtagh, 2015; Cihon, White, Zimmerman, Gesick, Stordahl, \& Eshleman, 2017; Weisenburgh-Snyder, Malmquist, Robbins, \& Lipshin, 2015; Kubina, Yurich, Durica, \& Healy, 2016).

Beck (1979) conducted a study in the Great Falls Montana School District which serves as an example of the impact precision teaching can have on student learning. Precision teaching for literacy was implemented with elementary students in the following manner:

- Teachers, administrators, and researchers decided on a specific model of direct instruction (flash cards) and formulated a session schedule (30 minutes a day, five days a week). Precision teaching was conducted in small groups and with individuals depending upon the severity of student needs. Success and failure were well defined by student performance criteria, with a procedure in place for each occurrence.

- Goals were set with each student that provided attainable challenges.

- A well-defined and disseminated definition of correct/incorrect was used by all involved and feedback for correct/incorrect responses was immediate and formative. 
- Students and teachers graphed progress together daily. Data was analyzed and next steps were determined. If students were not making adequate progress, students and teachers conferenced to consider revisions to the instruction and began again.

At the end of the intervention, all students in the district took the annual Iowa Test of Basic Skills. The students that had participated in precision teaching had a 19-40\% greater gain in percentile rank than did students not participating (Beck, 1979).

Research has shown us that effective literacy instruction has many components. They all act together as spokes in a wheel to keep the learner progressing. If any are missing, the progress is hampered greatly. The components of reading build upon themselves, yet no component is ever "finished." These components: phonemic awareness, phonics, fluency, and comprehension, work together to build what is known as literacy (NRP, 2000). Once students have mastered phonics and phonemic awareness, reading fluency is the next step. Reading fluency is defined as the ability to visualize phonetic code, and translate that into word meaning with an adequate rate, and prosody (NRP, 2000).

\section{Reading Fluency}

Oral reading fluency has a large impact on literacy. The very purpose of reading, in most cases, is comprehension. Without fluency, comprehension is difficult, if not impossible to achieve. Snow, Burns, \& Griffin (1998), in the National Research Council Report, stated, "Adequate progress in learning to read English (or any alphabetic language) beyond the initial level depends on sufficient practice in reading to achieve fluency with different texts" (p. 223). Because of the importance of reading fluency and 
the impact on reading comprehension, researchers have explored different fluency building methodologies with various populations.

As mentioned previously, individual reading without feedback, and oral reading with immediate feedback are the two categories of fluency intervention. Research shows that the former has little statistical impact on oral reading fluency of a wide variety of students, while the latter has significant positive impact. One hallmark of the feedback method is repetition, particularly of missed word and phrase (NRP, 2000).

\section{Repetition to Build Fluency: Repeated Reading Interventions}

Across all methodologies, it is commonly understood that practice and repetition are the key to acquiring fluency. Repeated reading has shown to be successful with students that struggle with oral reading fluency. The work of several reading experts in the 1970's led to what we now know as repeated reading (Laberge \& Samuels, 1974; Samuels, 1979; Chomsky, 1976; Dahl, 1974). Repeated reading has been explained and reframed in the literature for over fifty years. However, perhaps the best explanation is given by Kavale (2005) who explains that regardless of the variations, repeated reading consists of the student reading the same passage multiple times until a predetermined goal is met. This goal can either be the number of times read, or reading repeatedly until a criterion is met (2005). Repeated reading is popular because it is not an added expense, is easy to implement and adapt, takes minimal time, can be used in a wide range of settings, and requires minimal training of staff, students, faculty, and volunteers. (Strickland, Boon \& Spencer, 2013) The following statement, "rapid reading of high frequency words and rapid decoding as a means to enhance text understanding appear 
critical for typical reader development" (Chard, Vaughn, \& Tyler, 2002, p.386) explains the importance of mastery of oral reading fluency to each child.

There are two approaches to doing this, some formal and commercial and others unnamed and loosely aligned with curricular practices. The first approach is purely independent and involves students reading often, without feedback, simply for the experience of reading and interacting with the text. The second approach involves feedback from a teacher or other tutor immediately as the child reads aloud.

The independent approach involves programs such as sustained silent reading, Accelerated Reader, and reading incentive programs (Hunt, 1970; Shanahan, Wojciehowski, \& Rubik, 1998). There are numerous studies showing that students that read more are more fluent and better readers (Donahue, et al., 1999). However, none of the studies show clear statistical evidence that reading skills have increased as a result of these programs (NRP, 2000).

The feedback approach involves programs with repeated reading and guided repeated oral reading. The National Reading Panel completed a meta-analysis of research using both of these methodologies. All of the research included in the metaanalysis was conducted from 1970-1999 (NRP, 2000). In all but two of the studies, a positive effect, in some cases very large, was seen in the reading fluency of the participants. Several studies found that no specialized training is necessary for teachers to have a significant positive impact using repeated reading to increase reading fluency (Labbo \& Teale, 1990; Reutzel \& Hollingsworth, 1993; Conte \& Humphrey, 1989; Shany \& Biemiller, 1995). The National Reading Panel (2000), also states more research is necessary using repeated reading. 
Research on Repeated Reading Interventions. Many researchers over the past fifty years have found students gained oral reading fluency using this intervention. All types of students have been studied, including those with special needs. Due to its prevalence in classrooms across the world, many believe it is the most familiar and most researched fluency intervention. (Meyer \& Felton, 1999). Building on the work of Therrien, John Hattie (2009) found repeated reading to be beneficial as well. Hattie synthesized the work of Theirren (2004), with a large meta-analysis by Chard, Vaughn, and Tyler to determine an effect size for repeated reading of .67. In Hattie's opinion, repeated reading ranks sixteenth of all literacy interventions.

The National Reading Panel also supports the use of repeated reading as an intervention strategy. The NRP (2000) states repeated readings have "a consistent, and positive impact on word recognition, fluency, and comprehension, as measured by a variety of test instruments and at a range of grade levels" (p. 191).

Repeated reading has been found to have a statistically significant positive effect on oral reading fluency for all students. Criterion based repeated reading has the greatest impact in the least time (Kostowicz, Kubina, Selfridge, \& Gallagher, 2016; Kavale, 2005). Theirren's (2004) work supports this, finding repeated readings with criterion to have a mean effect size of 1.74 across 18 studies. He states, "results from this analysis...Confirmed previous findings that repeated reading improves students reading fluency and comprehension" (p. 258).

Studies of typical students have been conducted across all grade levels, and using various research methodologies, including randomized controlled trial, single case, case studies, and experimental designs. Studies were conducted in various parts of the world, 
although most were conducted in the United States. All studies and meta-analyses showed repeated reading to have a positive impact on student's oral reading fluency greater than that of those not receiving the repeated reading intervention, with some showing a lesser positive impact on reading comprehension skills, vocabulary, and phonemic awareness. Generalization results varied, however. Most studies showed generalization persisted as far as 14 weeks (Bennett, Gardner, Cartledge, Rammath, \& Council, 2017; Kostowicz, Kubina, Selfridge, \& Gallagher, 2016; Korat, Kozlov-Peratz, \& Segal-Drori, 2017; Lehner \& Ziegler, 2017; Ates, 2013; Swain, Leader-Janssen, \& Conley, 2017; Theirren, 2004; Chalfouleas, Martens, Dobson, Weinstein, \& Gardner, 2004; Kubina, Amato, Schwick, \& Therrien, 2008; Kostowicz \& Kubina, 2010). With so much research conducted using repeated reading with typical students that needed fluency intervention, the National Reading Panel synthesized fifty studies into a large meta-analysis. The mean weighted effect size of repeated reading across these studies was as follows: .44 fluency, .55 accuracy, and .35 comprehension. This meta-analysis found repeated reading to have a statistically significant positive impact on word recognition, fluency, and comprehension. (National Institute of Child Health and Human Development, 2000).

Although repeated reading has been shown to positively impact oral reading fluency with all populations through a wealth of research and meta-analysis, it is important that we focus on learners that have reading deficits and those with comorbid emotional behavioral disorders. What Works Clearinghouse (WWC) only provides information for students in grades nine through twelve. Although there are numerous studies using repeated reading as the intervention with this population, WWC only used 
fifteen studies and found twelve of those to not meet their standards. Using the three studies, their analysis showed repeated reading to have a positive impact on reading comprehension but no impact on other areas of literacy for students with learning disabilities (What Works Clearinghouse, 2014).

Fortunately, there is much more research to be studied. Skavale (2005) found repeated reading to have an effect size of .76 in his work with students with specific learning disabilities in literacy. A meta-analysis of fifteen studies showed that in each one, students participating in repeated reading showed greater gains than students that were not (Meyer \& Felton, 1999). In another meta-analysis of 24 studies on students with SLD, the repeated reading mean effect size on fluency was calculated at .68.

Interestingly, researchers found that the impact was greater for students that were further behind. These students showed an effect size of .71 on fluency after participating in repeated reading interventions (Chard, Vaughn, \& Tyler, 2002). Others found repeated reading to be effective for students with SLD as well (Strickland, Boon, \& Spencer, 2013; Hawkins, Marsicano, Schmitt, McCallum, \& Musti-Rao, 2015).

It is important to also study the research on repeated reading studies conducted with students comorbidly displaying literacy deficits and emotional behavioral disorders (EBD). Due to the nature of the emotional behavior disorder setting, most studies were conducted using single case design. A large meta-analysis of fifty-five studies conducted from 1975-2002 on students with both EBD and academic difficulties showed that 37\% of those studies focused on reading fluency. Repeated reading was found to be an effective intervention in each study that used it (Mooney, Epstein, Reid, \& Nelson, 2003). Others found that repeated reading positively impacted the oral reading fluency of 
students with both SLD in literacy and EBD, but also increased generalization, and in some cases comprehension (Staubitz, Cartledge, Yurick, \& Lo, 2005; Strong, Wehby, Falk, \& Lane, 2004). Interestingly, reward did not have a positive impact on behavior as well as fluency, yet repeated reading did in one study (Daly, Martens, Hamler, Dool, \& Eckert, 1999).

Research shows that repeated reading can be effective for both the general population of a school as well as those with special needs; particularly those that are classified as SLD and EBD. Dowhower (1989) states, "We have research evidence to show that repeated reading procedures produce gains in speed and accuracy, result in better phrasing and expression, and enhance recall and understanding for both good and poor readers" (p.506).

\section{The Great Leaps for Reading Fluency Intervention}

One reading intervention that is based on the foundations of direct instruction and repeated reading is the Great Leaps for Reading program (Campbell, 2018). Numerous researchers have found that repeated reading, combined with modeling, and immediate feedback is a very effective instructional method for reading fluency, particularly for those students with reading deficits (Lingo, 2014; Mercer, Campbell, Miller, Mercer, \& Lane, 2000; Campbell, 1998; Weinstein, \& Cooke, 1992; Scott \& Lingo, 2002; Patton, Crosby, Houchins, \& Jolivette, 2010; Walker, Jolivette, \& Lingo, 2005).

The purpose of the Great Leaps reading intervention is to facilitate increased reading fluency based on accuracy, speed and expressive language skills. The key components of Great Leaps for Reading include repeated readings with immediate feedback, positive correction, modeling, and daily analysis of data (Great Leaps, 2017). It 
is designed to work well in the classroom, requiring only $10-15$ minutes a day over a minimum of 3 days per week. The intervention package includes focus on: phonics, sight phrases, and short stories. Phonics instruction builds awareness and knowledge of sight/sound relationships by having students do repeated reading of phonemes to build sight fluency. Sight phrases allow the reader to master high frequency words and help to build student confidence and mastery of chunking, or the skill of retaining and acquiring small pieces of knowledge to build upon. Finally, the stories allow students to build fluency, including prosody (rate, intonation, expression, and rhythm), while providing motivation for continued reading.

Research on Great Leaps Reading. The Great Leaps intervention has been used with great success in all fifty states and over forty countries, with children at all levels of literacy. Hitt (2015), conducted a study using the Great Leaps curriculum, replicating those that had gone before her, (Lingo, 2014; Mercer, Campbell, Miller, Mercer, \& Lane, 2000; Campbell, 1998; Weinstein, \& Cooke, 1992; Scott \& Lingo, 2002; Patton, Crosby, Houchins, \& Jolivette, 2010; Walker, Jolivette, \& Lingo, 2005). While other research focused on students at the middle and elementary level, Hitt's study focused on using Great Leaps for Reading with high school students with literacy deficits. Her study showed that Great Leaps for Reading is a viable option for high school students as well. This work rounded the body of research to encompass all students K-12.

A key component of Great Leaps for Reading is repeated readings. There is a wealth of research showing that repeated reading has a profound positive impact on student's literacy skills. Therrien (2004) conducted a meta-analysis that found that the effect on comprehension and fluency on students was .76 on immediate assessment and 
.50 for new material. They found that timed repeated readings were also more effective than those that were untimed.

Great Leaps for Reading includes the components of goal setting as well. Hattie found goal setting collaboratively with students and teachers to have an effect size of .56, Mastery learning, another component of Great Leaps for Reading had an effect size of .58 , per Hattie's research. Small group learning, an additional tenet of Great Leaps for Reading, has an effect size of .49. A key component of Great Leaps for Reading is that students get immediate feedback. Feedback has an effect size of 73 (Hattie, 2009). Each component of the Great Leaps for Reading program has been found to have a large positive effect size.

Unfortunately, there are very few studies of the Great Leaps Reading Program conducted with young elementary students. A comparison study of K-2 students conducted in 2010 found that Great Leaps was not as effective as another intervention, nor as effective as it had been with other age levels (Begeny, Laugle, Krouse, Lynn, Tayrose, \& Stage, 2010). Additional research needs to be conducted at this level.

\section{Summary, Conclusions, and Remaining Questions}

After reviewing the literature with regard to effective pedagogy and strategies for teaching reading, it is apparent that instructivism is most aligned with empirical evidence for student success. Further, the greatest effects on student reading acquisition are associated with direct instruction, while fluency is dependent upon repeated reading strategies. This relationship is presented graphically as a conceptual framework in Figure iii below. 


\section{Figure iii.}

Conceptual Framework for Science-Based Effective Literacy Instruction

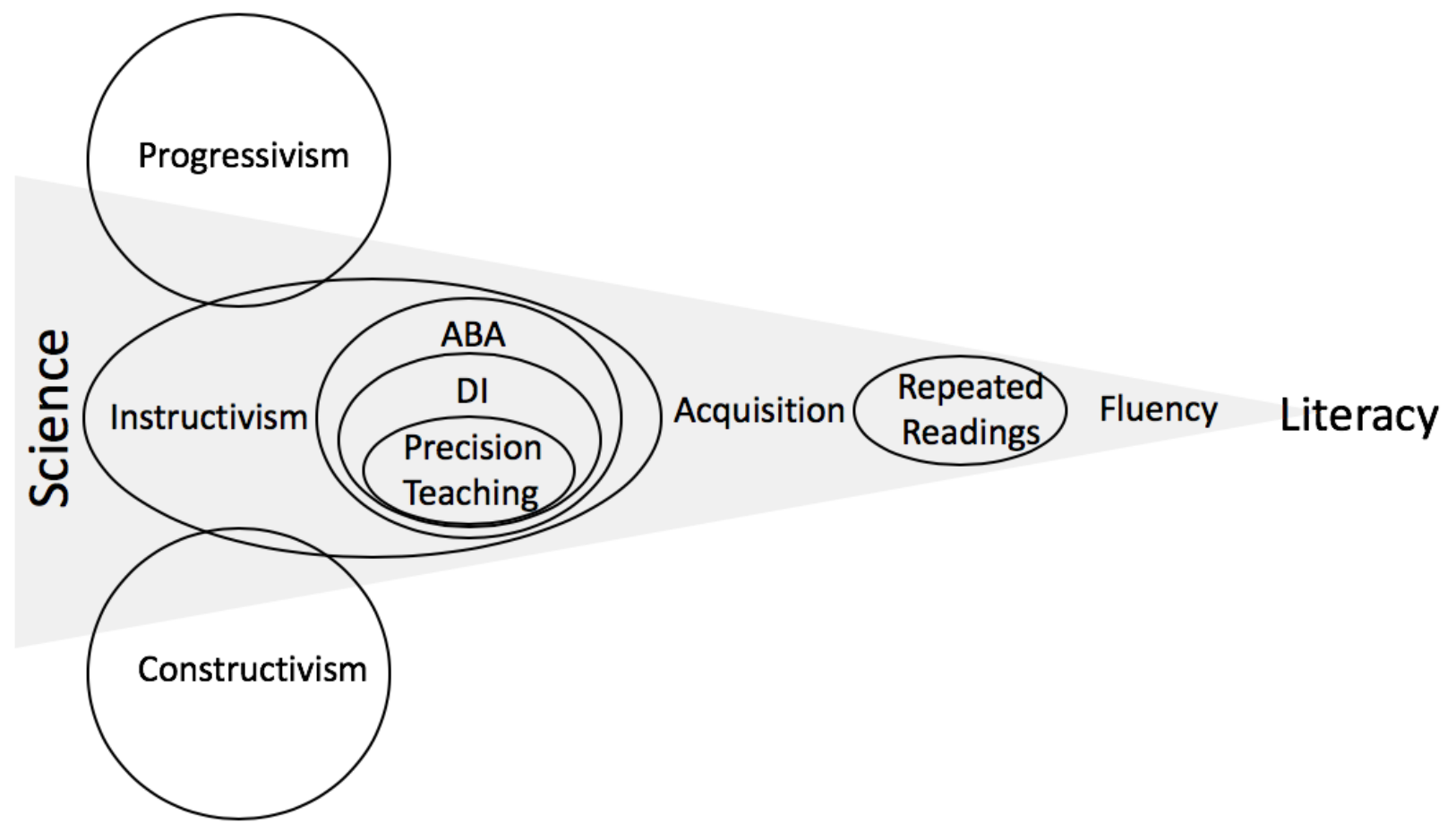

The fact that students with EBD need instruction that works for them in order to be successful has been well-established. In addition, what works for the general population of students, often will not have the greatest impact on students with both literacy deficits and challenging behaviors. For this reason, it is important to find interventions that have large effect sizes, and have been shown to work well with students that have both EBD and literacy deficits. Research has been conducted with high school and middle school students that have both EBD and literacy deficits, and it is clear that early intervention is more successful with this specific group. The purpose of this dissertation study is to determine the effect of the Great Leaps intervention for literacy on the reading levels of a group of elementary students that have both the classification of 
emotional behavioral disorders and severe reading deficits of at least two grade levels. 


\section{METHODS}

From the review of the literature it is clear that students with reading deficits and those with behavioral disorders struggle throughout school and adult life, and that these struggles are more prominent and dire among students with both of these conditions. Further, it is clear that direct instruction is an essential science-based instructional methodology for reading instruction, that reading fluency is an important but often missing component of effective reading instruction, and that repeated reading strategies such as Great Leaps have demonstrated promising effects with older students with comorbid academic and behavioral disabilities. The methodology described in this chapter was developed to examine the effects of an electronic version of the Great Leaps Reading Program on the reading fluency of elementary students with co-morbid academic and behavioral deficits.

The following research questions will serve as the focus for this study:

1. Does the Great Leaps for Reading Digital (electronic version) intervention for students identified as having co-morbid reading and behavioral deficits result in increased reading fluency using measures independent of Great Leaps?

2. Can the Great Leaps for Reading Digital (electronic version) intervention be implemented to fidelity by the researcher when working 
3. daily with students identified as having co-morbid reading and behavioral deficits?

4. Do teachers find that Great Leaps for Reading Digital (electronic version) is a program that is worth implementing to improve students reading fluency?

\section{Setting and Participants}

\section{Setting}

The study was conducted at a small elementary school in a rural suburb of a large southeastern city. Although in close proximity to an urban area, this particular school was in a largely agricultural area. The administration of the school included a principal, and an assistant principal. The school system had recently undergone reorganization, and at the time of this study was the only elementary school in the district. The school served approximately 830 children $2-5$, and the latest state data showed that sixty-three percent of students in third through fifth-grade scored proficient in reading on state assessments in the last school year. In terms of demographics, $28 \%$ of the school's students qualified for free/reduced lunch. However, during the current school year, the school received a grant for all students to receive free breakfast and lunch, as well as some meals to take home. The ethnicity of the school was nearly equal to that of the state as a whole, with slightly less diversity in a rural area. The demographics breakdown at the school was as follows, with state data in parentheses: 1\% African American (13\%), 2\% Asian (2\%), $11 \%$ Hispanic (12\%), $82 \%$ White (68\%), and $4 \%(5 \%)$ identifying as two or more races. The school had a 23:1 (17:1) student to adult ratio, including teachers and staff. 
This school was chosen due to its ease of access and openness to literacy, math, and behavioral interventions. Due to the covid-19 pandemic, the school had taken precautions and began the school year serving students all day, each school day, both virtually and in person. Although all students in this study were identified as having an Emotional Behavioral Disorder and the study took place in the resource/self-contained classroom, only one study participant was actually assigned to that classroom.

Covid-19 Protocol. The researcher attended training and designed a protocol to ensure the safety of all teachers, students and members of the school community during the study. The following steps were implemented, in addition to steps already in place.

1. The masked researcher came to the classroom door to get the student, ensuring the student applied his or her mask before leaving his or her desk

2. The masked researcher walked the student to the research area.

3. The masked researcher instructed the student to sit in the designated seat and gave the student a disposable copy of the daily quick read.

4. When applicable, the masked inter-rater reliability person joined the researcher, and the researcher handed the rater a copy, started the timer, and told the student to begin, as both begin scoring.

5. Once the student had finished, the rater and researcher copies were misted with Lysol and placed on the binder to dry, while the student threw his or hers away.

6. When the student was in baseline, he/she chose from three incentives shown to him/her. 
7. When the student was in intervention stage he/she was moved to the designated computer and typed in the given passcode.

8. The student and researcher proceeded through all three phases of the intervention.

9. At the end of all the phases, the student and researcher viewed the Great Leaps graph and discussed progress.

10. Student viewed three available incentives if he/she had been cooperative.

11. Student used hand sanitizer and researcher sanitized both work stations.

12. Student was walked back to class

\section{Student Selection}

The student selection criteria included formal identification as having both behavioral and academic disabilities and in grades 2-5, but excluded students with ESL or truancy issues. The seven students ultimately participating in the study were selected through a multiple-gating process in which the principal first identified potential students with co-morbid behavioral and academic deficits via available school data (e.g., MAP, DRA-2, TRC). It was not necessary that the student have IEP goals for both behavior and reading deficits to qualify for the study. The principal identified students with behavior deficits requiring tier three RTI intervention (individualized behavior plans), that also had reading deficits of at least two grade levels. This process is summarized in Table iii. 
Table iii.

Steps to Subject Selection

Step 1 School data used to compile a list of all students classified as having behavioral disorders and accompanying reading deficits of at least 2 grade levels. Excluded any student P-1, Step 2 ESL, or with truancy.

TOWRE-2 assessment administered to all remaining students and students with greatest

Step 3 fluency need (defined as discrepancy between grade level and actual oral reading fluency level) were selected to participate in the study.

Teachers and parents notified of study participation until seven students had been consented. If participants were lost to attrition, illness, or truancy, the student with the next highest level of need was be identified and informed consent forms were provided to the parent and/or guardian.

Assessment scores are of two different types because the school selected used Developmental Reading Assessment (DRA) for grades 3-5, and Text Reading Comprehension (TRC) scores for younger grades. More than the usual four students were chosen because it was suspected there may be attrition due to illness and/or quarantine guidelines. These scores are summarized in Table iv below. 
Table iv.

Spring 2019 Reading Levels of Selected Students

\begin{tabular}{lccccc}
\hline Student & $\begin{array}{c}\text { Spring } \\
\text { Reading Level }\end{array}$ & Teacher & $\begin{array}{c}\text { Grade } \\
\text { Level }\end{array}$ & $\begin{array}{c}\text { Screening } \\
\text { Permission }\end{array}$ & $\begin{array}{c}\text { Study } \\
\text { Permission }\end{array}$ \\
\hline M. J. & B (TRC) & A & 3 & Yes & Yes \\
T. S. & H (TRC) & A & 3 & Yes & Yes \\
B. S. & B (TRC) & B & 3 & Yes & Yes \\
K. J. & 14 (DRA) & C & 4 & Yes & Yes \\
T. P. & 6 (DRA) & D & 4 & Yes & Yes \\
N. C. & 14 (DRA) & E & 5 & Yes & Yes \\
K. R. & B (TRC) & F & 3 & Yes & Yes \\
\hline
\end{tabular}

Screening for Reading Fluency Using the TOWRE-2. Students were further screened by the researcher using the Test of Word Reading Efficiency, second edition (TOWRE-2) in order to identify those with the lowest reading fluency. On the first day, students identified by school administrators were given the informed consent for screening form. Any questions were answered, and meetings were held with parents if requested. During the second day, all participants took the Test of Word Reading Efficiency-2 (TOWRE-2). This instrument had been used as an outcome measure in the national Reading First Impact Study (Gemse, Jacob, Horst, Boulay, \& Unlu, 2008) and was designed in 1999 as a concise, reliable tool to measure sight word recognition and phonemic decoding (Pro-Ed, 2019). New normative data was collected in 2008-2009 in order to keep the test up to date. The assessment also has four forms, and has been featured in over 200 peer-reviewed articles. The test is made of two subtests. First, The Sight Word Efficiency (SWE) subtest, consisting of students being given a list of real words in vertical columns. Students read as many words as they can, aloud, in forty-five seconds. Second, The Phonemic Decoding Efficiency (PDE) assessment consists of 
pronounceable non-words listed in vertical columns. The student reads aloud as many as they can in forty-five seconds. Both assessments have four forms of equivalent difficulty, and have been normed across over 1700 people aged six through twenty-four, with the most recent norming using data from 2009-2012. The alternate forms reliability coefficient exceeds .90 , the test-retest coefficient using the same form also exceeds.90., and test retest using a different form exceeds .87 . One of the suggested uses of this assessment is to monitor reading fluency growth. (Pro-Ed, 2019)

The assessment was completed by administering both the test of Sight Word Efficiency and the Test of Phonemic Decoding Efficiency subtests of the TOWRE-2. This test consists of four forms and for the purposes of this research, all students were given only Form A. The test of Sight Word Efficiency requires a stopwatch, score sheet A, a writing utensil, and Sight Word Reading Efficiency card A. The researcher gave the student card A, and asked the student to read the practice words. The researcher then read the following script:

"I want you to read some lists of words as fast as you can. Let's start with this practice list. Begin at the top, and read down the list as fast as you can. If you come to a word you cannot read, just skip it, and go to the next word. You may use your finger to help you keep your place if you want to" (TOWRE-2, 2019, p.2).

The student was given opportunity to practice the words and ensured they were reading from top to bottom. If they were not, review of the directions was implemented, having them try again until they were reading from top to bottom. After practice was complete, the following directions were given: 
"Ok, now you will read some longer lists of words. The words start out pretty easy, but they get harder as you go along. Read as many words as fast as you can until I tell you to stop. Begin here, (indicating the beginning on the back of the card), and read down the list (move finger down the card), before you start on the next list (point to the second list). Read the words in order, but if you come to one you cannot read, skip it and go to the next one. Use your finger to keep your place if you want to, and if you skip more than one word, use your finger to show me the word you are reading next." (TOWRE-2, 2019, p.2)

The card was then placed with the practice side face up, while confirming student understanding. The student was directed, "As soon as I turn the card over, you will begin." (TOWRE-2, 2019, p. 2). The card was then turned over and the timer was started as soon as the student read the first word. Errors were marked on the score sheet as the student read. After 45 seconds, the student was asked to stop. A line was drawn under the last word read on the score sheet, as well as a notation of the time and number of words read correctly (TOWRE-2, 2019)

The Phonemic Decoding Efficiency assessment also requires a stopwatch and writing utensil, in addition to score sheet A and Phonemic Decoding Efficiency reading card Form A. The practice items were presented to the student with the direction, "I want you to read some made up words that are not real words. Just tell me how they sound. Let's start with the practice list. Begin at the top and read down the list as fast as you can. If you come to a made up word you 
cannot read, just skip it and go to the next word. Use your finger to help you keep your place if you want to." (TOWRE-2, 2019, p.3)

The student was then allowed to read the non-words while the researcher observed to make sure reading was top to bottom. If the student was not reading top to bottom the directions were reviewed and the student tried again. Once completed, the researcher held the card and stated,

"Ok, now you will read some longer lists of made up words. The made up words start out pretty easy, but they get harder as you go along. Read as many of them as you can until I tell you to stop. Begin here, (indicate the starting point) and read down the list (slide your finger down the list), before beginning the next list. Read the made up words in order, but if you come to one you can't read, skip it and go to the next one. Use your finger to keep your place if you want to, and if you skip more than one word, point to the word you are reading next" (Flip the card back to the practice words). "Do you understand? Ok. We will begin as soon as I turn the card over." (TOWRE-2, 2019, p.3).

The card was then turned over and the watch started as soon as the student read the first non-word. Errors were marked on the score sheet as the student read. After 45 seconds the student was asked to stop and the researcher drew a line under the last word read on the score sheet. The number of words correct and the time were then recorded on the score sheet.

At this point, the student chose an incentive from the treasure chest and returned to the classroom with the researcher. The researcher used the examinee record book to record 
both scores. The student's exact age was calculated and written on the record book. The raw scores from each sub test were entered. Using the Examiner's Handbook, the raw scores were converted to age-based norms, grade equivalents, and scaled scores. Scaled scores were then converted to percentile ranks, grade equivalent scores, and Total Word Reading Efficiency scores. For the purpose of this research, grade equivalent scores for Sight Word Efficiency and Phonemic Decoding Efficiency were used. This determined whether the child was two or more grade levels behind in reading fluency as indicated by school data. Once this data was gathered, the discrepancy between assessed fluency reading level and actual grade level was ranked. The log presented in Figure iv was used to track students during this process.

\section{Figure iv.}

Log for tracking student performance on the TOWRE-2

\begin{tabular}{|c|c|c|c|c|}
\hline Student & Grade & Teacher & DRA, TRC, District Level & TOWRE-2 Grade Equivalent \\
\hline M. J. & 3 & A & D (TRC) & SWE 1.0/PDE <1.0 \\
\hline T.S. & 3 & A & H (TRC) & SWE 1.2/ PDE 1.5 \\
\hline B.S. & 3 & B & B (TRC) & SWE 2.0/ PDE <1.0 \\
\hline K.J. & 4 & C & 14 (DRA) & SWE 2.5/PDE 1.0 \\
\hline T.P. & 4 & D & 6 (DRA) & SWE 1.0/PDE 1.2 \\
\hline N.C. & 5 & E & 14 (DRA) & SWE 2.5 PDE 1.2 \\
\hline K.R. & 3 & F & B (TRC) & SWE 1.0 PDE <1.0 \\
\hline
\end{tabular}




\section{Procedures}

This section details the daily processes and procedures that make up the intervention and measurement protocol.

\section{Independent Variable: Great Leaps for Reading Digital}

The Great Leaps for Reading Digital (GLRD) intervention served as the sole independent variable but was used in addition to whatever regular tier-three interventions (i.e., intensive remediations) these students were receiving in their classrooms. Because the involved classrooms had varying schedules for each child, GLRD was implemented without taking away from core literacy instruction, with intervention occurring during times that were not instructional for each student. The intervention took place five days a week for fifteen to twenty minutes per day, over approximately six weeks. Each child continued to have access the intervention after the study was complete. After the study, students were able to access their account from any internet connected device.

Baseline Procedures. During baseline each student continued to participate in the school's typical reading instruction. This included Jan Richardson guided reading instruction. Because the Jan Richardson curriculum involves pulling books from the bookroom, and the bookroom was sealed for sanitation, guided reading instruction needed to be converted to electronic resources. This was not ready for the teachers and students to use until late October, after the study had ended. In the interim, students participated in sustained silent reading with a book brought from home, and work sheets during the guided reading block. This varied by classroom. Although the school had interventions in place for Tier Two and Tier Three reading interventions, the school board had decided to discontinue these during the pandemic and children with reading 
deficits instead participated in Moby Max, which is a software designed to automatically assess deficits related to core standards and provide daily differentiated instruction and practice, on their Chromebook ${ }^{\mathrm{TM}}$. Because the students Chromebooks were not distributed until October 2, the researcher was encouraged to pull students during this time. The researcher asked students to be involved in daily quick reads to monitor reading fluency scores. The quick reads were selected from the Journey's Quick Read book at the student's academic grade level (Baumann, 2014), not their instructional level. These were disposable, and students threw them away after each use. The researcher kept the copies used by her and the IOA rater, but they were sanitized. The detailed steps followed during this phase can be found in Appendix A.

Great Leaps Intervention Procedures. The intervention consists of students reading $G L R D$ passages at their instructional level (as determined by the software) aloud orally until mastery (accuracy) is met. The GLRD is scored much like a running record, with students reading aloud in one-minute sections for Phonics, Sight Phrases, and Stories. The intervention is conducted one-on-one with an instructor (in this case the researcher). Once the student has completed the sight words, phrases and passage selections, the researcher reads what was missed, the instructor and student then read it together, then student reads it alone for accuracy, If the student did not score at least $85 \%$ on all three sections, the procedure was repeated with a same level passage the next day. At the end of each session the student's performance score is graphed by entering the score into the digital interface for the GLRD. This continues until the student meets the mastery criteria, at which point the student is said to "leap" to a new level. The researcher provided verbal praise, the student selected an incentive, and the level was gradually 
increased before the next session by the program. Measurement of fluency using Journey's Quick Reads, at grade level followed daily GLRD time. The steps of the intervention, and the safety protocol are listed in Appendix A.

One reason Great Leaps for Reading Digital was chosen, is the fact that the program pulls missed skills from the current day, and ensures they are included in materials for the next three lessons. Although all other research had been done with the traditional paper and pencil form of Great Leaps, research has shown learners respond more quickly to electronic interventions (Reinking \& Rickmand, 1990; Roth \& Beck, 1987; Tobias, 1988). Studies within the NRP (2000) report, also show reluctant learners respond well to digital versions of interventions (Heise, Papelweis, \& Tanner, 1991; Davidson, Elcock, \& Noyes, 1996; Wise, 1992; Weber \& Henderson, 1989; Wise, Olson, \& Trieman, 1990; Reinking, 1988).

\section{Fidelity of Implementation Procedures}

Before the study began, the researcher met with the classroom teacher, classroom assistant, assistant principal, and principal to train them on how to score the reading passages, the fidelity check sheets, and the GLRD sessions. Any questions or concerns were addressed, with training using videos conducted until reliability scores of $90 \%$ had been achieved. The school principal, assistant principal, or classroom teacher observed the researcher during $25 \%$ of sessions and used a checklist of GLRD procedures to record the degree to which the procedure was being implemented with fidelity (see Appendix A). Although remediation of fidelity was planned for, it was not necessary. Nearly every procedure at the school was new and had a checklist, so the study checklist was easy for all participants to follow. Overall, fidelity needed to be at $100 \%$ during more than $80 \%$ of 
trials and not less than $80 \%$ at any time in order to believe that the GLRD was being implemented to fidelity. This relates to research question 2: Can the Great Leaps reading intervention be implemented to fidelity by the researcher when working daily with students identified as having co-morbid reading and behavioral deficits?

\section{Measures and Data Collection Procedures}

Dependent Variable. Importantly, data collected and graphed during the GLRD was not a dependent measure. Rather, it was simply a part of the intervention process. Quick reads at grade level were conducted daily to measure generalization and study any effects of the intervention with an independent measure. A quick read involved a student reading a selection he or she had not seen before and it was scored like a running record. Students were given a 100-word passage at the current grade level, selected from the grade-leveled Journey Quick Read book. As the student read, the researcher marked errors, missed words, and inserted words. Mispronunciations were scored as an error, unless the child had a recognized speech impairment with which all scorers were familiar. Students were stopped at the end of one minute. Scores were tabulated by recording the number of words read correctly during the time limit. These data points were then graphed and served as the dependent variable.

Inter Observer Reliability. Inter-rater reliability was conducted during $25 \%$ of sessions (Gast, 2010; Cooper, et al., 2007), as the school principal, or classroom teacher looked over the researcher's shoulder during the cold reads and calculated a separate score. When these scores were compared, the smaller number was divided by the larger number to create a percentage of agreement. 
Care was taken to not only insure $25 \%$ of sessions had interrater reliability, but $25 \%$ of sessions, per child, had inter rater reliability. Scoring was compared after each observation, and observers worked together to make sure they were rating students the same.

Social Validity. Gast (2010) states that social validity must be present in order for a single subject research study to be of good quality. The impact of the intervention must be socially important for the subject, as well as have a significant magnitude on his or her life. The study must also be practical, cost effective, and have the ability to help subjects generalize skills. For face validity, this study meets the above criteria. Improved reading fluency skills will enhance the student's life both in and outside of school. Being able to read more efficiently has a positive impact that is very large. In order to test social validity, teachers were asked the following question:

- Do you feel the time your student spent in the Great Leaps for Reading Digital sessions was beneficial to their reading fluency?

This relates to research question 3: Do teachers find that Great Leaps for Reading Digital is a program that is worth implementing to improve students reading fluency?

\section{Research Design}

The questions posed herein were studied using a single subject multiple baseline across participants design (Gast, 2010). Single subject designs are appropriate to investigate the impact of an intervention on one or a small number of subjects. While single subject designs are not generalizable without both direct and systematic replication, they do allow for the identification of predictable relationships between interventions and human behavior. The multiple baseline is particularly appropriate for 
research involving student learning. For example, the GLRD intervention teaches students to be more fluent with their reading, and this is not something that can be removed to create experimental control. The multiple baseline provides experimental control and replication across at least three subjects to demonstrate whether an independent variable can predict change in behavior. All single subject research requires that data be collected on behavior continually from the first day and graphed formatively. This design was also chosen because the intervention is performed much like interventions in the child's natural environment within the classroom.

The logic of the multiple baseline is that all students receive the same baseline condition and then the intervention is implemented with each student in a staggered manner so that the effect can be replicated across subjects. The key to experimental control is the ability of the researcher to ensure that (1) intervention is implemented to fidelity immediately and continuously with each successive student, (2) data is collected during every session to record the timing and degree of any change, (3) each successive student remains in baseline while others before him or her stay in intervention to create repeated comparisons.

\section{Baseline}

To begin, all seven students were in baseline, receiving nothing more than what they would typically get from instruction. Each day all students were administered grade level "quick reads" as a means of assessing their oral reading fluency. This data was graphed each day, and this baseline continued until the first subject demonstrated stable data for at least five data points. Stability was defined using the guidelines provided by Tawney and Gast, "if $80 \%$ to $90 \%$ of the data point values fall within $15 \%$ of a 
condition, applied researchers will consider the data stable" (p.161). (1984). This means that each day, the mean of the last five days was multiplied by $15 \%$ and each day's score was checked for stability to see if it fell within the acceptable range until that student entered into intervention.

Of course, there are ethical concerns with this methodology, as some students remain in baseline for an extended time. However, because there are no dangerous behaviors and all students continued to receive typical instruction, this was not an issue for this study. Assuming stable data, a new student would move from baseline to intervention every five days, with all four students being in intervention around day twenty.

\section{Intervention}

Intervention involved all of the procedures described as part of GLRD. While the first student in the design may begin intervention as early as day 6, each subsequent student of the four will add another 5 days per student ahead of them. As plan for intervention, once Student A is stable at baseline, intervention with this student will be initiated, while the others remain at baseline. Once five stable intervention data points have been collected on Student A and stability of baseline data has continued with

Student B, Student B will begin intervention using the Great Leaps curriculum. Similarly, once five stable data points have been collected on Student B and stability of baseline data has continued with student $\mathrm{C}$, Student $\mathrm{C}$ will begin intervention. Then again, once five stable data points have been collected on Student $\mathrm{C}$ and stability of baseline data has continued with student D, Student D will begin intervention. It is expected that intervention stages will begin approximately five days apart (depending on the stability of 
data). Thus, the earliest that the student $\mathrm{D}$ could receive intervention would be after 5 days of all baseline, plus 5 days of student B intervention and another 5 days of student $\mathrm{C}$ intervention - or 15 days. Data is reported daily on both the independent variable (implementation fidelity) and dependent variable (oral reading fluency).

Because of a districtwide shutdown, due to Covid-19, the district went completely virtual on October 5, 2020. I received permission from all committee members, and the school district, to move the study to a virtual platform. I was given five days warning and was able to make clear schedules and arrangements with parents, guardians, students, teachers, and an assistant to continue the study. Students did not receive their laptops until October 1, 2020, but I was able to meet with each child, one on one, that day and instruct them in the use of Zoom. Some were unable to use Zoom at home due to spotty or nonexistent internet. With those students, I was able to use FaceTime, email and phone calls to complete the tasks.

\section{Data Analysis}

Data from the study were graphed to provide quick visual analysis of all three participants at a glance. The key dependent measure was the one-minute grade level quick reads data. The Great Leaps for Reading software data was also graphed but is not a dependent measure. Baseline data consist of only the quick reads from the grade level Journey's books. This allows for quick visual analysis of the degree to which any changes in data occur immediately upon the introduction of intervention with each student. Further, the direction, degree, and nature (e.g., trend/slope, level, variability) allow the researcher to draw conclusions regarding the strength of the evidence. 
Visual analysis is conducted by attending to variability, the trend, and level changes across condition phases. Level changes were judged in consideration of the percentage of data points that overlap across phases, using the rule of stability established by Tawney \& Gast (1984) to determine stability of baseline. This method was used to establish stability of baseline in order to begin intervention.

As early as 1964 researchers began to see deficits in interrater reliability of visual analysis in single case design (Johnson \& Baer, 1978; Cooper, Heron, \& Heyward, 1987; Johnston \& Penypacker, 1993; Kazdin, 1982; Brossart, et al., 2006; Harbst, et al., 1991; Park, et al., 1990; Parker, et al., 2006; Manolov,et al., 2014; Gast, 2010). This is particularly true with extended baseline, variable baselines, and in studies where there is not an immediate effect upon implementation of intervention, such as reading. Johnston and Pennypacker caution viewers to avoid allowing circumstances in which, "apparently large differences among measures of central tendency visually overwhelm the presence of equally large amounts of uncontrolled variability" (1980, p.351). In other words, sometimes the extraneous noise can distort what the researcher is viewing and analyzing. Many statistical methods have been used to address this, ranging from Ordinary Least Squares regression analysis, to various nonparametric non-overlap indices.

Although varying non-overlap methodology may have differences, all methods have pairwise comparisons of all data points across phase A and B to determine the dominant set (Cliff, 1993). Non-overlap has many strengths when used in single case design. Non-overlap methods are well suited to single case design as they do not require things that other methods do, such as linear relationships between time and scores, constant variance, nor normal distribution (Armitage, Berry, \& Matthews, 2002; Brossart, 
et al., 2018; Chen, et al., 2019; Sullivan, et al. 2015). Non-overlap is also resistant to the impact of outliers or variable data. In these cases, it can be the clearest methodology. Perhaps most significant, although relatively new to single case methodology, Tau-U, if not distorted, can confirm visual analysis of single case design research (Parker, et al., 2011).

Tau-U combines non-overlap between phases with trend from the intervention phase. Sometimes, baseline will appear to have a positive or negative trend. Although Tau-U can be calculated by hand using the formula in Figure v, I used the free software provided by Kevin Tarlow at http://www.ktarlow.com/stats/tau (Tarlow, 2014).

Figure v. Tau-U Formula

Tau-U=S/numbers of pairs

Whereas, " $\mathrm{S}=$ the number of positive paired comparisons (+) minus the number of negative paired comparisons (-) made in a chronological direction. A (+) is assigned for each pairwise comparison in which the later value is improved over baseline. Likewise, a (-) is assigned for each pairwise comparison that is decreased from baseline (McKenna, et al., 2019). Although it is simple to construct and compute, I chose to use the software both for accuracy, and the added benefit of baseline correction if needed. Tarlow's software analyzes the data in the following steps:

1. Using nonparametric methods, to assess and determine if Baseline Corrected Tau or Tau will more accurately show the effect size. Using this method is efficient and "robust to outliers and serial dependency" (Tarlow, 2014)

2. Monotonic baseline trend is estimated and corrected if necessary using Kendall's Tau rank correlation coefficient, and using Theil-Sen estimator. 
3. After baseline is corrected, if necessary, the effect size is calculated as a Tau correlation between a dummy code and the original or corrected data.

4. The output, once all data is entered, determines whether baseline correction is appropriate. It also provides the effect size and the $p$ value, indicating whether we will accept or reject the null hypothesis for research question one."

5. The effectiveness of the intervention will be determined by using the scale put forth by Parker \& Vannest (2009), with <.65 effect size indicating a small effect, a medium effect is indicated by an effect size of .66-.92, and a strong effect is an effect size of .93-1.

Although Tau-U is an important component of analysis for this study, visual analysis remains equally important. Tau- $\mathrm{U}$ is used simply as supportive, standardized statistical evidence of change in level to supplement visual analysis. As the data is variable, visual analysis of trend is supplemented by calculation of slope of trend. This adds standardized mathematical support for the visual analysis of change of trend within the study. Slope of trend was calculated for each phase, and within the intervention and baseline phases to differentiate between face to face and virtual sessions. This was calculated using the slope formula, $(\mathrm{y} 2-\mathrm{y} 1) /(\mathrm{x} 2-\mathrm{x} 1)$, with $\mathrm{x}^{1}, \mathrm{y}^{1}$ indicating the first point on the trend line, and $\mathrm{x}^{2}, \mathrm{y}^{2}$ indicating the second. In order to calculate the slope of trend, one must first find the trend of each phase. In order to do this, I used the mid-date, midrate method often used in applied behavior analysis.

The mid-date, mid-rate method requires that all data first be graphed. Once graphed, the trend lines were constructed for each phase using the following steps:

1. Count the data points in each phase. 
2. Draw a dotted vertical line to divide the data points in half.

3. Draw a short vertical line at the mid-date point on each side of the dotted vertical line. If there are uneven numbers of dates, draw the line through the middle date.

4. Draw a horizontal line on each side of the dotted vertical line at the mid-rate.

5. Connect both intersections with a line segment. This is the trend line for this phase.

Once the trend line had been constructed for each phase, two points on each trend line were used to apply the slope formula of $(y 2-y 1) /(x 2-x 1)$, in order to determine slope of trend in each phase.

As Creswell (2014) concluded, the addition of statistical analysis to a single case design can clarify matters. By adding Tau-U statistical analysis, to further clarify change of level, and the calculation of slope of trend, to further clarify change of trend, along with visual analysis, to my single case design, I will more accurately determine the impact of this intervention for these children, in this setting, at this time. These measures relate to research question one: Does the Great Leaps reading intervention for students identified as having co-morbid reading and behavioral deficits result in increased reading fluency using measures independent of Great Leaps? However, all that can ever be concluded from a single subject research design is that, in this particular case, with this particular child, in this particular setting, there appears to be a predictable association between the intervention and behavior, although not functional. No conclusions regarding cause and effect or generalizability can be drawn. 


\section{RESULTS}

The results of the study are focused on the following three questions:

1. Does the Great Leaps reading intervention for students identified as having co-morbid reading and behavioral deficits result in increased reading fluency using measures independent of Great Leaps?

2. Can the Great Leaps reading intervention be implemented to fidelity by the researcher when working daily with students identified as having co-morbid reading and behavioral deficits?

3. Do teachers find that Great Leaps for Reading Digital is a program that is worth implementing to improve students reading fluency?

\section{Participating Students that Are Not Included in Analysis}

The study began with seven students, as there was concern there may be attrition due to the pandemic. None of the students dropped out because they did not like the intervention, and all were still participating as of this writing. The students that dropped out of the study are detailed below.

B.S. had a spring TRC level of B, placing him at early kindergarten level in reading. He was in general education $100 \%$ of the day but has a 1:1 aid $60 \%$ of the day. He participated in the study from the date of his screening, August 18, 2020, until the date of his positive COVID-19 test on September 3, 2020.T.P. had a spring DRA level of six, placing him at kindergarten level as a fourth grader. He was classified as EBD and was in general education $100 \%$ of the day, but was designated as tier three in all three 
areas, and had IEP goals for behavior, reading, and math. He participated in the study for quite a long time but dropped from the study due to absences. T.P participated daily, beginning intervention on September 17, 2020. September 28 through September 30, he was absent due to a family trip. On October 5, the district began virtual instruction, and the study went virtual as well. T.P. participated virtually as planned. On the night of October 5, his parent contacted me and informed me he had a hospitalization. She had signed consent forms for me to work with him. However, the hospital would not allow me to work with the student as I was not a paid employee of their facility. The student returned home October 12, and I had intervention sessions with him on the twelfth through the fifteenth. I was unable to work with the child the sixteenth, as the family had no electric. I worked with the child again on the nineteenth and twentieth. On the twentyfirst, the child returned to the hospital. The child left the study due to excessive absences.

N.C. had a fourteen spring DRA placing him at first grade level as a fifth-grade student. N.C. Participated in the study until nearly the end. One week before the end, the parent stated that the new ABA therapist was very time consuming and they just didn't have time for the intervention and they missed several sessions in a row. N.C. remained in Baseline stage throughout his time in the study. He is classified as a student with Emotional Behavioral Disorder, and is fully self-contained. Of his last sessions, minimal effort was given.

K.W. had a TRC score of B, placing her at kindergarten level as an entering third grader. She had many classic emotional behavioral disorder characteristics, but was in the general education classroom setting $100 \%$ of the day. K.W. began baseline one-minute 
grade level quick reads on August 28. Unfortunately, she sat by B.S. on the bus, and tested positive, had to be quarantined, then became ill.

\section{Students that Completed Participation in the Study}

Although a table was constructed ranking students according to greatest need, it was only necessary once. The table was used if two students reached stable baseline at the same time, the student with greatest need would begin intervention first. T.P and K.J had very similar scores and achieved stability of baseline at the same time. As T.P. had a greater discrepancy between reading fluency level and grade level, he began intervention first.

M.J. began the study on August 27, 2020. He was a third grader with a spring TRC score of B, which is kindergarten level. He was classified as EBD. He was in general education $100 \%$ of the school day. He completed the TOWRE-2 on August 17, 2020. His Sight Word Efficiency Grade Equivalence was 1.0 and his Phonemic Decoding Efficiency was $<1.0$.

KJ began the study on August 27, 2020. He was a fourth grader with a spring DRA score of 14, which is first grade level. He was classified as EBD, and is $100 \%$ in the general education classroom. He took the TOWRE-2 assessment screening on August 25, 2020. His Sight Word Efficiency score was Grade Equivalency 2.5, and his Phonemic Decoding Efficiency Grade Level Equivalency Score was 1.0. T.S. began the study on August 27, 2020. He was a third grader and had a spring TRC score of $\mathrm{H}$, which is kindergarten level. He was classified as EBD and was in general education $100 \%$ of the school day. He completed his TOWRE-2 screening on August 25, 2020. His Sight Word 
Efficiency Grade Equivalency score was 1.2, and his Phonemic Decoding Efficiency

Grade Equivalency score was 1.5.

\section{Analysis of Results by Student}

Results are described by student in the order in which intervention was

implemented. Figure vi presents the data as graphed as a part of the single subject design protocol and analyses are described in terms of the features described in the previous chapter. 
Figure vi. Words per Minute on Daily Grade-Level Reads.
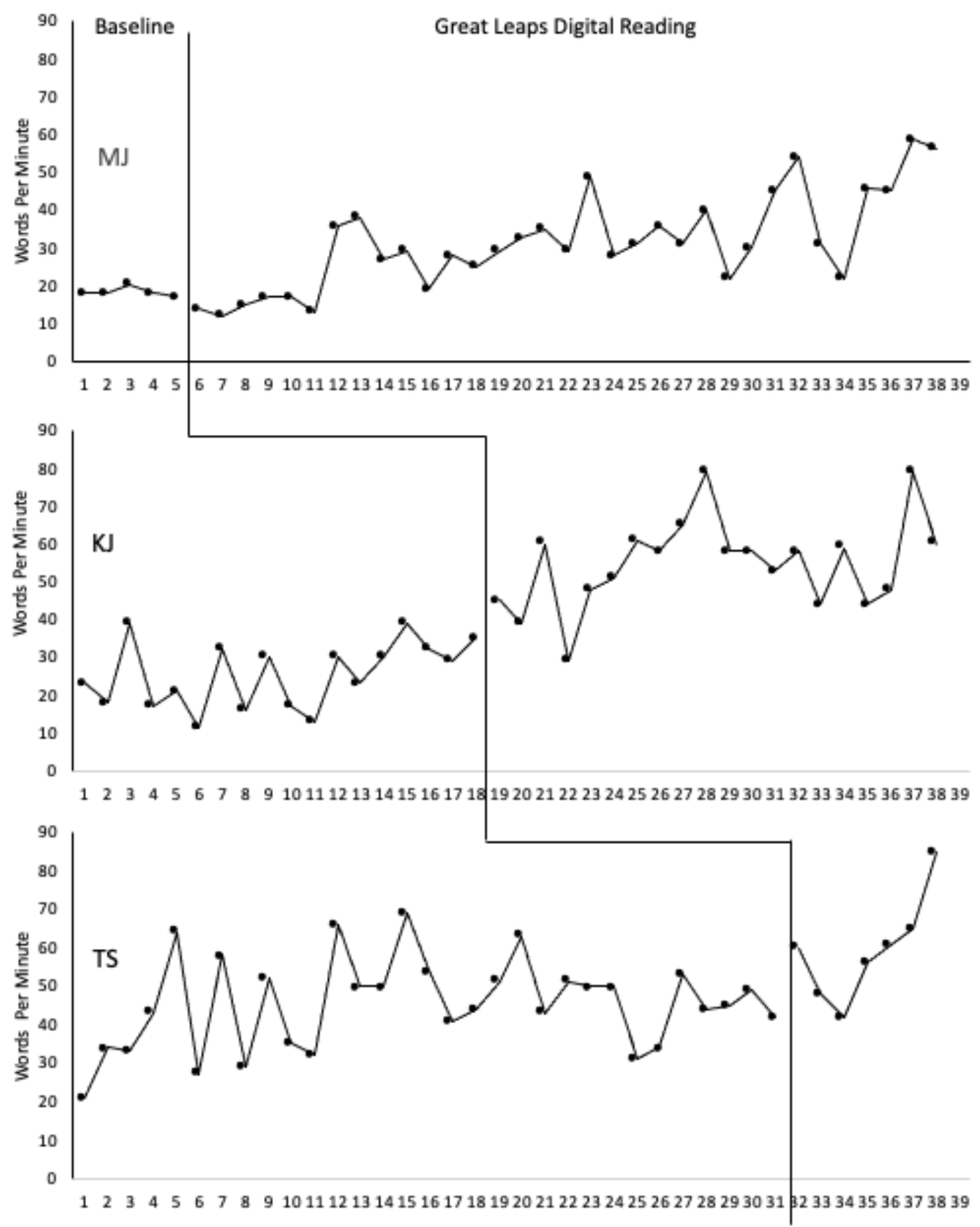


\section{Figure vii.}

Great Leaps for Reading Across Subjects Data

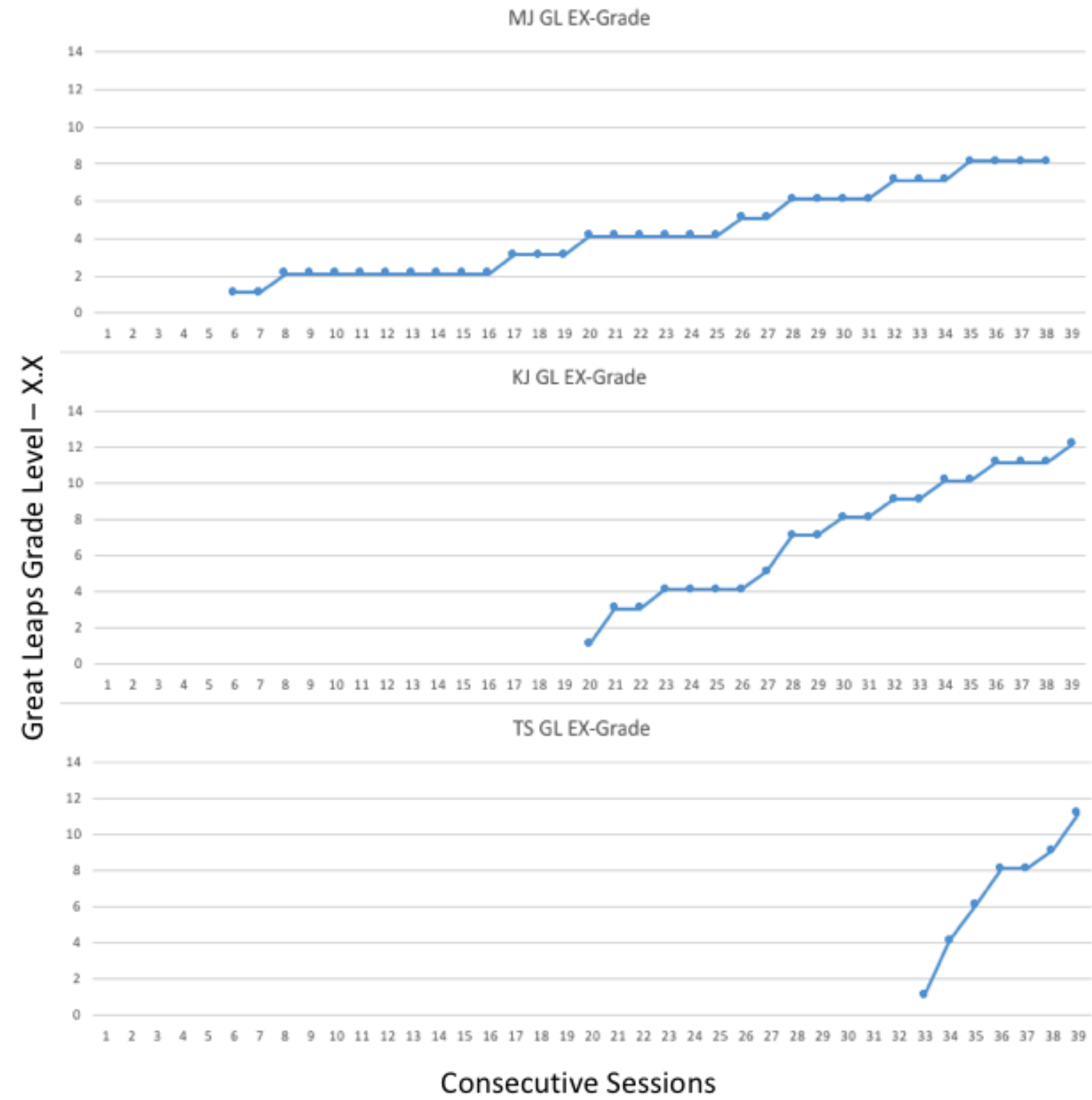

Student 1. M.J. was the first student to reach stability during baseline. His scores for the first five days were $18,18,20,18$, and 17 . Using the rule put forth by Tawney and 
Gast (1984), his mean was 18.2 , with a standard deviation (15\%) of 2.73 , allowing him to begin intervention on September 4, 2020.

According to the standards set forth by Wendt (2007), the data collected for the grade level one-minute quick reads indicate that the intervention was fairly effective for MJ, who began on Great Leaps for Reading virtual level 1.0, exercise 1. The levels he read on and the "leaps he made are detailed in the graph in Figure 7. He had "leaps" on September 8, September 11, September 15, 16, September 21, and October 15. He finished the study at level 1.4 , exercise 8 , although he is continuing the intervention. It is important to study trend in any single case design study. In the case of M.J. his baseline trend was fairly short and stable. Although he did have great variability in the intervention phase, the trend was decidedly positive, with a steep upward slope. When analyzing the difference between the trend lines for face to face and online intervention, face to face appears to have had a more positive impact in trend for M.J.

It must be noted, that with both the grade level quick reads and the Great Leaps reading passages increased in difficulty as the child progressed. Thus, some variability in scores is to be expected. That being said, it is difficult to evaluate true stability, as the same thing is not being assessed with each data point. However, MJ did achieve stability in baseline on September 4, 2020. Using the criteria set forth by Tawney and Gast (1987), his baseline mean was 18.2 , with a number of 2.73 being fifteen percent. This meant that any score between 15.47 and 20.93 would be considered within the acceptable range. There is a criterion of $80 \%$ of scores falling within the acceptable range to be considered stable, MJ had $100 \%$ of his scores for that time period fall within the acceptable range. 
Tarlow's Tau provides analysis of data which determines if baseline correction is necessary to account for variability of baseline scores. This was important, as variability of baseline was present in this study. In the case of M.J., baseline correction was not recommended (Tarlow, 2016). The overall analysis of MJ's scores reflect a Tau of .316 with a $P$ value of .018. Using Tarlow's standards, this means that the overall effect size for MJ was deemed small, as it is less than .65. Face to face session scores also did not require baseline correction and revealed a smaller Tau at .277 with a $P$ value of .088 , meaning the impact is not statistically significant. Interestingly, statistically and anecdotally, MJ had a much higher impact during virtual sessions. The virtual sessions did not require baseline correction, and had a Tau of .679, which is classified as a medium to high effect by Tarlow. The $P$ value of virtual sessions was .002 , deeming it significant (Tarlow, 2016, Tarlow, 2017). However, this could be due to a sequencing effect as the first part of intervention was flat.

Student 2. K.J. remained in baseline for some time, as there was difficulty achieving stability. Using the protocol set forth by Gast and Tawney (1987), the previous five days he had scores of $30,39,32,29$, and 35 . This made 33 the mean for the five-day period prior to intervention, with 4.95 the deviation of fifteen percent. At this point all but one score fell within the range, so he could proceed to intervention stage. His overall baseline mean was 25.68 , with a fifteen percent range of 3.85 . This gives a stability score range of 21.83 through 29.53. He only had four of nineteen scores fall within this range, giving his baseline phase a stability score of $21 \%$.

When looking at trend, it must be noted that K.J. did have outliers in his data in both phases. It must also be noted, due to difficulty in attaining stability at the level of 
Tawney \& Gast criteria (1987), K.J. was in baseline for an extended period. As mentioned before, he had wide variability in baseline scores, leading to a $21 \%$ baseline stability score. He qualified at the same time as T.P., but T.P. had greater discrepancy between his reading fluency level and grade level, so he began intervention first. K.J. then began intervention once five days had passed and his scores were once again stable. K.J. has a trend upward baseline. The trend can be observed in Appendix B. His trend line in Intervention phase continues upward at a more rapid rate. When data from online versus face to face intervention are compared, the trend is decidedly more accelerated in online intervention. Tarlow's Tau was used to determine effect of the intervention for this student as well. When examining the data for the overall intervention for KJ using Tarlow's software, it is not suggested to use baseline correction. By adhering to this suggestion, the software computes Tau for this student, in this overall study to be .584 , with a $P$ value of .000 , signifying the intervention had an overall small effect. When separating the data into face to face intervention and virtual, we find results similar to those of MJ. Face to face data for K.J. did not require baseline correction. The Tau for this data was .501 , with a $P$ value of .003 , meaning the effect was small, yet statistically significant. The Tau for virtual intervention was much greater at .718, indicating a medium to large impact, which was statistically significant with a $P$ value of .000 for this data (Tarlow, 2017).

According to Parker (2007) and Tarlow (2017), the intervention was fairly effective for KJ., after a delay. He began Great Leaps for Reading at level 1.0 exercise 1 and ended on level 1.6, exercise 12. He completed these levels in 20 sessions and had 
eight "leaps on September 23, September 25, September 29, October 1, October 2, October 8, October 12, and October 20. He continues the intervention daily.

Student 3. T.S. remained in baseline due to wide disparities in his baseline reading score. He was also the student with the lowest disparity between reading level and grade level of students accepted to the study. He was skilled at improving his scores, and had been in numerous reading interventions for many years. He would rush through his quick reads find all words he knew without attempting words he did not. The researcher had to instruct him in trying to read each word for three seconds before moving to the next. This resulted in frustration, but less disparity in scores, and finally stability. T.S. entered intervention on October 12, 2020. Using the rules set forth by Gast and Tawney (1987), his mean was 46.6, with the fifteen percent range being 6.99. the five scores were $42,49,45,44,53$. All of his scores fell within the acceptable range for $100 \%$ stability.

When looking at trend (Appendix B-D), and visual analysis, there are obvious visual differences between baseline and intervention stages. During the baseline phase, T.S. had a slight downward trend in his one-minute quick reads. Baseline data is highly variable. During intervention, he has a sharp upward trend.

Tarlow's Tau software showed that the data for T.S. did not require baseline correction, although the baseline phase was significantly long. The Tau for the intervention is .299, indicating a small effect size, with a $P$ value of .030 , indication it is statistically significant (Tarlow, 2016; Tarlow, 2017).

Because T.S. was still in baseline phase when the school reverted to one hundred percent online learning, it was necessary for T.S. to continue in baseline five additional 
days after baseline stability had been met. As the platform had changed, I needed to collect five stable baseline data points in the virtual platform before implementing the intervention. Luckily, the scores T.S. was achieving each day remained stable the first five days of virtual learning. As T.S. only had intervention during the virtual phase, there is no comparison data for this student between face to face and online intervention.

T.S. began Great Leaps for Reading at level 1.0 exercise 1. He finished at level 1.5 exercise 11, and had six "leaps" on October 12, October 13, October 14, October 15, October 16, and October 19. He continued Great Leaps daily as of this writing.

\section{Overall Analysis}

Visual analysis of data in single case design does have weaknesses. Studies by Normand \& Bailey (2006) showed interrater reliability to be only $72 \%$, even with the raters being Board Certified Behavior Analysts. Oddly, the rating without trend lines, $78 \%$, was higher than the interrater reliability for the data with trend lines (67\%). Campbell \& Herzinger (2010) concede that visual analysis is prone to Type I errors, because there is no standardized formula of observance. Because it is difficult to ascertain and compare degree of trend visually, it is appropriate to establish slope for the trend in each phase, for each student (Huitema, 1986b). Allyn \& Bacon (2007) suggest two ways of doing this: Using OLS (McCain \& Mccleary, 1979; Parsonson \& Baer, 1978; Campbell \& Herzinger, 2010; Cooper, et al., 2007), and computing slope by hand. As there is one phase for two students with an $\mathrm{N}$ below the required eight data points (Jenkins \& Quintana-Ascencio, 2020), I have chosen to compute slope for each phase by hand. In this way, visual analyzation can be supplemented by slope numbers to facilitate 
more accurate comparisons of the data. The slope of the trend for each phase, for each child, with online and face to face differentiated, can be found in Table v below. Slope was determined by using the formula $\left(y^{2}-y^{1}\right) /\left(x^{2}-x^{1}\right)$.

\section{Table v.}

Slope of Trend Lines in Phases.

\begin{tabular}{ccccc}
\hline Subject & Baseline & Baseline & Intervention & Online \\
& & Online & & 1.4 \\
M.J. & 0.0 & NA & 1.125 & 2.5 \\
K.J. & .50 & NA & 1.625 & 8.0 \\
T.S. & -.067 & NA & NA & \\
\hline
\end{tabular}

Even with the Lexile level increasing frequently, each child did have an increase in reading level. Table v. shows that each child did have an increase in rate and slope of their trend during the intervention stage. The slope of the trend line for each child increased in intervention, although much greater for M.J. and T.S. than K.J. The mean words per minute increased from baseline to intervention as well. This does show a replicated effect, although not a functional relation.

The Great Leaps graph, Figure 7, shows that although the level of the reading passage increased every few sessions, as students made "leaps", progress was continual. Visual analyzation of the Great Leaps graph, Figure 7 shows the progress of each individual student. M.J. had slow, steady, upward progress. K.J. had progress that was quicker and steeper than that of M.J., while T.S. had rapid, steep progress through the levels. 
When visually interpreting the graphs of both the Great Leaps words per minute and the quick read words per minute, it is important to note the similarities and differences. M.J. had data that was wildly divergent in the beginning of the intervention, then scores began to follow a similar pattern as the intervention progressed. K.J. had intervention graphs that followed the same peaks and valleys between the two data sets. Although the numbers are not the same, the acceleration and deceleration are nearly the same each day. T.S. did not have these similarities in data sets. His data sets show nearly an inverse relationship at several points during intervention.

Statistical analysis has often been implemented in single case design to clarify what visual analysis tells us, and to simplify interrater analysis. However, using Tarlow's Tau with the overall study is not appropriate. Although Tarlow's Tau makes no distributional assumptions and has excellent statistical power, it cannot be used for the overall study. Talow's Tau uses rank correlation to correct for baseline trend and variability. This method uses pairwise comparison to perform statistical analysis, comparing Phase A to Phase B. Because students in this study had different amounts of time in baseline, using Tarlow's Tau calculator will not give an accurate effect size for the overall study (Parker, et al., 2011; Tarlow, 2017; Tarlow, 2021).

\section{Fidelity of Implementation and Inter-Observer Reliability}

Fidelity of baseline and of intervention was checked weekly by the principal, assistant principal, or classroom teacher. Each time it was checked it was found to be at $100 \%$ fidelity. These documents can be found in the Appendix. Inter observer agreement (IOA) was checked twenty-five percent of sessions with each child, whether they be in baseline or in intervention stage, whether in person, or when the study reverted to virtual. 
IOA was checked by either the classroom teacher, the classroom assistant, or the principal, scoring the one-minute quick read along with the researcher. Those documents can be found in the appendix. All but three sessions scored $95 \%$ or above. The three sessions that scored lower were due to a child purposely not enunciating to try to get a higher score. He was unaware the scores did not affect his point sheet nor his grade, and he needed to be reassured several times. Finally, a conversation in the presence of his grandmother, reassuring him that we just wanted him to learn how to read, solved the problem.

\section{Social Validity}

All three teachers responded to the social validity question positively. All reported that T.S., M.J. and K.J read aloud in class voluntarily and there were less behavioral outbursts related to reading. Both teachers (T.S. and M.J. are in the same class) reported that all three students had logged in to Great Leaps every day since the study ended, and it is documented. All three parents/guardians, and both teachers felt that it was beneficial for the student, and had increased their confidence and ability in reading. All parent/guardians have requested the intervention continue with their students. 


\section{DISCUSSION}

The purpose of this single case design study was to analyze the impact the Great Leaps Digital intervention had on the fluency levels of students who had behavioral deficits and were two or more grade levels behind in reading. The study took place with second through fifth grade students at an elementary school in the suburbs of a large city in the Midwest. This study took place during the COVID-19 pandemic, so procedures were a bit different in order to maintain the health and safety of all involved. The students spent eight weeks and three days in face to face mode which included screening, and three weeks and three days in virtual mode, due to pandemic quarantines, at which time all school functions were converted to virtual protocols. Coordination between myself, teachers, administrators, parents, guardians, and caregivers was necessary to conduct training on new Chromebooks; find access to internet; and use phones, FaceTime, and other methods when computer access was not available.

In this chapter, I will discuss the research questions:

1. Does the Great Leaps for Reading Digital (electronic version) intervention for students identified as having co-morbid reading and behavioral deficits result in increased reading fluency using measures independent of Great Leaps? 
2. Can the Great Leaps for Reading Digital (electronic version) intervention be implemented to fidelity by the researcher when working daily with students identified as having co-morbid reading and behavioral deficits?

3. Do teachers find that Great Leaps for Reading Digital (electronic version) is a program that is worth implementing to improve students reading fluency? I will also discuss inter-observer agreement, limitations, generalizability, and future research.

\section{Interpretation of the Findings}

\section{Limitations}

Although care was taken to minimize issues related to internal validity, this study does have numerous limitations. Perhaps most confounding, the Lexile level increased in difficulty every few times the child read with both the one-minute quick reads and the Great Leaps for Reading Digital selections. This meant that, over time, students' scores were actually a measure of reading more difficult passages. As such, one would not expect to see the type of steady growth that would be apparent through visual analysis. Although the passages remained on grade level, the Lexile progression within each grade level can actually be quite different. For the purpose of teaching, remediating, and measuring growth, educators and researchers have assigned passages a level that corresponds with the difficulty of the passage. This level is determined by software, called the Lexile Analyzer, that takes into account both the semantic difficulty and syntactic complexity. Any writing that includes punctuation can be analyzed with this software. (The Lexile Framework for Reading, 2021). This is the case with the Journey's Quick Read passages as well. The quick passages are meant to be used throughout the 
school year, so there is graduated growth every few passages. K.J. is a fourth-grade student. The selections in his quick read book span 360 points (570L-930L). The span for M.J. and T.S. was 400 points (420L-820L), as they are both in third grade. Although the students did all show increases, that data would have been more accurate if every selection had been at the same Lexile level, as opposed to increasing every few days.

A second limitation is the fact that, because the study was conducted during a pandemic, it is unlikely that it can be replicated in the same way. Hygiene and sanitation were implemented with utmost care, resulting in the use of many materials that normally would not be used due to cost. Further, the study took place both face to face and virtually, due to quarantining by the school district and students had to be removed from the study due to extensive quarantine, lack of internet, and lack of resources.

Many families have lost income through the closures caused by the pandemic. They are unable to afford home internet, and in one case utility services. Although the school helped for several months, there is not funding to keep paying the bill. One particular parent has three boys with EBD that are quite physical. None of her family members are willing to take them in. She wants to return to work, but it is also very difficult to find and afford childcare for children with behavioral challenges on a minimum wage salary. She usually worked during school hours. The children had access to internet, and electricity while at school, and she did not need to pay for childcare. All of that changed with the restrictions of the pandemic.

Another parent lost internet, and could not handle the stress of dealing with two children with classifications of EBD, and recent outside evaluations of autism spectrum 
disorder, doing virtual education. She withdrew from the study, and eventually, four days later, school. Normally, these students would have been able to remain in the study.

The fact that this study made use of a single case design is a third limitation. When conducting a single case design study, we know before we begin, all that it can tell us is that for this group of students, under these conditions, in this place, at this time, this happened. The only way to generalize at all is to replicate. While I believe the study was done in a valid manner, issues with Lexile scores previously described presented problems for both typical visual analysis and statistical analyses.

Finally, while I have compared the results of face to face and virtual intervention because I found the data interesting, all virtual intervention sessions took place at the end of the study. All students except one had already been in intervention. The risk of maturity is very real in this study. Although this data does show interesting trends, nothing can be concluded and more research is needed.

\section{Research Question One}

In this section, I will analyze the findings for each participant, then for the study as a whole in regard to the research question:

1. Does the Great Leaps for Reading Digital (electronic version) intervention for students identified as having co-morbid reading and behavioral deficits result in increased reading fluency using measures independent of Great Leaps?

\section{Student 1: MJ}

Although family and teachers feel that the intervention was a huge success for MJ, we, as researchers, must not rely on anecdotal findings, but must use data. MJ began 
the intervention on September 4, 2020, once his baseline scores showed stability. Using criteria set for the by Tawney and Gast (1987), his baseline mean was 18.2 words per minute, with 2.73 being fifteen percent. This meant any quick read score between 15.47 and 20.93 would be considered stable given that I only counted whole words, and score between 15 and 20 was considered stable. Tawney and Gast (1987) require that $80 \%$ of the scores fall within the acceptable range. MJ had 100\% of his scores fall within the acceptable range on September 4, 2020.

By analyzing the data presented in Figures 6 and 7, it is obvious from visual analysis that the data is trending positively. Visual trend analysis also shows us he had greater gains during online intervention, as opposed to face to face intervention. Tarlow’s Tau (Tarlow, 2016) was used to analyze data further. This particular software determines if baseline correction is necessary in order to provide more accurate interpretation of the data. T tests were not used, as they do not account for overlap ( Broussard, et al., 2018). In the case of MJ, baseline correction was not recommended. The overall analysis of data for MJ reflected a Tau of .316 with a $P$ value of .018 , meaning it is statistically significant, as it is less than .05. Using Tarlow's standards, the overall effect size for MJ after using this intervention was small, as it was less than .65. Tarlow states that an effect size of .65 or less is considered small, an effect size of .66-.92 is medium to high, and an effect size of .93-1.0 is deemed strong (Tarlow, 2016).

Face to face sessions also did not have baseline correction. Face to face sessions had a smaller Tau at .277 with a $\mathrm{P}$ value of .088 , meaning the impact is not statistically significant. Both statistically and anecdotally, MJ seemed to experience a much higher effect during virtual sessions. Virtual sessions also did not require baseline correction. 
These sessions had a calculated Tau of .679, and a $P$ value of.002 deeming them statistically significant. This Tau is classified as a medium to high effect size (Tarlow, 2016; Tarlow, 2017). Although there are confounds to separating the intervention by presentation mode, I feel the data is interesting, and should be noted. Limitations will be discussed in later parts of this chapter.

When analyzing the Great Leaps data, MJ began at a level 1.0 on Exercise 1. When the study ended, he was at level 1.4, indicating he had gained .4 grade level in reading fluency, and had gained 45 words per minute. It must be noted that this data was calculated solely by Great Leaps software. These findings must be considered in light of the identified limitations and potential confounds. He continues the intervention daily.

\section{Student 2: KJ}

$\mathrm{KJ}$ was the third student, to begin intervention. The second student had to leave the study. K.J. remained in baseline for quite some time due to lack of stability. He achieved more stability as baseline continued. Although he achieved baseline stability five days earlier than when he began, the study protocol determined that another child achieving stability at the same time had greater discrepancy between actual fluency level and grade level, so that child began the intervention first. KJ's mean for stable baseline was 33, with a fifteen percent deviation of 4.95 . All but one score within the five-day time period fell within this range, so he was able to proceed.

Because of outliers in both phases of his data, visual analysis is difficult. He does have a slight upward trend in baseline. However, it can be noted that the slope of his trend in intervention is more positive. When differentiating between online and face to 
face intervention, the trend is decidedly more positive with greater slope during online intervention.

Because of difficulties in visual analysis, Tarlow's Tau (Tarlow, 2016) was used with this student as well. The data for overall intervention with this student was entered and baseline correction was not recommended. The software computes the Tau for the overall intervention for this student as .584 with a $P$ value of .000 , which is statistically significant. This signifies, by the criteria set forth by Tarlow $(2017,2016)$, that the overall intervention had a small effect size. When separating the data from the two phases of the intervention, neither were recommended for baseline correction. Face to face intervention resulted in a Tau of .501 with a $P$ value of .003 , which is statistically significant, yet still a small effect size, as it is under.65. The virtual component had a Tau of .718, with a $P$ value of .000 . This indicates a medium to large impact. Again, these findings must be considered in light of the identified limitations and potential confounds

When analyzing the data provided by the Great Leaps software, and the oneminute quick reads, $\mathrm{KJ}$ is shown to have made progress. He began Great Leaps on level 1.0, Exercise 1, and finished the study on level 1.6, Exercise 12. This indicates he had growth of .6 grade level and 48 words per minute in fluency growth. He continues the intervention daily.

\section{Student 3: T.S.}

As the third student to begin and complete the intervention, T.S. remained in baseline the longest. He also had the least discrepancy in actual reading fluency and grade level of any student entering the study. T.S. had experienced a wide variety of reading interventions in his four years of school, and was very skilled at improving 
scores, while not necessarily increasing skills. I say this to inform the reader that T.S. knew how to "play the game". This is not said to indicate he did not give good effort. He simply knew the goal and had sufficient intelligence to find ways to achieve scores without completing the task as planned. He would often rush through quick reads picking out all words he knew, without attempting those he did not. Direct instruction and insistence that he try each word for three seconds before moving on resulted in frustration, but less disparity, and finally stability of baseline. T.S. entered intervention on October 12, 2020. Using the rules set forth by Tawney and Gast (1987), his mean was 46.6, with the fifteen percent range being 6.99. All of his scores for the five days fell within this range. Because the school switched to virtual learning while T.S. was still in baseline, it was extended an additional five days. This was to provide five days of stable data with the same mode of presentation.

When looking at trend with visual analysis, there are obvious visual differences between baseline and intervention stages. During baseline phase, T.S. had a slight downward trend in his one-minute quick read scores. His baseline data was highly variable. During intervention, he had a more pronounced positive trend.

Tarlow's Tau software (2017) did not recommend baseline correction for T.S.'s data, although he did have extended baseline. The Tau for his intervention was .299, with a $P$ value of .030 , which is statistically significant as it is less than .05 . According to Tarlow $(2017 ; 2016)$ this indicates a small effect size. As T.S. entered intervention after the school had reverted to virtual learning, all of his intervention data was in virtual mode. 
T.S. began Great Leaps at level 1.0, Exercise 1, and finished the study at level 1.5, Exercise 11. This means he gained .5 a grade level, and 54 words per minute. Given the short time of intervention, he made the greatest progress in the shortest amount of time. As with the others, however, these findings must be considered in light of the identified limitations and potential confounds. He continues the intervention daily. Overall Analysis

Research has shown visual analysis to have weaknesses in single case design, particularly when there is extended baseline, or outliers (Normand \& Bailey, 2006). Visual analysis alone is also prone to Type 1 errors (Campbell \& Herzinger, 2010). For this reason, I wanted supportive data to supplement visual analysis. The data found in Table v shows the slope in each phase for each student. This slope was computed using the standard formula: $\left(y^{2}-y^{l}\right) /\left(x^{2}-x^{l}\right)$. The data for each student was graphed for each phase. Trend lines were constructed for each phase using standard ABA mid-rate, middate graphing. Using these graphs, the data points can be used to give us our numbers to enter into the above equation. This is done by determining the coordinates for each trend line at the beginning and end of each phase. The coordinate values are placed in the formula above, with $\mathrm{Y}$ being rise and $\mathrm{X}$ being run. In this way, the slope of the trend line can be determined. Using slope of trend for each phase allows us to more accurately compare the data overall and between students. Even with confounding factors (Lexile level), each child did have an increase in reading level, indicative of a positive impact. Table $\mathrm{v}$ shows that each child had an increase in rate and slope during intervention. This increase was much greater for M.J. and T.S. than K.J. The mean words per minute increased for each student in intervention as well. Each participant did show an increase 
in reading fluency during the intervention phase of this study that was greater than any increase found in baseline. However, across subjects, growth was either insufficiently different from baseline (lacking an obvious level change), delayed (lacking temporal contiguity), or too variable conclude the existence of a functional relationship. As noted, more positive results may have been muted by the increasing Lexile levels.

Question 1 and Talow's Tau. Although I did use Talow's Tau to determine Tau, and whether baseline correction was necessary for student data, I have found that it is inappropriate to use Tarlow's Tau for the study as a whole. After discussing the study at length with Kevin Tarlow, it was determined that it is appropriate for student data, but not the overall data set. Tarlow's Tau uses rank correlation to correct for baseline trend and variability and, when necessary, a pairwise comparison is used to compare baseline to intervention. Because of the construction of the single case study and the different lengths of baseline, the calculator would blend data sets, thus making the output for the overall study inaccurate (Tarlow, 2021; Parker, et al., 2011; Tarlow, 2017). That being said, the study can be seen as effective in that it did have at least a small positive effect for each student.

\section{Research Question Two}

The second research questions was as follows:

2. Can the Great Leaps for Reading Digital (electronic version) intervention be implemented to fidelity by the researcher when working daily with students identified as having co-morbid reading and behavioral deficits?

Data was carefully collected using a fidelity checklist by administrators and the classroom teacher. There were separate checklists for baseline and intervention phases. 
Because I may have had students in both phases on the same date, both were collected until there were no longer students in baseline phase. Fidelity checks were conducted randomly at least once a week. Each of these signed and dated check sheets can be found in the appendix. Fidelity was found to be at $100 \%$ on each date for both phases.

\section{Research Question Three}

The third research question was less formal and focused on teacher perceptions of the impact of the study. This question was as follows:

3. Do teachers find that Great Leaps for Reading Digital (electronic version) is a program that is worth implementing to improve students reading fluency?

Each of the teacher responses can be found in the appendix. Both felt that the intervention had an overwhelmingly positive impact on the students. For M.J., the teacher noted that he is having less tantrums during academic tasks, reads aloud willingly, and is more attentive during small group and class activities. T.S. is in the same classroom, and the teacher noted his reading skill had increased dramatically, along with his willingness to try to read things he doesn't readily know. She also noted greater effort and resiliency toward literacy tasks, and less physical aggression toward peers after literacy activities. K.J.'s teacher noted an eagerness to attend to literacy activities and increased fluency when doing so. She noted increased scores on district math tests as well, attributing it to reading of directions and problems. K.J.'s teacher noted increased social interaction and no physical aggression since the student had begun participating in the study.

Although anecdotal, the teachers felt that the intervention was valuable to the students. Teachers of students that remained in the study and those that did not have 
asked for the intervention to continue, and it has. We received district approval, as well as the donation of the software. In addition, I was able to secure a grant, which allows students to meet virtually, before or after school, and participate in the intervention. I trained a paraprofessional, K.M. to conduct the intervention. She does so daily with support from me, and homeroom teachers. Fifteen students participate per day.

\section{Generalizability}

While results of this study cannot be generalized, there are lessons to be learned regarding how one might operate a program such as this under the restrictions of a pandemic. I do believe it was important that the study continued when the school reverted to fully virtual learning. Although there were challenges with equipment, scheduling, and internet access, I think it is important that the study and the intervention continued with $100 \%$ fidelity. This shows that even during the pandemic, we can continue research and we can continue intervention. We should not stop looking for ways to teach and reach our children, remediate and enrich their learning, and continue the process of educating every student at the highest level possible. Once the pandemic is over, and schools return to some semblance of normalcy, I do believe the study could be easily altered and generalized to most schools in the United States.

\section{Future Research}

Research in this area needs to continue and there is much to be learned. This study should be conducted again, with quick reads on one Lexile level for each grade. In future studies, selections would need to be made from grade level texts, making sure that one type of selection, fiction or nonfiction, was used throughout. These selections should be entered into the Lexile Analyzer, which is software on the Lexile site that can determine 
the Lexile level of any written work that contains punctuation. The Lexile level is determined by analyzing syntactic and semantic level of each individual piece of writing. The researcher should decide on a Lexile level within the grade level of the child, and use only selections at that level. In this way, true progress, or lack thereof, can be measured.

This was not done in the current study, as it was determined the Quick Read books should be used for the independent measure, the study was approved by IRB, and the discrepancy in Lexile levels in the books of Quick Reads was not revealed until six weeks into the study. The researcher questioned why the students were not making greater progress, noticed the difficulty of passages seemed to be increasing, and investigated further. At that point, the Lexile levels of each passage were discovered. The researcher decided to continue the study, as she felt it would provide valuable data, but plan to do further research in the future with equal Lexile levels per day, per grade.

Although a single case design was appropriate for this study due to its exploratory nature, broad research should be conducted to determine whether virtual or face to face intervention has a larger impact on reading fluency for this population. A comparison study, perhaps a randomized controlled trial, within a district or two, with one group participating in the intervention face to face, and another group doing so virtually, would also be helpful.

Research should also continue that measures the impact of reading fluency improvement on behavioral performance within the school day. Anecdotally, we know my study and reading intervention had a positive impact on behaviors throughout the school day for all three participants, and even those that had to leave the study for various reasons. More research is needed in this area. 


\section{CONCLUSION}

Great Leaps for Reading Digital did have a positive impact on the reading fluency of the subjects of this study. There were confounding factors, yet the data does show a small to medium effect size for these students, in this situation, at this time. Preliminary data also shows that it is more effective for the students in virtual mode than in face to face. Because of confounding factors, it cannot be said with certainty that Great Leaps for Digital has any more than a small effect on the reading fluency of participants. I hope that the study can be repeated, completely in virtual mode, on a larger scale, in the near future.

Although this study took place during a global pandemic, I think that lessons can

be learned from the process. Most importantly, learning and research can, and should continue. As educators, we are taught to differentiate and change our teaching to reach every student "where they are". These words have never been more literal, or more impactful than during this time. Importantly, this research was implemented to fidelity, with students that are often considered the most difficult population to reach. I had a special Covid-19 protocol while in the school, and had to be flexible and find new ways of reaching and motivating students once the school had to go to an all virtual platform. We used numerous virtual platforms to find what worked best for each family. When the internet was down, or a family didn't have electricity, they went to a fast food restaurant, or we used cell phones. I partnered with the families, and we found a way. That must occur in every school, with every student. Although we may need to differentiate in new and innovative ways, that perhaps have not been used in P-12 education in the past, we 
cannot stop. The students, even those with disabilities, want and need to learn. We must find ways to motivate and reach them. Once we do, learning will occur.

Although my study is small, it does have implications for those in the education profession as well. We must alter the way we prepare our P-12 educators. We must develop pedagogy at the undergraduate and graduate level which will require candidates to be more flexible than ever before. We must welcome creativity, and encourage our teacher candidates to seek new technology throughout their career, allowing them to continue to reach students in innovative ways. We must teach numerous methods of motivation, so online teaching is not done with an empty virtual classroom. We can look back with nostalgia, and keep what still fits, but we must be willing to accept change as we move into the future. Although teaching is one of our oldest professions, and there are core components to pedagogy that should continue, we must make a push for new pedagogical methods that will lead our profession, and our students forward, with the skills, and knowledge, that is required for our population to remain an educated people. 


\section{REFERENCES}

Ackerman, P. L. (1987). Individual differences in skill reading: An integration of psychometric and information processing perspectives. Psychological Bulletin, $102,3-27$.

Adams, M. J. (1990). Beginning to read: Thinking and learning about print. Cambridge, MA: MIT Press.

Alber-Morgan, S.R., Ramp, E.M., Anderson, L.L., \& Martin, C. M. (2007). Effects of repeated readings, error correction, and performance feedback on the fluency and comprehension of middle school students with behavior problems. Journal of Special Education, 41, 17-30.

Algozzine, B., Wang, C., Violette, A. (2011). Reexamining the relationship between academic achievement and social behavior. Journal of Positive Behavior Interventions, 13(1), 3-16.

Algozzine, B., Wang, C., White, R., Cooke, N., Marr, M.B., Algozzine, K., Helf, S., \& 
Duran, G.Z. (2012). Effects of multi-tier academic and behavior instruction on difficultto-teach students. Exceptional Children, 79, 45-64.

Allington, R. L. (2006, April). Research and the three tier model. Reading Today. p. 20.

Allington, R. L. (2006). Fluency: Still waiting after all these years.

Allington, R. L. (2013). What really matters when working with struggling readers. Reading Teacher, 66(7), 520-530.

Al Otaiba, S. (2001). Children who do not respond to early literacy instruction: A longitudinal study across kindergarten and first grade. Reading Research Quarterly, 36,344-349.

Al Otaiba, S. \& Fuchs, D. (2002). Characteristics of children who are unresponsive to early intervention: A review of the literature. Remedial and Special Education, 23, 300-316.

Allday, R.A., Hinkson-Lee, K., Hudson, T., Neilson-Gatti, S., Kleinke, A., \& Russel, C.S. (2012). Training general educators to increase behavior specific praise: Effects on students with EBD. Behavioral Disorders, 37, 87-98.

Anderson, R. C., Hiebert, E. F., Wilkinson, I. A. G., \& Scott, J. (1985). Becoming a nation of readers. Champaign, IL: Center for the Study of Reading.

Armbruster, B.B., Lehr, F., Osborn, J., O’Rourke, R., Beck, I., Carnine, D., \& Simmons, D. (2001). Put Reading First.Washington, D.C.: National Institute for Literacy.

Ates, S. (2013). The effect of repeated reading exercises with performance-based feedback on fluent reading skills. Reading Improvement, 50(4), 158-165. 
Atkinson, T.S., Wilhite, K.L., Frey, L.M., \& Williams, S.C. (2002). Reading instruction for the struggling reader: Implications for teachers of students with learning disabilities or emotional/behavioral disorders. Preventing School Failure. 46 (4), $158-162$.

Ball, C., Homes Finch, W., Gettinger, M., Classroom-level effects on the reading and behavior of at risk kindergarteners. Preventing School Failure, 58(2), 80-89.

Balmuth, M. (1982). The roots of phonics: A historical introduction. New York: McGraw-Hill.

Banda, D.R., \& Therrien, W.J. (2008). A teacher's guide to meta-analysis. Teaching Exceptional Children, 41(2), 66-71.

Bauer, A.M., \& Shea, T.M. (1999). Learners with emotional and behavioral disorders: An introduction. Upper Saddle River, NJ: Merrill Prentice Hall.

Baumann, J. F. (2014). Houghton Mifflin Harcourt journeys: Common core. Orlando, FL: Houghton Mifflin Harcourt.

Beane, J.A. (2016). Curriculum integration: Designing the core of democratic education. Teacher's College Press.

Beaver, J.M., \& Carter, M.A. (2006). The Developmental Reading Assessment-Second Edition (DRA2). Upper Saddle River, NJ: Pearson.

Beck, R. (1979). Report for the Office of Education joint dissemination review panel. Great Falls, Montana: Precision Teaching Project. 
Beck, I. L., Perfetti, C. A., \& McKeown, M. G. (1982). Effects of long-term vocabulary instruction on lexical access and reading comprehension. Journal of Educational Psychology, 74 (4), 506-521.

Becker, W. (2001). Teaching reading and language to the disadvantaged: What have we learned from research. Journal of Direct Instruction, 1, 31-52.

Becker, W.C., Engelmann, S., Carnine, D.W., \& Maggs, A. (1982). Direct instruction technology: Making learning happen. In P. Karoly \& J.J. Steffen (Eds.), Improving children's competence: Advances in child behavioral analysis and therapy, volume one. Lexington, MA: D.C. Health.

Begeny. J., Laugle, K., Krouse, H., Lynn, A., Tayrose, M., \& Stage, S. (2010). A controlgroup comparison of two reading fluency programs: The helping early literacy with practice reading strategies (HELPS) program and the great leaps K-2 reading program, School Psychology Review, 39(1), p. 137-155.

Benner, G.J., Allor, J.H., \& Mooney, P. (2008). An investigation of the academic processing speed of students with emotional and behavioral disorders served in public school settings. Education and Treatment of Children, 31, 307-332.

Benner, G.J., Nelson, R.J., Ralston, N.C., \& Mooney, P. (2010). A meta-analysis of the effects of reading instruction on the reading skills of students with or at-risk of behavioral disorders. Behavioral Disorders, 35, 86-102.

Bennett, J.G., Gardner, R.I., Cartledge, G., Ramnath, R., \& Council, M.I. (2017). Second grade urban learners: Preliminary findings for a computer-assisted, culturally 
relevant, repeated reading intervention. Education and Treatment of Children, 40(2), 145-186.

Burnett, N. (2005). Education for all: Literacy for life. Paris: UNESCO.

Bijou, D., Birnbauer, J., Kidder, J., Tague, C. (1966). Programmed instruction as an approach to teaching reading, writing, and arithmetic to retarded children. Psychological Record, 16, 505-522.

Binder, C. (1996). Behavioral fluency: Evolution of a new paradigm. The Behavior Analyst, 19, 163-197.

Binder, C., Haughton, E., \& Van Eyk, D. (1990). Increasing endurance by building fluency: Precision teaching attention span. Teaching Exceptional Children,22(3), 24-27.

Binder, C., \& Watkins, C. L. (1990). Precision teaching and direct instruction: Measurably superior instructional technology in schools. Performance Improvement Quarterly, 3(4), 74-96.

Borenstein, M., Hedges, L.V., Higgins, J.P.T., \& Rothenstein, H.R. (2009). Introduction to meta-analysis. West Sussex, UK: John Wiley \& Sons.

Bostock, S.J. (1998). Constructivism in mass higher education: A case study. British Journal of Educational Technology, 29(3), 225-237.

Botts, D., Losardo, A., Tillery, C., Werts, M. (2014). A comparison of activity-based intervention and embedded instruction when teaching emergent literacy skills. The Journal of Special Education, 48(2), 120-134. 
Bower, B., \& Orgel, R. (1981). To err is divine. Journal of Precision Teaching,2(1), 312.

Brett, A., Rothlein, L., \& Hurley, M. (1996). Vocabulary acquisition from listening to stories and explanations of target words. Elementary School Journal, 96(4), 415422.

Brophy, J. (1981). Teacher praise: A functional analysis. Review of Educational Research, 51, 5-32.

Brophy, J., \& Evertson, C. (1974). Process-product correlations in the Texas teacher effectiveness study: Final Report. Austin: University of Texas, R \& D Center for Teacher Education.

Brossart, D.F., Laird, V.C., \& Armstrong, T.W. (2018). Interpreting Kendall's tau and tau-u for single case experimental designs. Cogent Psychology, 5(1), 1518687.

Brown, L., Perimutter, L. (1971). Teaching functional reading to trainable level retarded students. Education and Training of the Mentally Retarded, 6, 74-84.

Bushell, D. (1978). An engineering approach to the elementary classroom: The behavior analysis follow through project. In A.C. Catania \& T.A. Brigham (Eds.) Handbook of Applied Behavior Analysis, pp. 525-563. New York: Irvington.

Calfee, R. C., \& Piaotkowski, D. C. (1981). The reading diary: Acquisition of decoding. Reading Research Quarterly, 16, 346-373.

Campbell, J. M. (2013). Commentary on PND at 25. Remedial and Special Education, $34,20-25$. 
Campbell, J.M. \& Herzinger, C.V. (2010). Statistics and single subject research methodology. In Gast, D.L. (ed.), Single-subject research methodology in behavioral sciences (pp.417-463). New York, NY: Routledge.

Campbell, K. U. (1998). Great Leaps Reading ( $4^{\text {th }}$ edition). Micanopy, FL: Diamuld, Inc.

Campbell, K. (n.d.). Reading, and Math Intervention Programs. Retrieved February 20, 2018, from http://www.greatleaps.com/

Carney, J. J., Anderson, D., Blackburn, C., \& Blessing, D. (1984). Preteaching vocabulary and the comprehension of social studies materials by elementary school children. Social Education, 48(3), 195-196.

Castle, J. M., Riach, J., \& Nicholson, T. (1994). Getting off to a better start in reading and spelling: The effects of phonemic awareness instruction within a whole language program. Journal of Educational Psychology, 86, 350-359.

Chadwick, B., Day, R. (1971). Systematic reinforcement, academic performance of underachieving students. Journal of Applied Behavior Analysis, 4, 311-319.

Chafouleas, S.M., Martens, B.K., Dobson, R.L., Weinstein, K.S., \& Gardner, K.B. (2004). Fluent reading as the improvement of stimulus control: Additive effects of performance based intervention to repeated reading on student's reading and error rates. Journal of Behavioral Education, 13(2), 67-81.

Chall, J. S. (1967). Learning to read: The great debate (1st ed.). New York, NY: McGraw-Hill. 
Chall, J. (1996). Stages of reading development (2nd ed.). Fort Worth, TX: HarcourtBrace.

Chandler, A., McLaughlin, T.F., Neyman, J., \& Rinaldi, L. (2012). The differential effects of direct instruction flashcards with and without a shorter math racetrack to teach numerical identification to preschoolers: A failure to replicate. Academic Research International, 2(3), 308-313.

Chard, D.J., Vaughn, S., \& Tyler, B. (2002). A synthesis of research of effective interventions for building reading fluency with elementary students with learning disabilities. Journal of Learning Disabilities, 35(5), 386-406.

Chen, L.T., Wu, P.J., \& Peng, C.Y.J. (2019). Accounting for baseline trends in intervention studies: Methods, effect sizes, and software. Cogent Psychology, 6, 1679941.

Chomsky, C. (1976). After decoding: What? Language Arts, 53(3), 288-296.

Cihon, T. M., White, R., Zimmerman, V. L., Gesick, J., Stordahl, S., \& Eshleman, J. (2017). The effects of precision teaching with textual or tact relations on intraverbal relations. Behavioral Development Bulletin, 22(1), 129-146

Clark, C., Wahlberg, H. (1979). The use of secondary reinforcement in teaching innercity school children. Journal of Applied Behavior Analysis, 4, 311-319.

Clements, M.A., Bolt, D., Hoyt, W., \& Kratochwill, T.R. (2007). Using multilevel modeling to examine the effects of multi-tiered interventions. Psychology in the Schools, 44, 503-513. 
Cobb, P. (2005). Where is the mind? A coordination of sociocultural and cognitive constructivist perspectives in: C.T. Fosnot (ed). Constructivism: Theory, perspectives, and practice ( $2^{\text {nd }}$ Ed.) (New York, Teachers College, Columbia University), 39-60.

Coleman, M., \& Vaughn, S. (2000). Reading interventions for students with emotional behavioral disorders. Behavioral Disorders, 25, 93-104.

Conroy, M.A., Alter, P.J., \& Sutherland, K.S. (2014). Classroom-based research in the field of EBD: Future research directions. In P. Garner, J. Kauffman, \& J. Elliot (Eds.). The SAGE Handbook of Emotional and Behavioral Difficulties ( $2^{\text {nd }}$ ed.) (pp. 465-477). London: SAGE.

Conte, R., \& Humphreys, R. (1989). Repeated readings using audiotaped material enhances oral reading in children with reading difficulties. Journal of Communications Disorders, 22, 65-79.

Cook, C. R., Dart, E., Collins, T., Restori, A., Daikos, C., \& Delport, J. (2012). Preliminary study of the confined, collateral, and combined effects of reading and behavioral interventions: Evidence for a transactional relationship. Behavioral Disorders, 38-56.

Cooper, J.O., Heron, T.E., \& Heward, W.L. (2007). Applied Behavior Analysis, Second Edition. Pearson Education:Upper Saddle River, New Jersey.

Council of Chief State School Officers. (2020) InTASC Model Core Teaching Standards and Learning Progressions for Teacher. Downloaded January 3, 2020.

Crewell, J. (2014). Research Design;Sage Publications. 
Crowley, K., McLaughlin, T., \& Kahn, R. (2013). Using direct instruction flashcards and reading racetracks to improve sight word recognition of two elementary students with autism. Journal of Developmental and Physical Disabilities, 25(3), 297-311.

Dahl, P.J.R. (1974). An experimental program for teaching high speed word recognition and comprehension skills. Final Report. Washington, DC. Government Printing Office.

Daly, E., Garbacz, S., Olson, S., Persampieri, M., Ni, H. (2006). Improving oral reading fluency by influencing students' choice of instructional procedures: An experimental analysis with two students with behavior disorders. BIN Behavioral Interventions, 21(1), 13-30.

Daly, E.J., Martens, B.K., Hamler, K.R., Dool, E.J., \& Eckert, T.L. (1999). A brief experimental analysis for identifying instructional components needed to improve oral reading fluency. Journal of Applied Behavior Analysis, 32, 83-94.

Daly, E.J., \& Martens, B.K. (1994). A comparison of three interventions for increasing oral reading performance: Application of the instructional hierarchy. Journal of Applied Behavior Analysis, 27, 459-468.

Datchuk, S. M., \& Kubina Jr., R. M. (2017). A writing intervention to teach simple sentences and descriptive paragraphs to adolescents with writing difficulties. Education \& Treatment of Children, 40(3), 303-326.

Davidson, J., Elcock, J., \& Noyes, P. (1996). A preliminary study of the effect of computer-assisted practice on reading attainment. Journal of Research in Reading, 19(2), 102-110. 
Davis, F. B. (1942). Two new measures of reading ability. Journal of Educational Psychology, 33, 365-372.

Day, S. L., Connor, C. M., \& McClelland, M. M. (2015). Children's behavioral regulation and literacy: The impact of the first grade classroom environment. Journal of school psychology, 53(5), 409-428.

Deci, E., Chandler, C., (1986). The importance of motivation for the future of the ld field. Journal of Learning Disabilities, 19(10), 587-594.

Delgano, B. (2001). Interpretations of constructivism and consequences for computer assisted learning. British Journal of Educational Technology, 32/2, 183-194.

DeWalt, D.A., Berkman, N.D., Sheridan, S., Lohr, K.N., \& Pignone, M.P. (2004). Literacy and health outcomes. Journal of General Internal Medicine, 19(12), 1228-1239.

Dewey, J. (1916). Democracy and Education (New York Free Press).

Donahue, P. L., Voelkl, K. E., Campbell, J. R., \& Mazzeo, J. (1999). NAEP 1998 reading report card for the nation and states. Washington, DC: U.S. Department of Education, Office of Educational Research and Improvement, National Center for Education Statistics.

Dowhower, S.L. (1989). Repeated reading: Research into practice. The Reading Teacher, $42(7), 502-507$

Drabman, R., Spitalnik, R., O’Leary, K. (1973). Teaching self-control to disruptive children. Journal of Abnormal Psychology, 82, 10-16. 
Dunlap, G., Kern, L., Worcester, J. (2001). Aba and academic instruction. Focus on Autism and Other Developmental Disabilities, 16(2), 3-16.

Durkin, D. (1993). Teaching them to read. (6th ed.) Boston, MA: Allyn and Bacon.

Dykstra, R. (1968). The effectiveness of code- and meaning-emphasis in beginning reading programs. The Reading Teacher, 22, 17-23.

Education for All Global Monitoring Report. (2006) Education for All Global Monitoring Report. Chapter 5: Why literacy matters. Paris:UNESCO:

Ehri, L. (1994). Development of the ability to read words: Update. In R. Ruddell, M. Ruddell, \& H. Singer (Eds.), Theoretical models and processes of reading (4th ed. pp. 323-358). Newark, DE: International Reading Association.

Ellis, J. (2013). “Inequalities of Children in Original Endowment”: How Intelligence Testing Transformed Early Special Education in a North American City School System. History of Education Quarterly, 53(4), 401-429.

Engelmann, S. \& Canine, D. (1991). Theory of instruction: Principles and applications (Revised edition). Eugene, OR: ADI Press.

Evans, G., Oswalt, G. (1968). Acceleration of academic progress through the manipulation of peer influence. Behavior and Research Therapy, 6, 189-195.

Ferster, C., Skinner, B. (1957). Schedules of Reinforcement. East Norwalk, CT: Appleton-Century-Crofts. 
Finnegan, E., \& Mazin, A. L. (2016). Strategies for increasing reading comprehension skills in students with autism spectrum disorder: A review of the literature. Education and Treatment of Children, 39(2), 187-219.

Fleming, C.B., Harachi, T.W., Cortes, R.C., Abbott, R.D., \& Catalano, R.F. (2004). Level and change in reading scores and attention problems during elementary school as predictors of problem behavior in middle school, Journal of Emotional and Behavioral Disorders, 12(3), 130-144.

Fosnot, C.T. (1989). Enquiring teachers enquiring learners: A constructivist approach for teaching. (New York, Teachers College, Columbia University).

Freeman, S. F., \& Alkin, M. C. (2000). Academic and social attainments of children with mental retardation in general education and special education settings. Remedial and Special Education, 21(1), 3-26.

Gage, N. A., \& Lewis, T. J. (2013). Analysis of effect for single-case design research. Journal of Applied Sport Psychology, 25(1), 46-60.

Gage, N., MacSuga-Gage, A., Prykanowski, D., Coyne, M., \& Scott, T.M. (2015). Investigating the collateral effects of behavior management on literacy skills. Education and Treatment of Children, 38(4), 524-540.

Gagnon, J. C., \& Barber, B. R. (2014). Instructional practice guide for teaching reading and mathematics in juvenile correctional schools. Journal of Correctional Education (1974-), 65(3), 5-23.

Garza, R., Lipton, J. (1978). Culture, personality, and reactions to praise and criticism. Journal of Personality. 46(4), 743-761. 
Gast, D.L. (2010). Single subject research methodology in behavioral sciences. New York: Routledge.

Gersten, R., Woodward, J., \& Darch, C. (1986). Direct instruction: a research based approach to curriculum design and teaching. Exceptional Children, 53, 17-31.

Gibb, G., \& Wilder, L.K. (2002). Using functional analysis to improve reading instruction for students with learning disabilities and emotional/behavioral disorders. Preventing School Failure. 46 (4), 152-157.

Gindis, B. (1999). Vygotsky's vision: Reshaping the practice of special education for the 21st century. Remedial and special education, 20(6), 333-340.

Golding, C. (2011). The many faces of constructivist discussion. Educational Philosophy and Theory, 43(5), 1469-1486.

Gordon, M. (2009). The misuses and effective uses of constructivist teaching. Teachers and Teaching: theory and practice, 15(6), 737-746.

Grant, L. \& Evans, A. (1994). Principles of behavior analysis. New York: HarperCollins College Publishers.

Griffith, A., Hurley, K., Hagaman, J. (2009). Treatment integrity of literacy interventions for students with emotional and/or behavioral disorders. Remedial and Special Education, 30(4), 245-255.

Griffin, C. P., \& Murtagh, L. (2015). Increasing the sight vocabulary and reading fluency of children requiring reading support: the use of a Precision Teaching approach. Educational Psychology in Practice, 31(2), 186-209 
Grossen, B. (1995). The story behind Project Follow Through. Effective School Practices, 15(1), 1-5.

Harris, L., Sherman, J. (1972). Effects of homework assignments and consequences on performance in social studies and mathematics. Journal of applied Behavior Analysis, 7, 505-519.

Harris, T. L., \& Hodges, R. E. (1995). The literacy dictionary: The vocabulary of reading and writing. International Reading Association: Newark, DE.

Harris, L., Sherman, J., Henderson, D., Harris, M. (1973). Effects of peer tutoring on the spelling performance of elementary classroom students. A new direction for education: Behavior analysis. Lawrence, Kansas. University of Kansas support and Development Center for Follow Through.

Hart, B., Risley, T. (1968). Establishing use of descriptive adjectives in the spontaneous speech of disadvantaged preschool children. Journal of Applied Behavior Analysis, 1,109-120.

Hatcher, P., Hulme, C., \& Ellis, A. (1994). Ameliorating early reading failure by integrating the teaching of reading and phonological skills: The phonological linkage hypothesis. Child Development, 65, 41-57.

Hattie, J. (2012). Visible learning for teachers: maximizing impact on learning. London: Routledge.

Hattie, J. (2009). Visible learning: a synthesis of over 800 meta-analyses relating to achievement. London: Routledge. 
Hawkins, R.O., Marsicano, R., Schmitt, A.J., McCallum, E., \& Musti-Rao, S. (2015). Comparing the efficiency of repeated reading and listening-while-reading to improve fluency and comprehension. Education and Treatment of Children, 38(1), 49-70.

Hay, C. (2006). Constructivist institutionalism. In The Oxford handbook of political institutions.

Heise, B. L., Papalewis, R., \& Tanner, D. E. (1991). Building base vocabulary with computer-assisted instruction. Teacher Education Quarterly, 18(1), 55-63.

Herman, P. A. (1985). The effect of repeated readings on reading rate, speech pauses, and word recognition accuracy. Reading Research Quarterly, 20, 553-565.

Hewett, F., Taylor, F., Artuso, A. (1968). The Madison plan really swings. Today's Education, 59, 15-17.

Heyneman, S.P. (2004). Education and corruption. International Journal of Educational Development, 24(6), 637-648.

Hitt, S. (2015). Effects of peer-delivered fluency instruction on the oral reading fluency of high school students with mild disabilities (Doctoral dissertation, The University of North Carolina Charlotte).

Hunt, L. C., Jr. (1970). The effect of self-selection, interest, and motivation on independent, instructional, and frustrational levels. The Reading Teacher, 24, 146$151,158$. 
Huitema, B.E.(1986b). Statistical analysis and single subject designs: Some misunderstandings. In A.S. Bellack \& MHersen (Series Ed.)\& A. Poling \& R.W. Fuqua (Vol. Eds.) Applied clinical psychology: Research methods in applied behavior analysis: Issues and advances (pp.187-208). New York: Plenum.

Ialongo, N., Poduska, J., Werthamer, L., \& Kellam, S. (2001). The distal impact of two first-grade preventative interventions on conduct problems and disorder in early adolescence, Journal of Emotional and Behavioral Disorders, 9/3, 146-161.

Iversen, S., \& Tunmer, W. (1993). Phonological processing skills and the Reading Recovery Program. Journal of Educational Psychology, 85, 112-126.

Jenkins, D.G. \& Quintana-Ascencio, P.F. (2020). A solution to minimum sample size for regressions. PLos One, 15(2).

Johnson, K. R., \& Layng, T. V. J. (1992). Breaking the structuralist barrier: Literacy and numeracy with fluency. American Psychologist, 47, 1475-1490.

Johnson, K. R., \& Layng, T. V. J. (1994). The Morningside Model of generative instruction. In R. Gardner III, D. M. Sainato, J. O. Cooper, T. E. Heron, W. L. Heward, J.Eshleman, \& T. A. Grossi (Eds.), Behavior analysis in education: Focus on measurably superior instruction (pp. 173-197). Monterey, CA: Brooks/Cole.

Jones, S. M., Brown, J. L., \& Lawrence Aber, J. (2011). Two-year impacts of a universal school-based social-emotional and literacy intervention: An experiment in translational developmental research. Child development, 82(2), 533-554. 
Jones, S. M., Brown, J. L., Hoglund, W. L., \& Aber, J. L. (2010). A school-randomized clinical trial of an integrated social-emotional learning and literacy intervention: Impacts after 1 school year. Journal of consulting and clinical psychology, 78(6), 829.

Kameenui, E.J., \& Carnine, D.W. (1998). Effective teaching strategies that accommodate diverse learners. Upper Saddle River, NJ: Merrill.

Kamps, D.M., \& Greenwood, C.R. (2005). Formulating secondary level reading interventions. Journal of Learning Disabilities, 38, 500-509.

Kamps, D., Abbott, M., Greenwood, C., Arreaga-Mayer, C., Wills, H.P., Longstaff, J. et al (2007). Use of evidence based, small group reading instruction for English language learners in elementary grades: Secondary tier intervention. Learning Disability Quarterly, 30, 153-168.

Kamps, D., Abbott, M., Greenwood, C., Wills, H.P., Veerkamp, M., \& Kaufman, J. (2008). Effects of small-group reading instruction and curriculum differences for students most at risk at kindergarten: Two year results for secondary- and tertiarylevel interventions. Journal of Learning Disabilities, 41(2), 101-114.

Kauffman, J. M., \& Landrum, T. J. (2013). Characteristics of emotional and behavioral disorders of children and youth. New York, NY: Pearson.

Kaufman, L., McLaughlin, T.F., Derby, K.M., \& Waco, T. (2011). Employing reading racetracks and DI flashcards with and without cover, copy, and compare rewards to teach sight words to three students with learning disabilities in reading. Educational Research Quarterly, 34, 24-44. 
Kavale, K.A. (2005). Identifying specific learning disability: Is responsiveness to intervention the answer? Journal of Learning Disabilities, 38(6), 553-562.

Kern, L., \& Clemons, N.H. (2007). Antecedent strategies to promote appropriate classroom behavior. Psychology in the Schools, 44, 65-75.

Kirschner, P.A., Sweller, J., Clark, R.E. (2006). Why minimal guidance during instruction does not work: An analysis of the failing of constructivist, discovery, problem-based, experiential, and inquiry-based teaching, Educational Psychologist, 41(2), 75-86.

Korat, O., Kozlov-Peretz, O., Segal-Drori, O. (2017). Repeated e-book reading and its contribution to learning new words among kindergartners. Journal of Education and Training Studies, 5(7), 60-72.

Kostowicz, D.E., Kubina, R.M., Selfridge, K.A. \& Gallagher, D.L. (2016). A review of fixed fluency criteria in repeated reading studies. Reading Improvement, 53(1), $23-41$.

Kozioff, M. A., LaNunziata, L., Cowardin, J., \& Bessellieu, F. B. (2000). Direct instruction: Its contributions to high school achievement. High School Journal, $84(2), 54$.

Kostewicz, D.E., \& Kubina, R.M.Jr. (2010). A comparison of two reading fluency methods: Repeated Readings to a fluency criterion and interval sprinting. Reading Improvement, 47(1), 43-63. 
Kubina, L.M. Jr., Amato, J., Schwilk, C.L., \& Therrien, W.J. (2008). Comparing performance standards on the retention of words read correctly per minute. Journal of Behavioral Education, 7(1), 328-338.

Kubina, R., Yurich, K., Durica, K., \& Healy, N. (2016). Developing behavioral fluency with movement cycles using SAFMEDS. Journal of Behavioral Education, 25(1), 120-141)

Kupzyk, S., Daly, E., Ihlo, T., Young, N. (2012). Modifying instruction within tiers in multi-tiered intervention programs. PITS Psychology in the Schools, 49(3), 219230.

Labaree, D. (2005). Progressivism, schools, and schools of education: An American romance, Pedagogica Historica, 41(1/2), 275-288.

Labbo, L. D., \& Teale, W. (1990). Cross-age reading: A strategy for helping poor readers. Reading Teacher, 43, 362-369

LaBerge, D., \& Samuels, S.J. (1974). Toward a theory of automatic information processing in reading. Cognitive Psychology, 6(2), 293-323.

Lane, K.L. (2007). Identifying and supporting students at risk for emotional and behavioral disorders within multi-level models: Data-driven approaches to conducting secondary interventions with an academic emphasis. Education and Treatment of Children, 30, 135-164. 
Lehner, E., \& Ziegler, J.R. (2017). Testing the National Reading Panel's Fluency Claims: A Study Examining Repeated Readings and Tracking the Nature of Miscues. City University of New York Academic Works.

Levy, S., Chard, D. (2001). Research on reading instruction for students with emotional and behavioral disorders. International Journal of Disability, Development, and Education, 48(4), 947-959.

Levy, S. \& Vaughn, S. (2002). An observational study of teacher's reading instruction of students with emotional or behavioral disorders. Behavioral Disorders, 27, 215235.

The Lexile Framework for Reading, (2021). Retrieved February 11, 2021, from https://lexile.com/

Lindsley O. R. (1972). From Skinner to precision teaching: The child knows best. In Jordan J. B. \& Robbins L. S. (Eds.), Let's try doing something else kind of thing (pp. 1-11). Arlington, VA: The Council for Exceptional Children.

Lindsley, O. R. (1990a). Our aims, discoveries, failures, and problem. Journal of Precision Teaching, 7, 7-17.

Lindsley, O. R. (1990b). Precision teaching: By teachers for children. Teaching Exceptional Children, 22(3), 10-15.

Lindsley, Ogden R. (1991). Precision teaching's unique legacy from B. F. Skinner, Journal of Behavioral Education. 1 (2): 253-266. 
Lindsley, O. R. (1995). Ten products of fluency. Journal of Precision Teaching,13(1), 211.

Limage, L.J. (1999). Literacy practices and literacy policies: Where has UNESCO been and where might it be going? International Journal of Educational Development, 19, 75-89.

Lingo, A. S. (2014). Tutoring middle school students with disabilities by high school students: Effects on oral reading fluency. Education and Treatment of Children, $37(1), 53-76$.

Logan, G. D. (1997). Automaticity and reading: Perspectives from the instance theory of automatization. Reading and Writing Quarterly, 13, 123146.

Maag, J. W. (2006). Social skills training for students with emotional and behavioral disorders: A review of reviews. Behavioral Disorders, 4-17.

MacSuga-Gage, A. S., \& Gage, N. A. (2015). Student-Level Effects of Increased Teacher-Directed Opportunities to Respond. Journal of Behavioral Education, 24(3), 273-288.

MacSuga-Gage, A. S., \& Simonsen, B. (2015). Examining the effects of teacher-directed opportunities to respond on student outcomes: a systematic review of the literature. Education and Treatment of Children, 38(2), 211-239.

Manolov, R., \& Solanas, A. (2009). Percentage of nonoverlapping corrected data. Behavior Research Methods, 41, 1262-1271. 
Marcus, B., Vollmer, T. (1996). Combining non-contingent reinforcement and differential reinforcement schedules as treatment for aberrant behavior. Journal of Applied Behavior Analysis, 29(1), 43-51.

MaCain, L.J. \& McCleary, R. (1979). The statistical analysis of the simple interrupted time series quasi-experiment. In T.D. Cook \& D. T. Campbell (Eds.), Quasiexperimentation: Design and analysis issues for field settings. Chicago; Rand McNally.

Manolov, R., Gast, D. L., Perdices, M., \& Evans, J. J. (2014). Single-case experimental designs: reflections on conduct and analysis. Neuropsychological rehabilitation, 24(3-4), 634-660.

McClelland, M., Cameron, C., Connor, C., Farris, C., Jewkes, A., Morrison, F. (2007). Links between behavioral regulation and preschoolers' literacy, vocabulary, and math skills. Developmental Psychology, 43(4), 947-959.

McFalls, E. L., Schwanenflugel, P. J., \& Stahl, S. A. (1996). Influence of word meaning on the acquisition of a reading vocabulary in second-grade children. Reading and Writing, 8(3), 235-250.

McGreevy, P. (1983). Teaching and learning in plain English. Kansas City, MO: Plain English Publications (University of Missouri).

McIntosh, K., Chard, D., Boland, J., \& Horner, R.H. (2006). A demonstration of combined efforts in school-wide academic and behavioral systems and incidence of reading and behavioral challenges in early elementary grades, Journal of Positive Behavior Interventions, 8, 146-154. 
McIntosh, K., Filter, K., Bennett, J., Ryan, C., Sugai, G. (2010). Principles of sustainable prevention: Designing scale-up of school-wide positive behavior support to promote durable systems, psychology in the Schools, 47(1), 5-21.

McIntosh, K., Horner, R., Chard, D., Dickey, C., Braun, D. (2008). Reading skills and function of problem behavior in typical school settings. The Journal of Special Education, 42(3), 131-147.

McIntosh, K., Sadler, C., Brown, J. (2012). Kindergarten reading skill level and change as risk factors for chronic problem behavior. Journal of Positive Behavior Interventions, 14(1), 17-28.

McKenna, J.W., Shin, M., Solis, M., Mize, M. Pfannenstiel, K. (2019). Effects of singlecase reading interventions for students with and at-risk of emotional behavioral disorders in grades K-12: A quantitative synthesis. Psychology in Schools, 56(1), 608-629.

McKeown, M. G., Beck, I. L., Omanson, R. C., \& Perfetti, C. A. (1983). The effects of long-term vocabulary instruction on reading comprehension: A replication. Journal of Reading Behavior, 15(1), 3-18.

McKeown, M. G., Beck, I. L., Omanson, R. C., \& Pople, M. T. (1985). Some effects of the nature and frequency of vocabulary instruction on the knowledge and use of words. Reading Research Quarterly, 20(5), 522-535.

McMasters, K.L., Fuchs, D., Fuchs, L.S., \& Compton, D.L. (2005). Responding to nonresponders: An experimental field trial of identification and intervention methods. Exceptional Children, 71, 445-463. 
Medo, M. A., \& Ryder, R. J. (1993). The effects of vocabulary instruction on readers' ability to make causal connections. Reading Research and Instruction, 33(2), 119134.

Mier, M. (1984). Comprehension monitoring in the elementary classroom. Reading Teacher, 37(8), 770774.

Mercer, C. D., Campbell, K. U., Miller, M. D., Mercer, K. D., \& Lane, H. B. (2000). Effects of a reading fluency intervention for middle schoolers with specific learning disabilities. Learning Disabilities Research \& Practice, 15(4), 179-189.

Meyer, M.S., \& Felton, R.H. (1999). Repeated reading to enhance fluency: Old approaches and new directions. Annals of Dyslexia, 49(1), 283-306.

Miles, S.B., Stipek, D. (2006). Contemporaneous and longitudinal associations between social behavior and literacy achievement in a sample of low-income elementary school children. Child Development, 77, 103-117.

Miller, L., Schnieder, R. (1970). The use of a token system in project Head Start. Journal of Applied Behavior Analysis, 3, 213-220.

Mooney, P., Epstein, M.H., Reid, R., \& Nelson, J.R. (2003). Status of trends in academic intervention research for students with emotional disturbance. Remedial and Special Education, 24(1), 273-287.

National Center for Education Statistics. (n.d.). Digest of Education Statistics. Retrieved from http://nces.ed.gov/programs/digest/d15/tables/dt15_219.90.asp?current=yes on December 4, 2016. 
National Institute for Direct Instruction, (n.d.). Retrieved December 04, 2016, from http://www.nifdi.org/research/history-of-di-research/projectfollowthrough

National Reading Panel. (1999). NRP Progress Report. Retrieved from http://www.nationalreadingpanel.org?Publications on December 4, 2016.

National Reading Panel (NRP). (2000). Report of the National Reading Panel, Teaching children to read: An evidence based assessment of the scientific research on reading and its implications for reading instruction, Washington, DC: US Government Printing Office.

National Institute of Child Health \& Human Development. (2000). Report of the National Reading Panel. Teaching children to read: An evidence-based assessment of the scientific research literature on reading and its implications for reading instruction. Washington, DC: United States Government Printing Office.

Nelson, R.J., Benner, G.J., \& Gonzalez, J. (2003). Learner characteristics that influence the treatment effectiveness of early literacy interventions: A meta-analytic view. Learning Disabilities Research and Practice, 18, 255-267.

Nelson, J.R., Benner, G.J., Lane, K., \& Smith, B.W. (2004). An investigation of the academic achievement of K-12 students with emotional and behavioral disorders in public school settings. Exceptional Children, 71, 59-74.

Nelson, J.R., Lane, K.L., Benner, G.J., \& Kim, O. (2011). A best evidence synthesis of literacy instruction on the social adjustment of students with or at-risk for behavior disorders. Education and Treatment of Children, 34, 141-162. 
Nevin, J., Shahan, T. (2011). Behavioral momentum theory: Equations and applications. Journal of Applied Behavior Analysis, 44, 877-895.

Newmann, F., Marks, H., \& Gamoran, A. (1995). Authentic pedagogy: Standards that boost student performance. Issues in Restructuring Schools, 8, 1-12.

Normand, M.P. \& Bailey, J.S. (2006). The effects of celebration lines on visual data analysis. Behavior Modification, 30, 295-314.

Oakes, W. P., Mathur, S. R., \& Lane, K. L. (2010). Reading interventions for students with challenging behavior: A focus on fluency. Behavioral Disorders, 120-139.

O’Leary, K., Becker, W. (1967). Behavior modification of an adjustment class. Exceptional Children, 9, 637-642.

Oliver, R., Wehby, J., \& Reschly, D.J. (2011). Teacher classroom management practices: Effects on disruptive or aggressive student behavior. Campbell Systematic Reviews 2011.

Palinscar, A. S., \& Brown, A.L. (1984). Reciprocal teaching of comprehension-fostering and comprehension-monitoring activities. Cognition and Instruction, 2, 117-175.

Paris, S. G., Sarnio, D. A., \& Cross, D. R. (1986). A metacognitive curriculum to promote children's reading and learning. Australian Journal of Psychology, 38(2), 107-123.

Parker, R.I., Cryer, J. , \& Byrns, G. (2006). Controlling baseline trend in single-case research. School Psychology Quarterly, 21(4), 418-444. 
Parker, R. I., Hagan-Burke, S., \& Vannest, K. (2007). Percent of all non-overlapping data (PAND): An alternative to PND. The Journal of Special Education, 40, 194-204.

Parker, R.I., \& Vannest, K. (2009). An improved effect size for single case research: Non overlap of all pairs. Behavior Therapy, 40, 357-367.

Parker, R.I., Vannest, K.J., Davis, J.L., \& Sauer, S.B. (2011). Combining nonoverlap and trend for single-case research: Tau-U. Behavior Therapy, 42,284-299.

Patton, B., Crosby, S., Houchins, D., \& Jolivette, K. (2010). The Comparative Effect of Fluency Instruction with and without a Comprehension Strategy for Elementary School Students. International Journal of Special Education, 25(2), 100-112.

Perlstein, D. (2002). Minds stayed on freedom: Politics and pedagogy in the AfricanAmerican freedom struggle. American Educational Research Journal, 39(2), 249277.

Piaget, J. (1978). The Development of Thought: Equilibration of Cognitive Structures, A. Rosin, trans. (Oxford, Blackwell).

Pinnell, G. S., Pikulski, J. J., Wixson, K. K., Campbell, J. R., Gough, P. B., \& Beatty, A. S. (1995). Listening to children read aloud. Washington, DC: Office of Educational Research and Improvement, U. S. Department of Education.

Posner, M. I., \& Snyder, R. R. (1975). Attention and cognitive control. In R. L. Solso (Ed.), Information processing and cognition: The Loyola Symposium (pp. 55-85). Hillsdale, NJ: Erlbaum. 
Pressley, M. (1998). Reading instruction that works: The case for balanced teaching. NY: The Guilford Press.

Pressley, M., \& Afflerbach, P. (1995). Verbal protocols of reading: The nature of constructively responsive reading. Mahwah, NJ: Erlbaum.

Pressley, M., Almasi, J., Schuder, T., Bergman, J., \& Kurita, J. A. (1994). Transactional instruction of comprehension strategies: The Montgomery County, Maryland, SAIL program. Reading \& Writing Quarterly: Overcoming Learning Difficulties, $10(1), 519$.

Ravitch, D. (2016). The death and life of the great American school system: How testing and choice are undermining education. Basic Books.

Reinking, D., \& Rickman, S. S. (1990). The effects of computer-mediated texts on the vocabulary learning and comprehension of intermediate-grade readers. Journal of Reading Behavior, 22 (4), 395-411.

Reutzel, D. R., \& Hollingsworth, P. M. (1993). Effects of fluency training on second graders' reading comprehension. Journal of Educational Research, 86, 325-331.

Rivera, M. O., Al-Otaiba, S., \& Koorland, M. A. (2006). Reading instruction for students with emotional and behavioral disorders and at risk of antisocial behaviors in primary grades: review of literature. Behavioral Disorders, 31(3), 323-339.

Robbins, C., \& Ehri, L. C. (1994). Reading storybooks to kindergartners helps them learn new vocabulary words. Journal of Educational Psychology, 86(1), 54-64. 
Rogers-Adkinson, D., Melloy, K., Stuart, S., Fletcher, L., \& Rinaldi, C. (2008). Reading and written language competency of incarcerated youth. Reading \& Writing Quarterly, 24(2), 197-218.

Rosenshine, B., \& Meister, C. (1994). Reciprocal teaching; A review of the research. Review of Educational Research, 64(4), 479-530.

Rosenshine, B., Meister, C., \& Chapman, S. (1996). Teaching students to generate questions: A review of the intervention studies. Review of Educational Research, 66(2), 181-221.

Ryder, R. J., Burton, J. L., \& Silberg, A. (2006). Longitudinal study of direct instruction effects from first through third grades. The Journal of Educational Research, 99(3), 179-192.

Sadler, C., \& Sugai, G. (2009). Effective behavior and instructional support: A district model for early identification and prevention of reading and behavior problems. Journal of Positive Behavior Interventions, 11(1), 35-46.

Samuels, S. J., LaBerge, D., \& Bremer, C. (1978). Units of word recognition: Evidence for developmental changes. Journal of Verbal Learning and Verbal Behavior, 17, 715-720.

Samuels, S.J. (1979). The method of repeated reading. The Reading Teacher, 32(4), 403408.

Samuels, S.J. (1997). The method of repeated reading. The Reading Teacher, 50(1), 376380. 
Schmitt, M. C., \& Gregory, A. E. (2005). The Impact of an Early Literacy Intervention: Where Are the Children Now? Literacy Teaching and Learning, 10(1), 1-20.

Schwanenflugel, P. J., Stahl, S. A., \& McFalls, E. L. (1997) Partial word knowledge and vocabulary growth during reading comprehension. Journal of Literacy Research, $20,531-553$.

Schweitzer, L., \& Stephenson, M. (2008). Charting the challenges and paradox of constructivism: A view from professional education. Teaching in Higher Education, 13 (5), 583-593.

Scott, T.M., Shearer-Lingo, A. (2002). The effects of reading fluency instruction on the academic and behavior success of middle school students in a self-contained EBD classroom. Preventing School Failure, 46(4), 167-174.

Scott, T., Anderson, C., Alter, P. (2011). Managing classroom behavior using positive behavior supports. Columbus, OH: Pearson.

Scruggs, T. E., Mastropieri, M. A., \& Regan, K. S. (2006). Statistical analysis for single subject research designs. Applications of Research Methodology: Advances in Learning and Behavioral Disabilities, 19, 33-53.

Senechal, M. (1997). The differential effect of storybook reading on preschoolers' acquisition of expressive and receptive vocabulary. Journal of Child Language, 24(1), 123-138.

Shanahan, S., Wojciehowski, J., \& Rubik, G. (1998). A celebration of reading: How our school read for one million minutes. The Reading Teacher, 52, 93-96. 
Shany, M. T., \& Biemiller, A. (1995). Assisted reading practice: Effects on performance for poor readers in grade 3 and 4. Reading Research Quarterly, 30, 382-395.

Shavelson, R. J. (2007). Statistical Reasoning for the Behavioral Sciences. Boston: Allyn $\&$ Bacon.

Simmons, D.C., Kame'enui, E.J., Harn, B., Coyne, M.D., Stoolmiller, M., EdwardsSantoro, L., et al. (2007). Attributes of effective and efficient kindergarten reading intervention: An examination of instructional time and design specificity. Journal of Learning Disabilities, 40(4), 331-347.

Simonsen, B., Fairbanks, S., Briesch, A., Myers, D., \& Sugai, G. (2008). Evidence-based practices in classroom management: Considerations for research to practice. Education and Treatment of Children, 31, 351-380.

Simonsen, B., MacSuga-Gage, A.S., Briere, D.E., Freeman, J., Myers, D., Scott, T.M., \& Sugai, G. (2014). Multi-tiered support framework for teachers' classroom management practices: Overview and case study of building the triangle for teachers. Journal of Positive Behavior Interventions, 16, 179-190.

Skrtic, T. (1991). The special education paradox: Equity as the way to excellence. Harvard educational review, 61(2), 148-207.

Smeaton, P. S., \& Waters, F. H. (2013). What happens when first year teachers close their classroom doors? An investigation into the instructional practices of beginning teachers. American Secondary Education, 41(2), 71-93. 
Snow, C. E., Burns, M. S., \& Griffin, P. (1998). Preventing reading difficulties in young children. Washington, DC: National Academy Press.

Splitter, L.J. (2009). Authenticity and constructivism in education. Studies in Philosophy and Education, 28, 135-151.

Stahl, S., Duffy-Hester, A., \& Stahl, K. (1998). Everything you wanted to know about phonics (but were afraid to ask). Reading Research Quarterly, 33, 338-355.

Stahl, S. A., \& Fairbanks, M. M. (1986). The effects of vocabulary instruction: A modelbased meta analysis. Review of Educational Research, 56(1), 72210.

Stahl, S. A., Richek, M. A., \& Vandevier, R. J. (1991). Learning meaning vocabulary through listening: A sixth-grade replication. In J. Zutell \& S. McCormick (Eds.), Learner factors/teacher factors: Issues in literacy research and instruction: Fortieth Yearbook of the National Reading Conference (pp. 185-192) Chicago, IL: The National Reading Conference.

Stanovich, K. (1990). Concepts in developmental theories of reading skill: Cognitive resources, automaticity, and modularity. Developmental Review, 10, 72-100.

Stanovich, K. (1994). Constructivism in reading education. The Journal of Special Education, 28(3), 259-274.

Staubitz, J.E., Cartledge, G., Yurick, A.L., \& Lo, Y. (2005). Repeated readings for students with emotional or behavioral disorders: Peer and trainer mediated instruction. Behavioral Disorders, 31, 51-64. 
Stein, M., Carnine, D., \& Dixon, R. (1998). Direct instruction: Integrating curriculum design and effective teaching practice. Intervention in School and Clinic, 33, 4, 227-335.

Stevens, R. J., Slavin, R. E., \& Farnish, A. M. (1991). The effects of cooperative learning and direct instruction in reading comprehension strategies on main idea identification. Journal of Educational Psychology, 83(1), 8-16.

Stewart, R., Benner, G., Martella, R., Marchand-Martella, N. (2007). Three-tier models of reading and behavior. Journal of Positive Behavior Interventions, 9(4), 239253.

Stockard, J., \& Engelmann, K. (2010). The development of early academic success: The impact of Direct Instruction's Reading Mastery. Journal of Behavior Assessment and Intervention in Children, 1(1), 2.

Strickland, W.D., Boon, R.T., \& Spencer, V.G. (2013). The effects of repeated readings on the fluency and comprehension skills of elementary-age students with learning disabilities (LD), 2001-2011: A review of research and practice. Learning Disabilities: A Contemporary Journal, 11(1), 1-33.

Strong, A.C., Wehby, J.H., Falk, K.B., \& Lane, K.L. (2004). The impact of structured reading curriculum and repeated reading on the performance of junior high students with emotional and behavioral disorders. School Psychology Review, 33(4), 561-581. 
Sullivan, K. J., Shadish, W. R., \& Steiner, P. M. (2015). An introduction to modeling longitudinal data with generalized additive models: Applications to single-case designs. American Psychological Association, 20(1), 26-42..

Sutherland, K.S., \& Snyder, A. (2007). Effects of reciprocal peer tutoring and selfgraphing on reading fluency and classroom behavior of middle school students with emotional or behavioral disorders, Journal of Emotional and Behavioral Disorders, 15, 103-119.

Swain, K.D., Leader-Janssen, E.M., \& Conley, P. (2017). Effects of repeated reading and listening passage preview on oral reading fluency. Reading Improvement, 54(3), 105-111.

Tawney, J. W., \& Gast, D. L. (1984). Single subject research in special education. Columbus, OH: Merrill.

Therrien, W.J. (2004). Fluency and comprehension gains as a result of repeated readings: a meta-analysis, Remedial and Special Education, 25(4), 252-260.

Therrien, W.J., \& Kubina, R.M. (2007). The importance of context in repeated reading. Reading Improvement, 44(4), 179-188.

Therrien, W.J., Kirk, J., \& Woods-Groves, S. (2012). Comparison of a reading fluency intervention with and without passage repetition on reading achievement. Remedial and Special Education, 35(5), 309-319.

Thurlow, R., \& van den Broek, P. (1997). Automaticity and inference generation. Reading and Writing Quarterly, 13, 165-184. 
Tommredahl, J. (2013). Links between emotional and behavioral difficulties and speech and language difficulties. In T. Cole, H. Daniels, \& J. Visser (Authors), The Routledge international companion to emotional and behavioral difficulties (pp. 154-160). Milton Park, Abingdon, Oxon: Routledge.

Toshev, B.V. (2015). Recent papers on constructivism in education. Chemistry Bulgarian Journal of Chemical Education, 24(1), 145-149.

Treacy, J., McLaughlin, T.F., Derby, K.M., Dolliver, P., \& Carosella, M. (2012). The effects of flashcards and student selected reinforcers with goals and additional practice with multiplication facts for two intermediate elementary students with behavioral disorders. Academic Research International, 2(1), 469-476.

Trout, A.L., Epstein, M.H., Nelson, R., Synhorst, L., \& Hurley, K.D. (2006). Profiles of children served in early intervention programs for behavioral disorders: Early literacy and behavioral characteristics. Topics in Early Childhood Special Education, 26, 206-218.

U.S. Department of Education, (2014). U.S. Department of Education, Retrieved April 17, 2014, from http://www.ed.gov.

Volpe, R., Young, G., Piana, M., Zaslofsky, A. (2012) Integrating class wide early literacy intervention and behavior supports: A pilot investigation. Journal of Positive Behavior Interventions, 14(1), 56-64.

Vaughn, S., Levy, S., Coleman, M., Bos, C. (2002). Reading instruction for students with ld and ebd. The Journal of Special Education. 36(1), 2-13. 
Vygotsky, L. (1986). Thought and language: The development of higher psychological processes (Cambridge, MA, MIT Press).

Wagner, M. (1995). Outcomes for youths with serious emotional disturbance in secondary school and early adulthood. The Future of Children, 5, 90-112.

Wagner, T. (1998). Change as collaborative inquiry: A'constructivist'methodology for reinventing schools. Phi Delta Kappan, 79(7), 512.

Wagner, M., \& Davis, M. (2006). How are we preparing students with emotional disturbances for the transition to young adulthood? National longitudinal transition study 2. Journal of Emotional and Behavioral Disorders, 14, 86-98.

Walker, H.M., Colvin, G., Ramsey, E. (1995). Antisocial behavior in school: Strategies and best practices. Pacific Grove, CA: Brooks/Cole.

Walker, L. L., Jolivette, K., \& Lingo, A. S. (2005). Improving Reading Fluency: A Case Study Using the. Beyond Behavior, 14(2), 21-27.

Weinstein, G., \& Cooke, N. L. (1992). The effects of two repeated reading interventions on generalization of fluency. Learning Disability Quarterly, 15(1), 21-28.

Weisenburgh-Snyder, A. B., Malmquist, S. K., Robbins, J. K., \& Lipshin, A. M. (2015). A model of MTSS: Integrating precision teaching of mathematics and a multilevel assessment system in a generative classroom. Learning Disabilities -- A Contemporary Journal, 13(1), 21-41.

Wendt, O. (2007, November). Meta-analysis of single-subject experimental designs. Paper presented at the Panel "Roles of Single-Subject Experimental Designs in 
EBP Times" at the Annual Convention of the American Speech-LanguageHearing Association (ASHA), Boston, MA.

West, R. P., \& Young, K. R. (1992). Precision teaching. In R. P. West \& L. A. Hamerlynck (Eds.), Designs for excellence in education: The legacy of B. F. Skinner (pp.113-146). Longmont, CO: Sopris West, Inc.

What Works Clearinghouse. (2014). Repeated reading. What Works Clearinghouse Intervention Report.

Whipple, G. (Ed.). (1925). The Twenty-fourth Yearbook of the National Society for the Study of Education: Report of the National Committee on Reading. Bloomington, IL: Public School Publishing Company.

White, O. R. (1986). Precision teaching—Precision learning. Exceptional Children, 52, $522-534$.

Wills, H., Kamps, D., Abbott, M., Bannister, H., Kaufman, J. (2010). Classroom observations and effects of reading interventions for students at risk for emotional and behavioral disorders, Behavior Disorders, 35(2), 103-119.

Wise, B., King, J., \& Olson, R. (2000). Training phonological awareness with and without explicit attention to articulation. Journal of Experimental Child Psychology, 72, 271-304.

Wixson, K. K. (1986). Vocabulary instruction and Wu, H.-M., \& Solman, R. T. (1993). Effective use children's comprehension of basal stories. Reading of pictures as extra stimulus prompts. British Journal of Research Quarterly, 21(3), 317-329. 
Wolf, M., Giles, D., Hall, R. (1968). Experiments with token reinforcement in a remedial classroom. Behavior Research and Therapy, 6, 51-64.

Wolfe, K. \& Slocum, T.A. (2015). A comparison fo two approaches to training visual analysis of AB graphs. Journal of Applied Behavior Analysis, 48, 472-477. 


\section{APPENDIX A.}

\section{Great Leaps and EBD Checklist-Baseline}

1.The researcher will hand student a prepared passage from the book room on the grade level the student is currently placed. She will have an identical passage in front of her.

2. The researcher will ask, "Are you ready?" If the student says yes, the researcher will say, "Begin", and click start on her stop watch.

4.The researcher will mark errors on the copy in front of her, as in a running record.

5. If the student does not know a word after three seconds, or asks for the word, the researcher will give it verbally, but will count it as an error.

6. When the student finishes reading the exercise, the researcher will stop the watch. If the one-minute time runs out before the student finishes, the researcher will request that the student stop, and will mark the last word read, on her paper.

7. The student and researcher will review the log and graph what was done in that session.

8. Student will choose an incentive.

9. Student will be returned to the classroom.

B. 


\section{Great Leaps and EBD Checklist-Intervention}

1. The researcher will select the exercise on her device and send it to the student's device. The student will open the exercise.

3.The researcher will ask, "Are you ready?" If the student says yes, the researcher will say, "Begin", and click start on her device.

4.The researcher will immediately correct errors verbally, and click on them on her device.

5. If the student does not know a word after three seconds, or asks for the word, the researcher will give it verbally, but will click it as an error on her device.

6. When the student finishes reading the exercise, the researcher will click stop on her device. If the one-minute time runs out before the student finishes, the researcher will request that the student stop, and will double click the last word read, on her device.

7. The researcher will model missed words for the student, read from flashcards. The student and teacher will read them together. Then, the student will read them alone.

8. The researcher will select submit for the exercise on her device.

9. The same steps will be taken for the other two sections.

10. At the end of the "Stories" component, the researcher will be given Depth of Knowledge questions once she clicks submit.

11. The researcher will ask a few of these questions, progressively increasing the level, in attempts to achieve dialogue, expressive language, and vocabulary enrichment.

12. The student and researcher will review the log and graph produced by the software.

13. Student and researcher will log out.

14. The researcher will hand student a prepared passage from the book room on the current grade level. She will have an identical passage in front of her.

15. The researcher will tell the student they have one minute and will tell them to begin. 
16. The student will read the passage and the researcher will score it as a running record, counting any pause of three seconds or longer as an error. Student will be told to stop at one minute.

17. Student and researcher will graph the score together.

18. Student will choose an incentive.

19. Student will be returned to the classroom. 
C.

\section{Great Leaps and EBD Checklist-Baseline Virtual}

1. The researcher will have a pre-set time, and method of communication with the student. Some student families prefer phone calls, and others prefer Zoom. For those preferring Zoom, a Zoom link has been established.

2. The researcher will email the daily quick read from the Journey's Quick Read book to the student's school email address after she has established contact with the student to ensure it is a fresh read.

3. Once contact is established, the student will open the quick read in email. If they have difficulty and are on Zoom, the researcher will share her screen. On some calls, Miss Webb and/or Ms. Morris will be present to collect IOA data. The student will be made aware of their presence.

4. The researcher will instruct the student to begin reading and will start the timer for one minute. As the student reads, the researcher, and any other scorer will score an identical passage in front of them. The student will read until one minute has passed and the researcher says, "stop". The researcher and other scorers will mark as a running record: omitted words, inserted words, and pauses of more than three seconds will count as errors. Mispronunciations will count as errors, unless the child has a documented speech impediment that all scorers are aware of.

5. The researcher and other scorers will count the words read, subtracting errors.

6. The score will be given to the student and comparisons will be made, showing the student their graph in Excel if via Zoom, verbally if via phone. 
7. Students will be presented with a choice of three incentives, of which they may choose one. These packages are mailed to their homes every week, or more often if the envelope fills.

8. The researcher confirms the time for the next day with the student and any present adult, and thanks them for their work, then ends the call.

9. If another person has been on the call or Zoom for fidelity or IOA, results will be discussed, with remediation taking place if necessary. 
D.

\section{Great Leaps and EBD Checklist-Intervention Virtual}

10. The researcher will have a pre-set time, and method of communication with the student. Some student families prefer phone calls, and others prefer Zoom. For those preferring Zoom, a Zoom link has been established.

11. The researcher will email the daily quick read from the Journey's Quick Read book to the student's school email address after she has established contact with the student to ensure it is a fresh read.

12. Once contact is established, the student will open the quick read in email. If they have difficulty and are on Zoom, the researcher will share her screen. On some calls, Miss Webb and/or Ms. Morris will be present to collect IOA data. The student will be made aware of their presence.

13. The researcher will instruct the student to begin reading and will start the timer for one minute. As the student reads, the researcher, and any other scorer will score an identical passage in front of them. The student will read until one minute has passed and the researcher says, "stop". The researcher and other scorers will mark as a running record: omitted words, inserted words, and pauses of more than three seconds will count as errors. Mispronunciations will count as errors, unless the child has a documented speech impediment that all scorers are aware of.

14. The researcher and other scorers will count the words read, subtracting errors.

15. The score will be given to the student and comparisons will be made, showing the student their graph in Excel if via Zoom, verbally if via phone.

16. The student will be asked to $\log$ in to Great Leaps.

17. The student will be given their password of the day. 
18. The researcher will add the phonics lesson to the student's que and ask the student to click on the specific lesson.

19. The researcher will ask, "are you ready?" If the student says yes, the researcher will click start and say, "go!". If the student is not ready, technical issues will be addressed until they are. Student errors will be corrected immediately.

20. When the time has ended, the researcher will say, "stop". She will then briefly review missed words or sounds with the student.

21. The researcher will que the Phrases lesson to the student's device and instruct the student to load it. She will then ask, "Are you ready?" If so, she will click start and the lesson will begin. If not, technical errors will be addressed until the student is ready.

22. Errors will be corrected verbally as they happen. When the time is up, the researcher will tell the student to stop. She will then briefly review errors.

23. The researcher will que the appropriate lesson to the student's device for Stories. The student will be instructed to load it.

24. The researcher will ask, "Are you ready?" If the student says yes, the researcher will begin the timer and correct errors as they happen, verbally. If the student says no, technical errors will be addressed until the student is ready. The lesson will then begin.

25. When the time has ended, the researcher will instruct the student to stop, and will briefly review errors, then echo read the story with the student.

26. The researcher will ask the student a few comprehension questions supplied by the software.

27. The researcher will share the graph of progress with the student if they are via Zoom, or email or text it to them if they are via phone. Great Leaps and progress will be 
celebrated verbally, with stagnation and regression resulting in shared planning between the student and researcher.

28. Students will be presented with a choice of six incentives, of which they may choose two. They receive an incentive for the quick read and for Great Leaps. These packages are mailed to their homes every week, or more often if the envelope fills.

29. The researcher confirms the time for the next day with the student and any present adult, and thanks them for their work, then ends the call.

21. If another person has been on the call or Zoom for fidelity or IOA, results will be discussed, with remediation taking place if necessary. 
CURRICULUM VITA

\author{
Gwendolynh J. Shultz Ashley \\ 400 East College Street, Knight Hall \\ Georgetown, KY 40324 \\ (812) 989-0532 \\ E-mail: gwendolynshultz@gmail.com
}

\title{
Education:
}

University of Louisville, Louisville, Kentucky

Doctoral $(\mathrm{PhD})$ program in Curriculum and Instruction

Dissertation: The Impact of Great Leaps Reading Intervention on the

Reading Fluency of Students with Co-Morbid Emotional Behavior

Disorder

Indiana University Southeast, New Albany, Indiana

Rank One Gifted and Talented, High Ability Education

University of Louisville, Louisville, Kentucky

Masters in the Art of Teaching/LBD (PreK-12) Certification

Indiana University Southeast, New Albany, Indiana

Bachelor of Science in Humanities

Georgetown College, Georgetown, KY

Elementary Education (PreK-8)

Minors in history and Spanish

\section{COLLEGE COURSES TAUGHT:}

\section{Georgetown College}




\section{Courses taught:}

Foundations 1: Being Human (Undergraduate) (Traditional)

Introduction to Learning Behavioral Disorders for Advanced Candidates (Graduate) (Virtual)

Introduction to Learning Behavioral Disorders for Initial Candidates (Graduate) (Virtual)

Introduction to Autism Spectrum Disorders (ASD) (Graduate) (Virtual)

Typical \& Atypical Child Development (Graduate) (Virtual)

Behavior Management for LBD (Graduate) (Virtual)

Educating Exceptional Children (Undergraduate) Traditional, Virtual)

Graduate Student Teaching (Virtual)

\section{Houston Community College}

\section{Courses taught:}

Student Success

\section{Indiana University Southeast}

\section{Courses Designed:}

Children's Literature for Special Education

Methods of High Incidence: Response to Intervention in Literacy Instruction (Graduate)

Methods of High Incidence: Response to Intervention in Mathematics Instruction (Graduate)

Methods of High Incidence: Response to Intervention in Behavioral Interventions (Graduate)

Introduction to Autism (Graduate)

Introduction to Autism (Undergraduate)

Motivating At-Risk Students

\section{College Programs Designed}

Undergraduate Bachelor of Science with Dual Certification in Elementary and Special Education

Post Baccalaureate additional license in Special Education 
Post Baccalaureate additional license in Special Education with Master's Degree

Post Baccalaureate initial license in Special Education

Post Baccalaureate initial license in Special Education with Master's Degree

\section{Online Courses Taught:}

Introduction to Special Education (Undergraduate)

Introduction to Special Education (Graduate)

Children's Literature for Special Education (Undergraduate)

Methods of High Incidence: Response to Intervention in Literacy Instruction (Graduate)

Methods of High Incidence: Response to Intervention in Mathematics Instruction (Graduate)

Methods of High Incidence: Response to Intervention in Behavioral Interventions (Graduate)

Motivating At-Risk Students (Graduate)

\section{Other Courses Taught:}

Academic/Behavioral Assessment of the Mildly Handicapped Child (Undergraduate)

Autism Spectrum Disorder (Graduate)

Autism Spectrum Disorder (Undergraduate)

Child as Learner Seminar (Undergraduate)

Classroom Management \& Behavior Support (Graduate)

Educating Students with Learning Disabilities (Undergraduate)

Education and Psychology of the Gifted and Talented (Graduate)

Education of the Socially and Emotionally Disturbed II (Undergraduate)

Education of the Socially and Emotionally Disturbed II (Graduate)

Independent Study-Special Education law and criteria (Undergraduate)

Introduction to Assessment (Graduate)

Introduction to Emotional Disorders (Graduate) 
Introduction to Exceptional Children (Undergraduate)

Introduction to Special Education (Undergraduate)

Introduction to Special Education (Graduate)

Management of Academic and Social Behavior (Undergraduate)

Management of Academic and Social Behavior (Graduate)

Methods and Materials for Gifted and Talented (Graduate)

Methods of High Incidence (Graduate)

Methods of High Incidence for New Teachers (Graduate)

Methods of High Incidence: Response to Intervention in Behavioral Interventions (Graduate)

Methods of High Incidence: Response to Intervention in Literacy Instruction (Graduate)

Methods of High Incidence: Response to Intervention in Mathematics Instruction (Graduate)

Teaching Students with Learning Disabilities (Undergraduate)

Traumatic Brain Injury, Assistive Technology, \& Autism Spectrum Disorder (Undergraduate)

Traumatic Brain Injury, Assistive Technology, and Autism (Graduate)

Undergraduate Fellowship Mentor

\section{Clinical Supervision:}

Child as Learner (Undergraduate)

Curriculum for Gifted and Talented Students (Graduate)

Education and Psychology of the Gifted and Talented (Graduate)

Introductory Practicum in Special Education (Undergraduate)

Lab/Field Experience in Special Education Block Two (Undergraduate)

Lab Field Experience in Special Education Block Three (Undergraduate)

Methods and Materials for Gifted and Talented (Graduate)

Practicum High Ability Students (Graduate) 
Practicum Block One Special Education (Undergraduate)

Student Teaching in Special Education (Undergraduate)

Student Teaching Emergency Certification (Graduate)

Block One Elementary Education (Undergraduate)

Block Two Elementary Education (Undergraduate)

Block Three Elementary Education (Undergraduate)

Student Teaching Elementary Education (Undergraduate)

Practicum Special Education (Graduate-all four blocks)

\section{Work Experience:}

2019-Present Georgetown College

Visiting Assistant Professor

Georgetown, Kentucky

2018- 2019 Centre for Neuro Skills

Director of Educational and Behavioral Rehabilitation

Houston, Texas

2018- Present Houston Community College

Adjunct Professor

Houston, Texas

2013- 2017 Indiana University Southeast

Visiting Lecturer of Special Education and Gifted Education

New Albany, Indiana

2005-2013 Jefferson County Public Schools

Special Education Teacher, EBD Self-Contained, Lead Teacher, School Technology Leader

Louisville, Kentucky

2013 Adjunct Instructor, Indiana University Southeast

Gifted Education 
New Albany, Indiana

2002-2005 New Albany Community Action Agency

Collaboration Head Start teacher for general education students and students with high incidence special needs.

New Albany, Indiana

2000-2002 Development Director

Catholic Social Services of Atlanta

Atlanta, Georgia

1998-2000 Interim Executive Director

Boys \& Girls Clubs of Roberta/Crawford County

Roberta, Georgia

1991-1995 Lottery Prek Pilot Program (Cobb’s Kids)

Lead Teacher

Atlanta, Georgia

\section{EXTERNAL FUNDING RECEIVED:}

Cobb's Kids-Teacher

Primary Investigator

A small $\$ 100,000$ grant to assist with integration of children with low incidence special needs into a general education four year old kindergarten- Department of Education

Boys \& Girls Clubs of Roberta/Crawford County

Executive Director/Primary Investigator

Responsible for raising annual \$200,000 budget. Responsible for all grant management, implementation, and applications. Grants applied for and received from Health and Human Services, SAMSHA, Department of Education, State of Georgia, Department of Juvenile Justice, Department of Interior (Forestry Division), and private foundations.

Catholic Social Services of Atlanta

Development Director/ Co-Investigator

Responsible for funding for annual \$6-7 million budget. Grants applied for and received included Carol M White grant, Health and Human Services, Department of Justice, Department of Education, SAMSHA, Department of Immigration, Department of the Interior, Department of Juvenile Justice, and numerous state 
and private foundation grants. Inclusion of private fundraising during tenure totals $\$ 44.5$ million.

Saint Vincent De Paul of Louisville

Development Director/ Primary Investigator

Responsible for annual 6 million dollar budget- Responsible for all development, including federal and state grant applications, reports, and oversight. Also included private foundation grants, and planned gifts and endowments and trusts. Government grants applied for and approved included Health and Human Services, Housing and Urban Development, Department of Education, and Department of Justice.

Boys \& Girls Clubs of Kentuckiana

Consultant Grant Writer/Development Director

Grants applied for both for this agency and collaborative partnerships with Boys \& Girls Clubs throughout the Commonwealth, and Local Education Agencies. Grants from Health and Human Services, Department of Justice, and Department of Education, as well as private foundations and State agencies.

Kentucky Baptist Homes for Children

Development Director/Primary Investigator

Responsible for annual \$21 million budget. Grants applied for and received from Health and Human Services, Department of Justice, Private Foundations, Carol M White, Department of Education, SAMHSA, and state agencies.

Indiana University Southeast 2015-2016 Received Permission from Vice Chancellor Uric Dufrene to apply for external and internal grants

Student research grant in partnership with Dean Doyin Coker-Kolo and Candidate Emily Clayton. This grant was in support of the Together We'll Grow Pipeline InititiativeAwarded

Talent Grant- US Department of Education: Annual budget of \$250,000.00 annually for five years. This grant is to provide assistance and support to under-represented groups. We partnered this with our TWG Pipeline to include 18 high schools. This grant targets low SES, First generation College Students, ESL, Minority, and learning differences students that wish to become teachers.- grant was awarded but not contracted by the university due to budget and faculty cuts.

\section{Paid Consulting:}

Boys \& Girls Clubs of Mobile, Alabama 1999-2001

Boys \& Girls Clubs of Roberta/Crawford County, Georgia 2001-2005

Boys \& Girls Clubs of Kentuckiana, Louisville, Kentucky 2002-2009

Boys \& Girls Clubs of Kentucky, 2002-2005 
Catholic Social Services of Atlanta, Georgia 2002- 2004

West Clark Community Schools, Sellersburg, Indiana 2002-2006

EdTPA Portfolio Scorer 2014

New Albany Floyd County Schools, New Albany, Indiana 2014

Jefferson County Public Schools, Louisville, Kentucky 2014

Jefferson County Public Schools, Louisville, Kentucky 2015

\section{Publications:}

Shultz, G., Havens, N., Gurney, B., Burt, J. (2017). You Can Help Every Provider Have a Better Understanding of Functional Behavior Assessment! A Review of the Website: Basic FBA to BSP, Beyond Behavior, 26/3, pp.152-154.

\section{Presentations:}

Teachers and Educators of Children with Behavior Disorder- 10/24/19, Tempe, Arizona, "Two Boys, Two Exceptionalities: Gifted and EBD. A Ten Year Case Study.

AACTE 2016 Diversifying the Teacher Workforce

AACTE 2016 The Responsible Diversification and Differentiation of Pedagogy Instruction within Field Placements in the Special Education Program

Multiculturism and Diversity in the Elementary Classroom, Indiana University Southeast, 2016

Professionalism for Public School Teachers- Indiana University Southeast, 2016

RTI in the Public School Classroom, Indiana University Southeast 2015

Autism on the College Campus, Indiana University Brownbag Series, 2016

Accommodations in Higher Education: What is our Responsibility, Indiana University Southeast 2015

Classroom Management for New Teachers- Indiana University Southeast, 2014

"Utilizing Data to Facilitate Positive Change for Students with Behavioral Challenges", Graduate Student Research Competition, First Place-Presentation, Indiana University, 2011

"TESL Grant: How to Track Progress and Best Meet Client Needs", Catholic Charities Summer Conference, Washington, DC, 2001 
"Using Grants to Rehabilitate our Clubs" Boys and Girls Clubs of America Southeastern Conference, Pine Mountain, GA, 2001

"Using Grants to Rehabilitate our Clubs" Boys and Girls Clubs of America Southeastern Conference, Pine Mountain, GA, 2000

"Using Grants to Rehabilitate our Clubs" Boys and Girls Clubs of America Southeastern Conference, Toccoa Falls, GA, 1999

"Utilizing SMART Tools to Build Community and Public School Bridges", Boys and Girls Clubs of America, Southeastern Conference, Toccoa Falls, GA, 1999

"Utilizing SMART Tools to Build Community and Public School Bridges", Boys and Girls Clubs of America, State Conference, Athens, GA, 2000

"Second Step: What is it, and is it right for us?", Georgia Teachers and Administrators Conference, Atlanta, GA 1994, 1995, 1996

"The Lottery Pre-K Program: An Overview of Strengths and Challenges-Year One", Georgia General Assembly, Special Meeting, Atlanta, GA, 1993

"The Lottery Pre-K Program: An Overview of Strengths and Challenges", Georgia General Assembly, Special Meeting, Atlanta, GA, 1994

\section{Current Certifications}

Program Evaluator (Gifted and Special Education) -Kentucky

Lead Assessment Reviewer CAEP

Site Visitor CAEP

Quality Matters

ILTE Online Course Construction-IUS

LBD P-12

Gifted and Talented

Safe Crisis Management

Life Skills Crisis Intervention

Second Step Trainer

Botvin Life Skills

\section{Service:}




\section{University and Higher Education:}

Program Evaluator- Kentucky

Evaluate Educational Program Providers to ensure quality of programs providing certification routs to those desiring to teach in the areas stated.

Georgetown Academic Council Policy Committee

Committee determines admission, expulsion, certification, and conferment of degrees to students in the graduate school.

Project Ahead Coordinator, Indiana University Southeast 2016-2017

A program to provide enrichment activities to local children 2-12 grade. Expanded program from twelve students to its former level of one hundred sixty students in six months.

Gifted and Talented Co-Coordinator, Indiana University Southeast 2016-2017

Elementary Block One Chair, Indiana University Southeast 2016-2017

Acting Special Education Chair, Indiana University Southeast 2014-2016

Together We'll Grow, Indiana University Southeast 2015-2016

CAEP Lead Assessment Reviewer, International 2016-2017

CAEP site visitor, International 2015-2016, 2016-2017

Caverna Independent Schools 2016 Behavioral and RTI Consulting, Caverna, Kentucky

PAUE Committee, Indiana University Southeast 2013, 2014, 2015,2016

AACTE TAG: Diversification of the Teacher Workforce, Professional Development Co Chair, International 2015-2016, 2016-2017

Student Research Conference, Spring 2015, 2016 Indiana University Southeast, Judge Caverna Middle School Career Fair, Caverna, Kentucky Spring 2015, 2016 Judge

AACTE Annual Conference Proposal Reviewer, International 2014, 2015,2016

EdTPA Portfolio Scorer, International 2014, 2015, 2018

NCATE Review Committee, International 2013-2014

Worked with colleagues on the NCATE review process and SPA reports for the SPED program and the GT program. 
PAUE Standard 2 Committee, Indiana University Southeast 2013-2014, 2014-2015

CAEP QT 4/5, Indiana University Southeast 2014-2015, 2015-2016

Worked with colleagues to ensure standards were being met and to implement changes for the future to ensure future standards are met in regard to assessment and data collection

Kentucky State Fair Recruitment, Indiana University Southeast 2013

Mentoring of Gifted and Talented Candidates, Indiana University Southeast 2013-2017,

Advise students in regard to job placement, masters programs, being hired, future steps, praxis review, interviewing process, and work/life balance.

Mentoring of Special Education Candidates, Indiana University Southeast 2013-2017

Advise students in regard to job placement, masters programs, being hired, future steps, praxis review, interviewing process, and work/life balance.

\section{Community:}

Clark County Youth Advocates Board, Jeffersonville, Indiana 2003

Council for the Homeless, Louisville, Kentucky 2003

Silver Creek Little League Board of Directors, Sellersburg, Indiana 2002-2010

Twelfth Man Club, Member/Executive Board, Sellersburg, Indiana 2007-2012

New Albany Floyd County Schools, New Albany, Indiana 2014-2017

Jefferson County Public Schools, Louisville, Kentucky 2014-2017

West Clark Community Schools 2014-2017

\section{Professional Organizations:}

Council for Exceptional Children, 2006-Present

Kentucky Education Association, 1989-present

National Education Association, 1987-present

Association for Applied Behavior Analysis International, 2011-Present

Kentucky Association for Applied Behavior Analysis, 2012-2017

ISTE 2014-2017 


\section{Research Interests}

Evoke Potential and Response to Intervention (Literacy, Math, and Behavior) Traumatic Brain Injury and Rehabilitation/Enhanced Neuro Pathways

Applied Behavior Analysis

Autism Spectrum Disorder/ Emotional Behavioral Disorders

Twice Exceptionalities

Brain Function and Environment

Cognitive Effects of Infection, particularly Lyme Disease

Childhood Trauma and High Level Learning

Dementia and Aging Cognition and Learning

Dementia and Alternate Pathways

AACTE/NCATE/CAEP Data driven assessments

Diversity in the Teacher Workforce

Teacher efficacy with marginalized populations

Brain Trauma and Maladaptive Behaviors 